\title{
Análise das Condições de Operação do Sistema de Informação de Agravos de Notificação (SINAN) nos Municípios Paulistas
}

Keler Wertz Schender de Lima

Tese apresentada ao Programa de Pós-Graduação em Saúde Pública da Faculdade de Saúde Pública da Universidade de São Paulo, para obtenção do título de Doutora em Ciências.

Área de Concentração: Epidemiologia

Orientadora: Prof ${ }^{a}$ Dra. Zilda Pereira da Silva

\section{Versão revisada}

São Paulo 
É expressamente proibida a comercialização deste documento, tanto na sua forma impressa como eletrônica. Sua reprodução total ou parcial é permitida exclusivamente para fins acadêmicos e científicos, desde que na reprodução figure a identificação do autor, título, instituição e ano da tese/dissertação. 


\section{DEDICATÓRIA}

A DEUS, a sua presença é marcante em minha vida. Grande é a tua fidelidade!

À minha querida mãe, Oraida, por ser tão atuante na minha vida, a minha eterna admiração, pois me ensinou a ser perseverante.

Ao meu amor, Oséias, por seu incentivo constante, por se esforçar para que eu tivesse momentos de dedicação a este trabalho, enquanto cuidava dos nossos filhos.

Aos meus filhos, Kauã e Kiara, vocês são a minha verdadeira inspiração. A vida fica muito mais suave quando estamos juntos.

Ao meu irmão, Klim, pelo incentivo e companheirismo. 


\section{AGRADECIMENTOS}

À professora. Zilda Pereira da Silva, pela paciência, dedicação, pela oportunidade de trabalhar com este tema tão entusiasmante.

Às professoras Gerusa Figueiredo e à Marília Louvison, por terem contribuído desde a qualificação com o desenvolvimento deste trabalho, pela participação na pré-banca, bem como por aceitarem compor a banca defesa da tese.

Às professoras Ana Vidor e Ana Freitas pela preciosa colaboração na validação do questionário, e por terem aceitado compor a banca de defesa da tese e contribuído valorosamente na fase de pré-banca.

À Cátia Martinez, pela sua amizade, parceria com este projeto.

À Faculdade de Saúde Pública, por proporcionar a formação tão desejada.

À Secretaria de Saúde do Estado de São Paulo, por apoiar a realização desta pesquisa nos municípios paulistas.

Ao COSEMS, pelo apoio e sensibilização junto aos secretários municipais de saúde em relação ao preenchimento do questionário eletrônico.

Ao Conselho Nacional de Desenvolvimento Científico e Tecnológico (CNPq), pelo apoio financeiro concedido o qual foi fundamental para realização deste projeto.

À Coordenação de Aperfeiçoamento de Pessoal de Nível Superior (CAPES), pelo viabilizar o financiamento da bolsa estudantil, permitindo dedicação integral a este trabalho. 


\section{EPÍGRAFE}

"Tu te tornas eternamente responsável por aquilo que cativas" Antoine de St-Exupèry 


\section{RESUMO}

Lima KWS. Análise das condições de operação do Sistema de Informação de Agravos de Notificação (SINAN) nos municípios paulistas. São Paulo. [tese]. São Paulo: Faculdade de Saúde Pública da USP; 2018.

Introdução: O Sistema de Informação de Agravos de Notificação (SINAN) é uma importante ferramenta no apoio às ações da vigilância epidemiológica, sendo capaz de fornecer informações necessárias para o planejamento e intervenções em saúde. Com a descentralização da gestão dos serviços de saúde, as ações de vigilância epidemiológica foram colocadas sob responsabilidade dos municípios, que contam com distintos graus de capacidade administrativa. Objetivo: Analisar as condições de operação do SINAN nos municípios paulistas, segundo o porte populacional, em relação à infraestrutura, processo e apoio institucional. Métodos: Foi aplicado questionário eletrônico para 644 responsáveis pela vigilância epidemiológica, em 2017. Os dados foram analisados segundo porte populacional dos municípios: pequenos (<30.000 habitantes), médios (30.001-200.000) e grandes (>200.000) e por meio de estatística descritiva, com medidas de distribuição e de tendência central; teste de qui-quadrado e ANOVA foram utilizados na comparação entre os grupos. Resultados: Obteve-se $63,2 \%$ de retorno. Nos municípios pequenos, os responsáveis são mulheres $(88,5 \%)$, jovens com <40 anos (60,2\%); formação superior (88,3\%), experiência com 0 SINAN $\leq 9$ anos (70,3\%); com vínculo efetivo (56,4\%); as equipes contam com $\leq 2$ profissionais $(49,6 \%)$ receberam capacitação $(75,9 \%)$ e apoio técnico do GVE $(98,1 \%)$ para trabalhar com o SINAN; apresentam maior proporção de alta dificuldade em capacitação (16,9\%) junto com os municípios médios (16,8\%), e avaliam o preenchimento das fichas como bom (59,8\%). Os municípios médios apresentam o perfil profissional e tempo de experiência com SINAN semelhante aos pequenos; com mais pós-graduados (47,7\%); equipe com 3-6 membros; receberam mais capacitação $(79,6 \%)$ em relação aos demais grupos. Receberam apoio técnico do GVE (91,2\%); apresentam maior proporção de alta dificuldade no item fluxo de retorno $(22,1 \%)$, como os grandes municípios (21,4\%); avaliam o preenchimento das fichas como razoável (48,7\%). Nos grandes municípios, predominou o responsável técnico com idade $\geq 50$ anos $(60,7 \%)$ e mais pós-graduados $(75,0 \%)$; maior número de efetivos (64,3\%); profissionais com mais experiência no SINAN; $80,0 \%$ possuem $\geq 11$ funcionários; receberam capacitação $(71,4 \%)$ e apoio do GVE $(64,3 \%)$ para trabalhar com o SINAN em menor proporção que os demais; apresentam maior proporção de alta dificuldade com recursos humanos e avaliam o preenchimento das fichas como razoável $(48,7 \%)$. Conclusões: 0 SINAN está implantado nos municípios paulistas, bem consolidado nos municípios grandes, porém os pequenos precisam de medidas de apoio que diminuam a disparidade entre os municípios: políticas e estratégias que estimulem a estabilidade profissional, bem como investimentos na capacitação profissional, aprimoramento dos recursos tecnológicos, avaliações periódicas do SINAN, além de incentivos financeiros voltados para gestão do SINAN.

Palavras-chave: Sistema de Informação; Sistema de Informação de Agravos de Notificação (SINAN); Vigilância Epidemiológica. 


\section{ABSTRACT}

Lima KWS. Analyse of operational conditions of the Notifiable Diseases Information System (SINAN) in municipalities of São Paulo State [thesis]. São Paulo: Faculdade de Saúde Pública da Universidade de São Paulo; 2017.

Introduction: Notifiable Diseases Information System is an important tool in supporting actions of epidemiological surveillance, being able to provide information necessary for health planning and interventions. Regards to decentralization of health services management, actions of epidemiological surveillance were placed under the responsibility of municipalities, which have different degrees of administrative capacity. Objective: To analyze SINAN's operational conditions in the municipalities of São Paulo State, according to population size, in relation to infrastructure, process and institutional support. Methods: An electronic questionnaire was applied to 644 epidemiological surveillance managers in 2017. Data were analyzed according to the population size of the municipalities: small-sized $(<30,000$ inhabitants), medium-sized $(30,001-200,000)$ and large-sized (> 200,000). We conducted a descriptive statistic analyse, distribution and central tendency measures were calculated. Chi-square test and ANOVA were used in the comparison between the groups. Results: $63.2 \%$ of questionnaires were answered. In small-sized municipalities, managers are female (88.5\%), younger ( $<40$ years old) $(60.2 \%)$, with higher education degree $(88.3 \%)$; mainly nurses; with experience with SINAN $\leq 9$ years $(70.3 \%)$; with career civil servant (56.4\%); teams have $\leq 2$ professionals $(49.6 \%)$, that received training $(75.9 \%)$ and technical support from the GVE $(98.1 \%)$ to work with SINAN. Small-sized municipalities present a higher proportion of high difficulty in the training item $(16.9 \%)$ as well as the mediumsized municipalities (16.8\%), and evaluated the completion of records as good $(59.8 \%)$. Medium-sized municipalities is similar to smaller ones in relation to time of experience with SINAN and professional profile. Team have more postgraduate persons $(47.7 \%)$, being composed of 3-6 members. staff received more training $(79.6 \%)$ in relation to the other groups. Team received technical support from the GVE (91.2\%). Staff reported a higher difficulty for flow of return item $(22.1 \%)$, as well as the large-sized municipalities $(21.4 \%)$. Team evaluated completeness of the records as reasonable (48.7\%). In the large-sized municipalities SINAN's managers are $\geq 50$ years old $(60.7 \%)$. This group have a higher percentage of postgraduate professionals $(75.0 \%)$; higher number of career civil servant $(64.3 \%), 80.0 \%$ of teams have $\geq 11$ members, that received training (71.4\%) and GVE support (64.3\%) to work with SINAN; professionals have more experience with SINAN. Units have higher number of computers. Managers reported higher difficulty for human resources item, and evaluated completeness of records as reasonable (48.7\%). Conclusions: SINAN was implemented in the municipalities of São Paulo State, being consolidated in large-sized municipalities, but small ones need government support measures that reduce disparities between municipalities: policies and strategies that stimulate professional stability, as well as investments in professional training, improvement of technological resources, periodic evaluations of SINAN and financial incentives for the management of SINAN.

Keywords: Information System; Notifiable Diseases Information System (SINAN); Epidemiological Surveillance. 


\section{SUMÁRIO}

1. INTRODUÇÃOO 14

1.1 Vigilância Epidemiológica $\quad 17$

1.2 Sistemas de Informação em Saúde 19

1.3 Sistema de Informação de Agravos de Notificação (SINAN) 22

1.3.1 Fluxo do SINAN 25

1.3.2 Avaliação do SINAN e Outros Sistemas $\quad 30$

1.3.3 Desafios do SINAN 32

2. OBJETIVOS $\quad 35$

2.1 Geral $\quad 35$

2.2 Específicos $\quad 35$

3. MATERIAL E MÉTODOS 36

3.1 Delineamento do Estudo 36

3.2 Local do Estudo $\quad 36$

3.3 Coleta de Dados 37

3.3.1 Etapa 1 - Entrevista $\quad 37$

3.3.2 Etapa 2 - Questionário 39

3.4 Análise dos Dados $\quad 41$

3.5 Aspectos Éticos $\quad 43$

4. RESULTADOS 44

4.1 Perfil do Responsável Técnico 44

4.2 Estrutura Organizacional da Vigilância Epidemiológica 51

4.2.1 Recursos Humanos 51

4.2.2 Recursos Físicos 53

4.3 Processos de Trabalho $\quad 60$

4.4 Capacitação Profissional 66

4.5 Disseminações de Dados 68

4.6 Avaliação sobre o SINAN 70

4.7 Comparação dos Resultados entre os Grupos de Municípios $\quad 75$

$\begin{array}{ll}\text { 5.DISCUSSÃO } & 79\end{array}$

5.1 Perfil do Responsável Técnico $\quad 79$

5.2 Estrutura Organizacional e Recursos da Vigilância Epidemiológica 83

5.3 Processos de trabalho 86

5.4 Capacitação Profissional $\quad 88$

5.5 Disseminações de Dados $\quad 90$

5.6 Avaliação Sobre o SINAN 91

6. CONSIDERAÇÕES FINAIS 98

7. REFERÊNCIAS $\quad 100$

APÊNDICES

$\begin{array}{ll}\text { ANEXOS } & 135\end{array}$

CURRÍCULOLATTES 


\section{LISTA DE TABELAS}

Tabela 01 Número e proporção de municípios existentes e participantes da pesquisa, por porte populacional, Estado São Paulo, 2017.

Tabela 02 Número e proporção de responsáveis técnicos municipais pela Vigilância Epidemiológica, segundo perfil, por porte populacional, Estado de São Paulo, 2017.

Tabela 03 Número e proporção de responsáveis técnicos municipais pela Vigilância Epidemiológica, segundo a área de conhecimento da formação mais avançada, por porte populacional, Estado de São Paulo, 2017.

Tabela 04 Número e proporção de responsáveis técnicos municipais pela Vigilância Epidemiológica, segundo a responsabilidade por outros sistemas além do SINAN, por porte populacional, Estado de São Paulo, 2017.

Tabela 05 Número de sistemas com responsabilidade conjunta com SINAN, Estados São Paulo, 2017.

Tabela 06 Número e proporção de municípios, segundo local de alocação da Vigilância Epidemiológica, por porte populacional, Estado de São Paulo, 2017.

Tabela 07 Número e proporção de profissionais que trabalham na vigilância epidemiológica segundo o nível de formação, por porte populacional, Estado de São Paulo, 2017.

Tabela 08 Número e proporção de municípios, segundo quantidade de profissionais da Vigilância Epidemiológica e formação pós-graduada em Epidemiologia, por porte populacional, Estado de São Paulo, 2017.

Tabela 09 Número e proporção de municípios, segundo a classificação da estrutura física do local de trabalho, por porte populacional, Estado de São Paulo, 2017.

Tabela 10 Número e proporção de municípios, segundo os problemas relatos em relação à estrutura física, por porte populacional, Estado de São Paulo, 2017.

Tabela 11 Número e proporção de municípios, segundo a disponibilidade de materiais para operar o SINAN, por porte populacional, Estado de São Paulo, 2017. 
Tabela 12 Número e proporção de municípios, segundo número de computadores com o SINAN instalado, tipo de sistema operacional e suporte técnico, por porte populacional, Estado de São Paulo, 2017.

Tabela 13 Número e proporção de municípios, segundo o tipo de backup realizado, por porte populacional, Estado de São Paulo, 2017.

Tabela 14 Número e proporção de municípios, segundo atividades desenvolvidas, por porte populacional, Estado de São Paulo, 2017.

Tabela 15 Número e proporção de municípios, segundo a realização de procedimento para monitorar o volume mensal dos eventos notificados pelas unidades, por porte populacional, Estado de São de Paulo, 2017.

Tabela 16 Número e proporção de municípios, segundo a utilização do aplicativo SINAN-Relatórios, por porte populacional, Estado São Paulo, 2017.

Tabela 17 Número e proporção de municípios, segundo a análise dos dados através da ferramenta Tabwin, por porte populacional, Estado São Paulo, 2017.

Tabela 18 Número e proporção de municípios, segundo as funções utilizadas do Tabwin, por porte populacional, Estado São Paulo, 2017.

Tabela 19 Número e proporção de municípios, segundo a análise espacial dos dados, por porte populacional, Estado São Paulo, 2017.

Tabela 20 Número e proporção de municípios, segundo a utilização de instrumentos paralelos, por porte populacional, Estado de São Paulo, 2017.

Tabela 21. Número e proporção de municípios, segundo o motivo para utilizar instrumentos paralelos, por porte populacional, Estado de São Paulo, 2017.

Tabela 22 Número e proporção de municípios, segundo recebimento de treinamento institucional para trabalhar com o SINAN, por porte populacional, Estado de São Paulo, 2017.

Tabela 23 Número e proporção de municípios, segundo a capacitação das unidades notificadoras, por porte populacional, Estados de São Paulo, 2017.

Tabela 24 Número e proporção de municípios, segundo a divulgação dados do SINAN para as unidades notificadoras (hospitais, UBS etc.), por porte populacional, Estado de São Paulo, 2017. 
Tabela 25 Número e proporção de municípios, segundo a disponibilização das informações geradas pelo SINAN, por porte populacional, Estado de São Paulo, 2017.

Tabela 26 Número e proporção de municípios, segundo o tipo de disponibilização das informações geradas pelo SINAN, por porte populacional, Estado de São Paulo, 2017.

Tabela 27 Número e proporção de municípios, segundo o uso das informações geradas pelo SINAN, Estado de São Paulo, 2017.

Tabela 28 Número e proporção de municípios, segundo a qualidade do preenchimento das fichas de notificação/investigação, por porte populacional, Estado de São Paulo, 2017.

Tabela 29 Número e proporção de município, segundo o atendimento do SINAN como instrumento epidemiológico e adequação da lista de Doenças de Notificação Compulsória, por porte populacional, Estado de São Paulo, 2017.

Tabela 30 Número e proporção de municípios, segundo o apoio técnico das instituições em relação ao SINAN, por porte populacional, Estado de São Paulo, 2017. 


\section{LISTA DE FIGURAS}

Figura 01 Linha do tempo do SINAN

Figura 02 Fluxo de Informações do SINAN

Figura 03 Distribuição dos Responsáveis Técnicos Municipais, segundo tempo de trabalho no setor público de saúde e no SINAN, por porte populacional. Estado de São Paulo, 2017.

Figura 04 Distribuição dos responsáveis técnicos municipais pela Vigilância Epidemiológica, segundo a formação mais avançada, por porte populacional Estado de São Paulo, 2017.

Figura 05 Distribuição do tipo de backup utilizado nos municípios, por porte populacional, Estado de São Paulo, 2017.

Figura 06 Distribuição dos motivos de não utilização do aplicativo SINAN Relatório, por porte populacional, Estado de São Paulo, 2017.

Figura 07 Principais problemas encontrados nas fichas de notificação/investigação no momento da digitação, Estado de São Paulo, 2017.

Figura 08 Municípios segundo grau de dificuldade na realização de algumas atividades do SINAN, por porte populacional, Estado de São Paulo, 2017.

Figura 09 Distribuição dos municípios, segundo avaliação dos benefícios do SINAN para o município, por porte populacional, Estado de São Paulo, 2017. 


\section{LISTA DE SIGLAS}

$\begin{array}{ll}\text { CDC } & \text { Center for Disease Control } \\ \text { CENEPI } & \text { Centro Nacional de Epidemiologia } \\ \text { CEP } & \text { Comitê de Ética e Pesquisa } \\ \text { CLT } & \text { Consolidação das Leis do Trabalho } \\ \text { CONASS } & \text { Conselho Nacional de Secretários de Saúde } \\ \text { COSEMS } & \text { Conselho de Secretários Municipais de Saúde } \\ \text { DATASUS } & \text { Departamento de Informática do Sistema Único de Saúde } \\ \text { DRS } & \text { Departamentos Regionais de Saúde } \\ \text { DNC } & \text { Doenças de Notificação Compulsória } \\ \text { FORMSUS } & \text { Formulários Eletrônico do SUS } \\ \text { GVE } & \text { Grupo de Vigilância Epidemiológica } \\ \text { MS } & \text { Ministério da Saúde } \\ \text { OMS } & \text { Organização Mundial de Saúde } \\ \text { SI-PNI } & \text { Sistema Programa Nacional de Imunizações } \\ \text { SES } & \text { Secretaria Estadual de Saúde } \\ \text { SIM } & \text { Sistema de Informações sobre Mortalidade } \\ \text { SINASC } & \text { Sistema de Informações de Nascidos Vivos } \\ \text { SINAN } & \text { Sistema de Informação de Agravos de Notificação } \\ \text { SIS } & \text { Sistema de Informação em Saúde } \\ \text { SNVE } & \text { Sistema Nacional de Vigilância Epidemiológica } \\ \text { SUS } & \text { Sistema Único de Saúde }\end{array}$




\section{INTRODUÇÃO}

As informações em saúde procuram refletir 0 processo de saúde/doença, condições de vida, bem como auxiliar em questões administrativas de interesse para os serviços de saúde, possibilitando um conhecimento ampliado da realidade sanitária da população (BRANCO, 2001).

$\mathrm{Na}$ área da saúde, é cada vez mais intenso o debate quanto ao papel da informação para o planejamento, execução e avaliação das atividades inerentes ao setor. No Brasil, o processo de implantação do Sistema Único de Saúde (SUS), iniciado em 1988, tem posto o tema em evidência, uma vez que os princípios e a legislação que norteiam o sistema enfatizam a importância das informações, indicadores gerenciais e epidemiológicos para o cumprimento das atribuições federais, estaduais e municipais (BRANCO, 2001). Considerando a relevância da informação em saúde, é importante destacar alguns aspectos da sua complexidade, tais como demanda crescente, com diferentes usuários e usos da informação: pacientes, comunidades, prestadores de serviços, gestores de programas, políticos, financiadores, agências globais e outras organizações. Todos precisam de informações, sobre diversas áreas, como: taxas de mortalidade e morbidade; surtos de doenças; determinantes da saúde (ambiente e nível socioeconômico); acesso, cobertura e qualidade dos serviços, custos e despesas. Essas informações são demandadas tanto em nível nacional quanto subnacional, incluindo regiões, municípios e equipamentos de saúde. Já do lado da oferta, um volume cada vez maior de dados e informações estão disponíveis, além das variedades de ferramentas e métodos. São necessárias diversas informações para satisfazer as necessidades de tomada de decisão em saúde pública e essas necessidades podem ser atendidas com 0 uso combinado dos principais subsistemas de informação em saúde: censo, pesquisas domiciliares, vigilância em saúde, registro de eventos vitais, estatísticas de serviços de saúde e monitoramento de recursos (WHO, 2007; STANSFIELD E COL., 2006). 
Segundo a OMS, Sistema de Informação em Saúde (SIS) é um sistema que integra a coleta de dados, processamento, comunicação e uso da informação necessária para melhorar a eficácia e eficiência dos serviços de saúde, através de uma melhor gestão em todos os níveis dos serviços de saúde (WHO, 2004).

No Brasil, a produção das informações em saúde iniciou-se de forma centralizada. Com o avanço da implantação do SUS (Sistema Único de Saúde), cuja principal diretriz é a descentralização da gestão dos serviços de saúde, passou a existir uma demanda crescente, também, para descentralizar a produção das informações em saúde, de modo a possibilitar a gestão e definição de prioridades em nível municipal (ALMEIDA, 1998), fator indispensável no processo de autonomia municipal (BRANCO, 2001; BRAGA e WERNECK, 2009).

Com a evolução da descentralização ocorrida no país, os municípios passaram para uma situação de destaque, uma vez que deixaram a condição de meros coletores de dados, para assumirem o papel de produtores e disseminadores de informações, com potencial para apoiar as decisões no nível local (BRANCO, 1996). Diante deste contexto, os municípios passaram a gerenciar vários sistemas de informação em saúde, dentre os quais, o SIM (Sistema de Informação sobre Mortalidade), o SINASC (Sistema de Informação sobre Nascidos Vivos), o SINAN (Sistema de Informação de Agravos de Notificação), e o SIH (Sistema de Informações Hospitalares do SUS), assumindo um importante papel no que diz respeito à vigilância epidemiológica.

O SINAN, objeto de estudo deste trabalho, tem como objetivo registrar e processar os dados sobre a ocorrência de doenças de notificação compulsória no país. Sua utilização permite a realização do diagnóstico dinâmico da ocorrência de eventos na população; a identificação de riscos aos quais as pessoas podem estar sujeitas; o reconhecimento de fatores associados a essas doenças e agravos. Com isso, o SINAN contribui para traçar o quadro das condições epidemiológicas de diferentes áreas geográficas, e constitui-se em instrumento relevante para auxiliar o planejamento da saúde, definir 
prioridades de intervenção e permitir que seja avaliado o impacto das intervenções.

Apesar da necessidade que os gestores têm de trabalhar com informações de qualidade, o cenário gerencial, por vezes, é marcado por informações inadequadas, dispersas, atrasadas ou não confiáveis (BRANCO, 2001). Para se obter informações confiáveis deve-se considerar que estas são consequências da qualidade com que se realizam todas as etapas, desde o registro até a disponibilização dos dados (CAETANO, 2009).

Os diversos sistemas de informações existentes compartilham de problemas comuns, sendo que alguns fatores podem contribuir para a baixa qualidade das informações geradas nos sistemas, tais como: deficiência na etapa de coleta de dados, no preenchimento de múltiplos formulários, o desinteresse em manipular os SIS, a falta de capacitação de vários profissionais de saúde, a superposição de informações nos diversos sistemas existentes e a resistência de alguns profissionais em relação ao uso de computadores (GRACIANO, ARAÚJO e NOGUEIRA, 2009). Assim, a qualidade da informação em saúde pode ser comprometida, resultando em falsos diagnósticos na avaliação da saúde da população, dificultando para os gestores os processos de análise, monitoramento, organização e controle das atividades desenvolvidas nos serviços de saúde, prejudicando ainda o planejamento e a formulação de políticas, planos e programas de saúde (GUIMARÃES e ÉVORA, 2004).

Desta forma, pode-se considerar que estudos acerca de informações em saúde têm importantes contribuições a oferecer ao sistema de saúde, principalmente no que se refere ao planejamento, à formulação, ao acompanhamento, à avaliação e à regulação do sistema de saúde (FERLA, 2001). É vasta a literatura que aborda os sistemas de informação, principalmente em relação aos sistemas SIM e SINASC, porém, nota-se uma lacuna em relação ao SINAN quanto às condições da operacionalização e aos aspectos que envolvem a sua utilização dos dados na gestão local. 


\subsection{VIGILÂNCIA EPIDEMIOLÓGICA}

Segundo a Lei Orgânica da Saúde, a vigilância epidemiológica é definida como "um conjunto de ações que proporciona o conhecimento, a detecção ou prevenção de qualquer mudança nos fatores determinantes e condicionantes de saúde individual ou coletiva, com a finalidade de recomendar e adotar as medidas de prevenção e controle das doenças ou agravos" (MS, 1990). Deve ser capaz de fornecer informações técnicas e contínuas para auxiliar os gestores nas ações de controle de doenças e agravos, tornando-se uma ferramenta para o planejamento, financiamento, avaliação, administração e provisão dos serviços de saúde, atuando na normatização das atividades técnicas correlatas (MALHÃO et al., 2010).

Com a descentralização, os municípios que atuavam essencialmente na assistência médica curativa e de urgência tiveram que assumir rapidamente novas ações para apoiar suas novas atribuições de gestão municipal (WALDMAN 1988, BRAGA e WERNECK, 2009).

WALDMAN (1998) apresenta a vigilância como um sistema composto por dois subsistemas:

a) subsistema de informações para agilização das ações de controle;

b) subsistema de inteligência epidemiológica, que tem interações entre si e com os serviços de saúde e de pesquisa.

A base do sistema de vigilância epidemiológica é a notificação compulsória de casos (PEREIRA, 2013). A disponibilidade dos seus dados pode auxiliar o processo de informação para ação.

As autoridades sanitárias elegem quais doenças e agravos devem ser acompanhados. A seleção das doenças e agravos de notificação compulsória segue alguns critérios como:

- Magnitude - são consideradas doenças com elevada frequência que afetam grandes contingentes populacionais. O critério leva em consideração incidência, prevalência, mortalidade, anos potenciais de vida perdidos; 
- Potencial de disseminação - se expressa pela transmissibilidade da doença, possibilidade da sua disseminação através de vetores e demais fontes de infecção, colocando sob risco outros indivíduos ou coletividades;

- Transcendência - características clínicas e epidemiológicas, como a gravidade (letalidade, hospitalizações e sequelas), a relevância social (estigmatização e medo) e a relevância econômica (perdas de vidas, absenteísmo ao trabalho, custo do tratamento);

- Vulnerabilidade - doenças para as quais existem instrumentos específicos de prevenção e controle, permitindo a atuação concreta e efetiva dos serviços de saúde sob indivíduos ou coletividades;

- Compromissos internacionais - acordos firmados entre o governo brasileiro e países membros da OPAS/OMS, que se referem a programas de eliminação ou de erradicação de doenças (PENNA et al., 2011; TEIXEIRA et al., 1998; MS, 2009).

Até 1973 , as notificações de doenças e agravos eram disponibilizadas em nível nacional através do Boletim Epidemiológico da Fundação Serviços de Saúde Pública. Por recomendação da $5^{\text {a }}$ Conferência Nacional de Saúde, foi instituído em 1976, o Sistema Nacional de Vigilância Epidemiológica (SNVE).

Com a construção do Sistema Único de Saúde (SUS) na década de 80, houve também a descentralização das ações de vigilância e o fortalecimento dos sistemas municipais de vigilância epidemiológica, exigindo a capacitação de recursos humanos a fim de facilitar a compreensão da situação epidemiológica de sua área de abrangência (PAIM e TEIXERA, 1992). Desde então, o SNVE vem buscando reestruturação operacional, baseado nos princípios que regem o SUS, usando como estratégia a descentralização. As Portarias GM/MS nํ⒈399, de 15 de dezembro de 1999, e ํㅜ 950, de 23 de dezembro de 1999 contribuíram nesse processo, estabelecendo o repasse de recursos do Governo Federal para o desenvolvimento das atividades de epidemiologia, vigilância e controle de doenças. Nelas, foram definidas as condições e atividades vinculadas a responsabilidade municipal (MS, 2009). Já em 2004, foi criada a portaria GM/1.172/04, que normatiza as funções da VE 
no âmbito municipal, onde algumas atividades deixaram de ser responsabilidade da esfera estadual.

A eficiência do SNVE está relacionada ao processo de reestruturação das atividades realizadas nos diversos níveis de gestão. Quanto mais preparado e eficaz estiver o serviço local, mais eficientes e oportunas serão as medidas de controle. Considera-se que a produção de dados e informações nesse nível de gestão seria mais consistente, capaz de contribuir para melhor definição, inclusive, do perfil sanitário estadual e nacional, sendo importante no planejamento governamental (TEIXEIRA et al., 2011.) Os sistemas de vigilância em saúde devem ser avaliados periodicamente, assim como a inclusão de recomendações para melhorias da qualidade, eficiência e utilidade. Para GAZE e PEREZ (2006), a avaliação dos sistemas de vigilância em saúde deve envolver alguns atributos, tais como:

- Simplicidade - é a capacidade de alcançar os objetivos do sistema da forma mais fácil e simples possível;

- $\quad$ Flexibilidade - é a capacidade de se adaptar às mudanças, garantindo o uso das informações;

- Aceitabilidade - é a capacidade de obter a participação convicta dos envolvidos;

- Sensibilidade - é a capacidade de encontrar casos verdadeiros do evento;

- Valor preditivo positivo - é a proporção de casos positivos que são verdadeiramente positivos.

\subsection{SISTEMAS DE INFORMAÇÃO EM SAÚDE}

Segundo o documento do Ministério da Saúde (MS), aprovado pela Portaria Ministerial n 3 de 04/01/96 e publicado no Diário Oficial da União de 08/01/96: "É essencial conceber o SIS (Sistema de Informação em Saúde) como um instrumento para o processo de tomada de decisões, seja na dimensão técnica, seja na dimensão de políticas a serem formuladas e 
implementadas. Um SIS deve assegurar a avaliação permanente da situação de saúde da população e dos resultados das ações de saúde executadas, fornecendo elementos para, continuamente, adequar essas ações aos objetivos do SUS" (MS,1996).

Os sistemas de informação em saúde foram concebidos como instrumento para o processo de tomada de decisões técnicas e/ou políticas. Têm como propósito a seleção de dados pertinentes e sua transformação em informações para aqueles que planejam, financiam, proveem e avaliam os serviços de saúde. Devem, ainda, proporcionar informações compatíveis com as distintas necessidades dos diferentes níveis de gestão e gerência do sistema de saúde (FERREIRA, 2001).

A Organização Mundial de Saúde (OMS), em seu relatório Strengthening Health Systems to Improve Health Outcomes, coloca os sistemas de informações em saúde como um dos seis blocos essenciais na construção de um sistema de saúde (prestação de serviços; profissionais de saúde, informação; produtos médicos, vacinas e tecnologias; financiamento; liderança e governança (WHO, 2007). Afirma, ainda, que um sistema de informações em saúde que funcione bem é aquele que não só garante a produção de informação confiável e oportuna sobre o estado de saúde da população, seus determinantes e o desempenho do sistema de saúde, mas também que produz análises para orientar as atividades em todos os outros blocos do sistema. Assim, as estatísticas de saúde devem permitir que os tomadores de decisão, em todos os níveis do sistema, possam identificar avanços, problemas e necessidades; tomar decisões baseadas em evidências sobre políticas e programas de saúde; e alocar de forma otimizada os recursos, na maioria das vezes, escassos (WHO, 2007; MUTALE et al., 2013).

Os serviços de saúde no Brasil têm apresentado, nas últimas décadas, o interesse em utilizar os bancos de dados como instrumento de planejamento e gestão dos serviços. Esta aproximação é decorrente de alguns fatores como: a descentralização das ações de saúde, acessibilidade ao uso da informática e com isso a disponibilidade das informações pertencentes ao sistema nacional, juntamente com a facilidade de obtenção de um grande volume de dados 
administrativos de saúde em curto espaço de tempo entre a ocorrência e seu registro (BITTENCOURT et al.,2006).

Para o Center for Disease Control (CDC, 2001), os dados divulgados pelos sistemas de vigilância em saúde podem ser utilizados para ações imediatas de saúde pública, planejamento e avaliação de programas e formulação de hipóteses de pesquisa. Seguem alguns exemplos de utilização dos sistemas de vigilância em saúde:

- $\quad$ orientar ações imediatas para doenças ou agravos de importância para a saúde pública;

- medir a carga de uma doença (ou outro evento relacionado à saúde), incluindo mudanças nos fatores relacionados, a identificação de populações de alto risco, bem como a identificação de novos problemas de saúde ou emergentes de saúde; monitorar as tendências da carga de uma doença (ou outro evento relacionado à saúde), incluindo a detecção de epidemias (surtos)e pandemias;

- orientar o planejamento, implementação e avaliação de programas de prevenção e controle de doenças, agravos ou exposições a fatores de risco;

- $\quad$ avaliar as políticas públicas;

- $\quad$ detectar mudanças nas práticas de saúde e os efeitos dessas mudanças;

- $\quad$ priorizar a alocação de recursos para a saúde;

- $\quad$ descrever o curso clínico da doença; e fornecer uma base para investigação epidemiológica. 


\subsection{SISTEMA DE INFORMAÇÃO DE AGRAVOS DE NOTIFICAÇÃO (SINAN)}

Entre os diversos sistemas de informação em saúde do SUS, o SINAN tem como objetivo registrar e processar os dados sobre a ocorrência de doenças de notificação compulsória no país, que constam na relação estipulada na Portaria $\mathrm{n}^{\circ}$ 204, de 17 de fevereiro de 2016, sendo facultado aos estados e municípios incluir outras doenças ou agravos que considerem importantes para a sua região (MS, 2016; DOMINGUES e SOUZA, 2009).

O SINAN fornece informações para análise do perfil da morbidade e contribui para a tomada de decisões em nível municipal, estadual e federal. Ele foi idealizado para ser utilizado como a principal fonte de informação para vigilância de doenças e agravos, permitindo monitorar as tendências, realizando estimativas de magnitude e de carga de doença, sendo capaz de detectar agregados e alteração do padrão epidemiológico de doenças de notificação compulsória (DNC) e de eventos de interesse para a saúde pública (DATASUS, 2014).

Tal sistema foi concebido e desenvolvido, no início dos anos 90, pelo Centro Nacional de Epidemiologia (CENEPI), com o apoio técnico do Departamento de Informação e Informática do SUS (DATASUS) e da Empresa de Processamento de Dados da Prefeitura de Belo Horizonte (Prodabel) (MS, 2005). Sua criação tinha como objetivo tentar sanar as dificuldades do Sistema de Notificação Compulsória de Doenças (SNCD), cuja existência pode ser retroagida à própria Lei no 6.259 , de 30 de outubro de 1975, que instituiu o Sistema Nacional de Vigilância Epidemiológica (SNVE) e estabeleceu a obrigatoriedade da notificação de algumas doenças no país (MS, 1975, 1976).

O SINAN apresenta uma lógica diferente dos outros sistemas de informação. Tal particularidade está relacionada à sua estrutura que, embora tenha sido idealizada como um sistema único, com capacidade de registrar o total de doenças/agravos definidos como de notificação obrigatória no país, trata-se de um sistema modular, com subsistemas concernentes a uma 
variedade de doenças/agravos com tradição de serem gerenciadas verticalmente. O que favorece a visão fragmentada sobre o perfil de morbidade relacionado às doenças de notificação compulsória. Isso estabelece para os gestores do SINAN uma heterogeneidade e complexidade para cada subsistema, sendo que cada um apresenta particularidades em relação à cobertura, atualização de dados, preenchimento das fichas etc. (CAETANO, 2009).

A concepção do SINAN foi norteada pela padronização de conceitos de definição de caso, pela transmissão de dados a partir da organização hierárquica das três esferas de governo, pelo acesso a base de dados necessária para a análise epidemiológica e pela possibilidade de disseminação rápida dos dados gerados na rotina do Sistema Nacional de Vigilância Epidemiológica do SUS (LAGUARDIA et al., 2004).

Se utilizado efetivamente, o SINAN permitirá a realização do diagnóstico dinâmico da ocorrência de um evento na população, podendo fornecer subsídios para explicações causais dos agravos de notificação compulsória, além de indicar os riscos aos quais a população está sujeita, contribuindo, assim, para a identificação da realidade epidemiológica de determinada área geográfica. O SINAN pode tornar-se um instrumento relevante para auxiliar o planejamento da saúde, definir prioridades de intervenção, além de permitir que seja avaliado o impacto das intervenções (MS, 2007). A utilização sistemática do SINAN, de forma descentralizada, favorece a democratização da informação, possibilitando que profissionais de saúde tenham acesso à informação e as tornem disponíveis para a comunidade (MS, 2007).

Em 18 de dezembro de 1997, o uso do SINAN foi regulamentado pela portaria MS/GM № 1.882 , tornando obrigatória a alimentação regular da base de dados pelos municípios, estados e Distrito Federal, bem como designado o Ministério da Saúde como gestor nacional do sistema (MS, 1997).

Desde a sua implantação, o SINAN passou por diversas reformulações, conforme ilustra a Figura 1 (MAIA, 2015). A instauração do aplicativo SINANDOS, em 1993, foi realizada de forma gradual, em virtude do caráter voluntário de adesão das Secretarias de Estado e Municipais de Saúde e, em razão de 
algumas limitações, foi substituído, em 2001, por uma versão em Windows (LAGUARDIA et al.; 2004, MAIA, 2015). Em 2007, foi implantado o SINAN-Net e em dezembro de 2010, foi apresentada uma versão on-line do SINAN, a qual tinha como objetivo substituir as versões anteriores. Ela não atendeu às expectativas quanto ao modelo de desenvolvimento, que não foi totalmente adequado às exigências do SUS, principalmente em relação à gestão das bases de dados locais (DATASUS, 2014).

A Secretaria de Vigilância em Saúde do Ministério da Saúde (SVS/MS) iniciou, em 2012, o desenvolvimento de um novo SINAN para substituir as versões em uso: SINAN Net, SINAN Dengue On-line e SINAN Influenza On-line (CONASS, 2013).

Figura 1 - Linha do tempo do SINAN

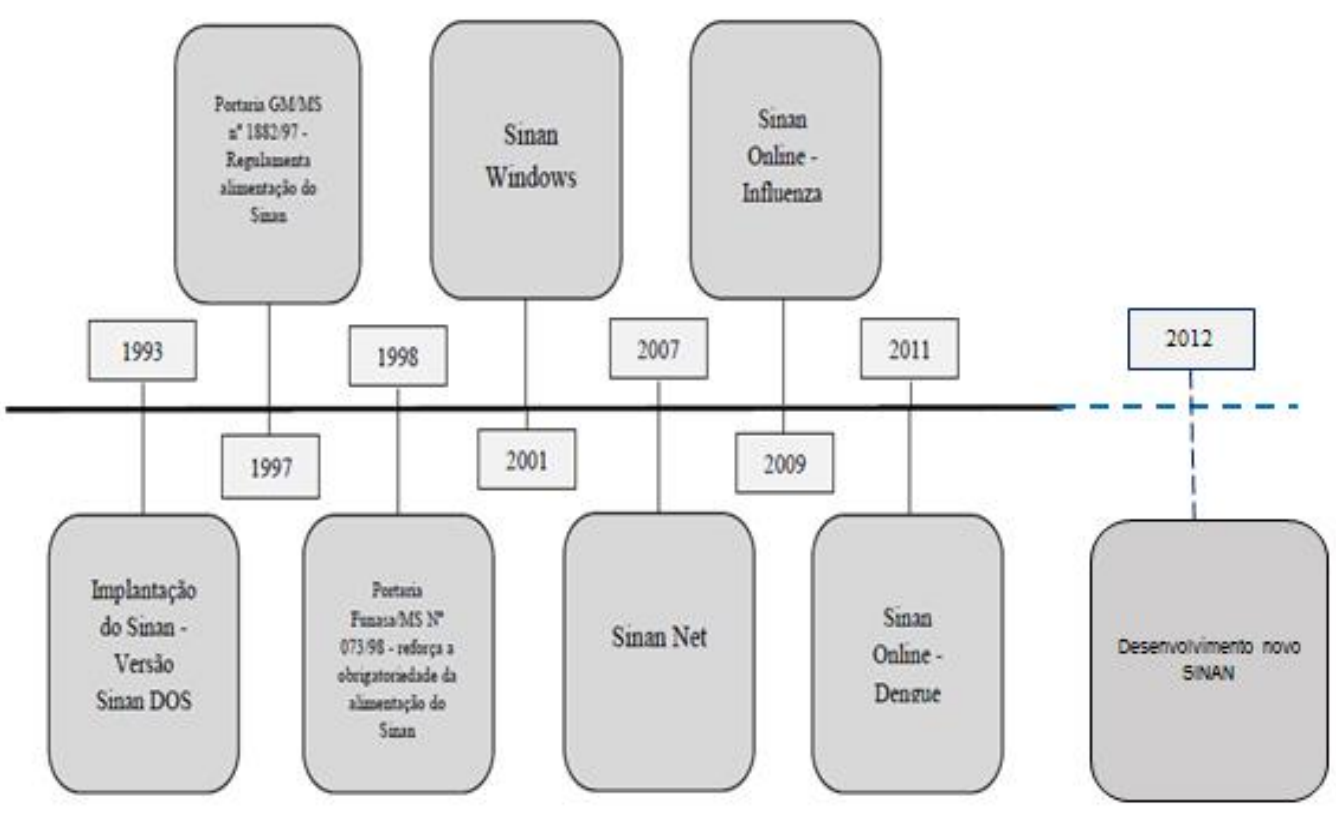

Fonte: Adaptado de Maia (2015) e Conass (2013).

As mudanças estruturais pelas quais o SINAN vem passando desde a sua criação demandam todo um processo de qualificação, informatização e 
capacitação de recursos humanos, visando à uniformidade na utilização do sistema pelos 5.565 municípios brasileiros.

Os principais indicadores gerados pelo SINAN são: taxa ou coeficiente de incidência, taxa ou coeficiente de prevalência e coeficiente de letalidade. Outras informações também podem ser obtidas, tais como o percentual de sequelas, o impacto das medidas de controle e o percentual de casos suspeitos e confirmados. Além disso, conforme a doença/agravo pode ser obter dados sociodemográficos, sinais clínicos dados laboratoriais entre outras informações (MS, 2010).

Para que o acompanhamento da situação epidemiológica dos agravos seja efetivo, é importante que o SINAN mantenha sua base de dados atualizada. Da mesma forma, dados de má qualidade, ou seja, fichas de notificação ou investigação com campos em branco, incongruências de informações, duplicidades de informações, entre outros problemas são identificados no nível municipal, estadual ou federal, indicando uma necessidade de avaliação constante da qualidade da informação do nível local, antes de serem transferidos (CAETANO, 2009).

\subsubsection{Fluxo do SINAN - Coleta de dados}

As informações referentes à ocorrência de determinada doença ou agravo à saúde de notificação deve ser enviada às autoridades sanitárias, a comunicação deve ser feita por profissionais da saúde ou qualquer cidadão, que deles tenha conhecimento, também poderá ser realizada pelos responsáveis por estabelecimentos públicos ou privados educacionais, de cuidado coletivo, além de serviços de hemoterapia, unidades laboratoriais e instituições de pesquisa (MS, 2016).

Para notificar agravos de notificação compulsória, existem dois documentos básicos, que complementam, entre si, as informações sobre cada caso notificado: a) ficha individual de notificação (FIN), é preenchida pelas 
unidades assistenciais, para cada paciente, a partir da suspeita clínica da ocorrência de algum agravo de notificação compulsória ou outro agravo sob vigilância. Ela é padronizada para todas as doenças e agravos; b) ficha individual de investigação (FII), que contém campos específicos de orientação para a investigação do caso, capaz de possibilitar a identificação da fonte de infecção e os mecanismos de transmissão da doença. As secretarias estaduais ou municipais de saúde são responsáveis pela impressão e distribuição dos formulários. Concebido como sistema modular e informatizado desde o nível local, pode ser operado a partir das unidades de saúde (MS, 2007; TROCCOLI, 2011).

A impressão, distribuição e o controle da Ficha de Notificação prénumerada para os municípios são de responsabilidade da Secretaria Estadual de Saúde, podendo ser delegadas para o município. Já as fichas de investigação de casos suspeitos e/ou confirmados e de surto poderão ser reproduzidas pelos municípios (MS, 2007).

A operacionalização do SINAN deve ser realizada no nível administrativo o mais periférico possível, ou seja, a unidade de saúde. Quando o município não dispuser de microcomputadores nas suas unidades, o mesmo pode ser operacionalizado a partir dos Distritos Sanitários, das Gerências de Vigilância Epidemiológica das Secretarias Municipais, das Regionais de Saúde e da Secretaria Estadual de Saúde, levando em consideração que a responsabilidade dessas atribuições depende da condição de gestão do município (MS, 2007). É importante salientar que no Estado de São Paulo todos os municípios possuem a Gestão Plena do Sistema, ou seja, tem o comando único do sistema de saúde no seu território (MINTO, 2015).

Considerando a importância dos hospitais como fonte para notificação das DNC, principalmente na detecção de casos mais graves, e que a investigação epidemiológica pode demonstrar o surgimento de novas doenças, a reemergência de outras e, até mesmo, mudanças na história natural de uma doença, instituiu-se, através da Portaria 2.529/2004, o Subsistema Nacional de Vigilância Epidemiológica em Âmbito Hospitalar, integrado ao Sistema Nacional de Vigilância Epidemiológica (MS, 2004). 
Normalmente, as fichas de notificação/investigação, preenchidas com a informação referente às doenças/agravos oriundas das unidades de saúde, são encaminhadas às vigilâncias epidemiológicas, onde ocorre a digitação das fichas, investigação e encerramento dos casos (MAIA, 2015; SOUZA et al., 2007). Estas, por sua vez, enviam, semanalmente, à respectiva Secretaria de Estado da Saúde (SES). Já a comunicação da notificação compulsória imediata deverá ser informada pelo município em até 24 horas do recebimento, às demais esferas de gestão do SUS (MS, 2016).

Os arquivos de transferência do SINAN são encaminhados pelas SES para o Ministério da Saúde, por meio eletrônico, quinzenalmente, conforme calendário anual pactuado entre a SVS/MS e as SES (DOMINGUES e SOUZA, 2009).

A Secretaria de Vigilância em Saúde processa e consolida os dados enviados pelas secretarias estaduais de saúde e disponibiliza na base do SINAN por meio do TABNET (TROCCOLI, 2011).

Quando não houver nenhuma suspeita de doença, as unidades precisam preencher o formulário de notificação negativa, que tem os mesmos prazos de entrega. Essa conduta foi estabelecida para demonstrar que os profissionais e o sistema de vigilância da área estão alertas para a ocorrência de tais eventos e para evitar a subnotificação (DOMINGUES e SOUZA, 2009).

Dentre as atribuições de cada nível do sistema, cabe a todos efetuar a análise da qualidade dos dados (duplicidade, completitude dos campos e consistência dos dados), as análises epidemiológicas e a divulgação das informações. No entanto, cabe somente ao primeiro nível municipal informatizado realizar a complementação de dados, a correção de inconsistências, a vinculação/exclusão de duplicidades e a exclusão de registros (MS, 2007). 
Figura 2 - Fluxo de Informações do SINAN

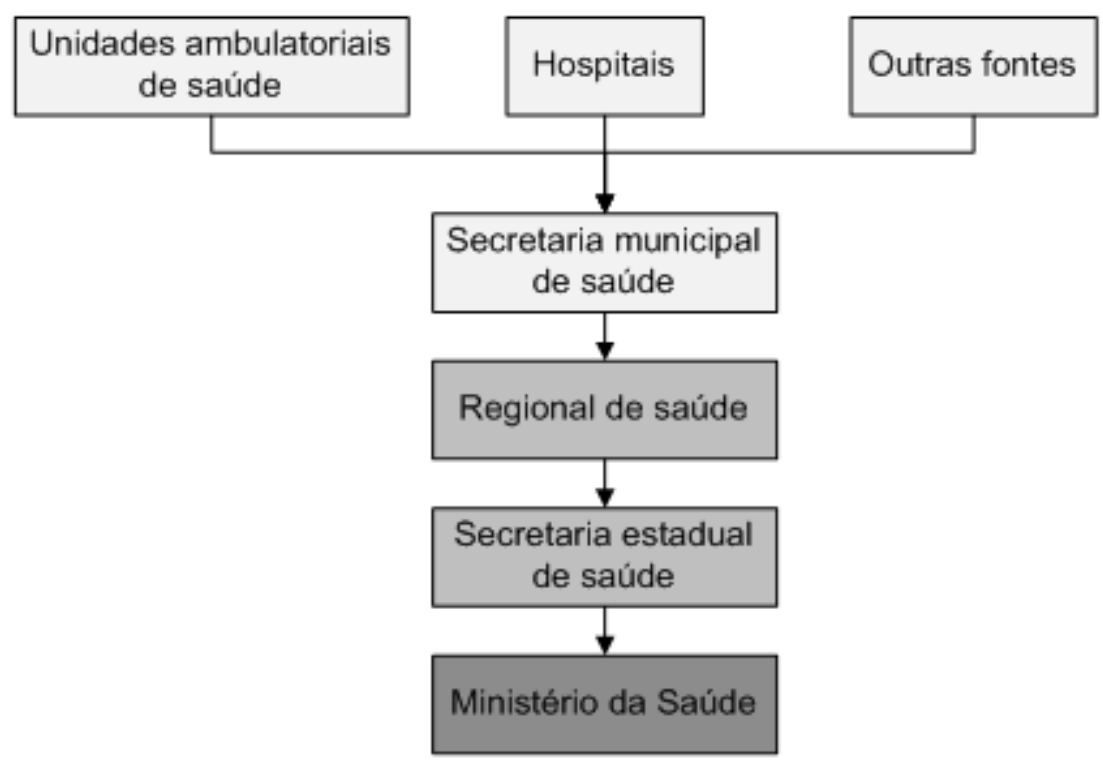

Municipal

Estadual

Nacional

Fonte: Guia de Vigilância Epidemiológica 2005.

Visando diminuir as subnotificações dos relatos de agravos à saúde e também melhorar adesão ao SINAN, normas e portarias atuam regularizando este processo nas três esferas de poder. A Portaria $n^{\circ} 47$, de 3 de maio de 2016, regulamenta parâmetros para monitoramento da regularidade na alimentação do SINAN, para fins de manutenção do repasse de recursos do Componente de Vigilância e Promoção da Saúde, do Bloco de Vigilância em Saúde. Os municípios devem seguir os seguintes parâmetros:

"I - será considerada situação irregular na alimentação do SINAN, a Secretaria Municipal de Saúde (SMS) que não registrar, no período de 8 (oito) semanas epidemiológicas de notificação consecutivas no período avaliado a:

a) notificação individual de agravos de notificação compulsória;

b) notificação de surtos;

c) notificação de epizootias; ou

d) notificação negativa." 
Alguns autores discutem a efetividade dessas medidas. Em trabalho de avaliação do SINAN, que entrevistou gestores e pesquisadores, esses avaliaram que as exigências de financiamento que incorporaram indicadores epidemiológicos como condição para liberação de recursos aos municípios tiveram um efeito contraditório. Consideraram que medidas empreendidas para enfrentar problemas de cobertura e de irregularidades de fluxo podem ter impacto negativo na qualidade da informação. Esses analistas avaliaram que a possibilidade de suspensão dos recursos, quando o município deixa de alimentar o sistema, se por um lado fortalece a importância do sistema de informação, por outro há a possibilidade de que esse mecanismo possa induzir a notificação de baixa qualidade. Os municípios podem tão somente alimentar os sistemas, sem necessariamente fazer um uso efetivo da informação para monitoramento e avaliação da situação de morbidade da população (CAETANO, 2009). 


\subsubsection{Avaliação do SINAN e de outros sistemas}

Estudos foram realizados visando avaliar a qualidade dos dados, fluxo das informações e condições técnicas para operar o SINAN, em geral circunscritos ao estudo de uma determinada doença ou agravo.

O estudo realizado por GALVÃO et al. (2009) em Pernambuco analisou o software do SINAN em relação à qualidade dos dados fornecidos, a transferência de dados computadorizados do nível municipal para o estadual, recursos humanos e outros fatores associados à infraestrutura do sistema de informação de saúde. Uma amostra das regiões de saúde e municípios foi escolhida. Formulários do SINAN desses municípios foram analisados e o fluxo de notificações foi seguido, do nível municipal até o regional e, finalmente, ao estadual. Foram entrevistados profissionais do Programa de Controle da Hanseníase $(\mathrm{PCH})$ de unidades de saúde, distritos, municípios e regiões, e coordenadores do Sistema de Vigilância Epidemiológica (SVE), secretários de saúde e gestores dos municípios e regiões de saúde selecionadas. Para os entrevistados, o software do SINAN está funcionando de acordo com as expectativas. No entanto, em todos os níveis do sistema de saúde, foram encontradas falhas graves não relacionadas com o software, variando desde falta de recursos humanos (número limitado de funcionários e falta de capacitação dos funcionários), falta de infraestrutura (espaço dos escritórios, computadores, suprimentos etc.) até a ausência de coordenação efetiva, gerenciamento e supervisão do SIS.

SOUSA e PINHEIRO (2011) analisaram a subnotificação de óbitos e internações por tuberculose no SINAN, em residentes do município do Rio de Janeiro, e observaram que $43,2 \%$ dos óbitos e $22,1 \%$ das internações não foram notificados ao SINAN no período de estudo. Os resultados sugerem problemas na detecção de casos e apontam barreiras de acesso ao tratamento oportuno e adequado e falhas na qualidade do sistema de informação, com diferenças entre as regiões do município. 
Em outro estudo, foram confrontados os dados de 55 óbitos relacionados à tuberculose, obtidos no Sistema de Informação sobre Mortalidade (SIM), ocorridos em dois hospitais de grande porte do Rio de Janeiro em 2006 (SELIG et al. 2010), com os registros do SINAN. Avaliou-se o incremento no número de notificações e na completitude dos dados, bem como o tipo de entrada e desfecho no SINAN. Observou-se que, dos 55 óbitos, apenas 28 estavam notificados no SINAN, o que resultou em incremento de $28 \%$ das notificações realizadas pelos dois hospitais, quando incorporadas as informações do SIM.

No estudo de LIMA et al., (2015), realizado em uma subprefeitura do município de São Paulo, sobre a percepção dos gestores de serviços de saúde em relação aos indicadores de saúde, verificou-se que os gestores entrevistados reconhecem a lentidão dos sistemas, o número reduzido de profissionais, a falta de capacitação periódica e a pouca integração entre os sistemas como dificuldades e limitações para uma utilização mais efetiva das informações em saúde. Na percepção dos gestores, esses itens deveriam ser contemplados para o aprimoramento institucional dos sistemas de informação, favorecendo o uso mais efetivo dos indicadores de saúde.

Atualmente, novas abordagens apontam a necessidade de uma avaliação multidimensional dos sistemas de informação, que contemple todo o processo de geração e uso da informação para além das avaliações de qualidade dos dados e indicadores (LIMA et al. 2010). Essas avaliações incluem a análise da disponibilidade de recursos, como os de infraestrutura, tecnologia da informação e comunicação, recursos humanos, além da realização de processos de capacitação. No Brasil, recentemente, foram desenvolvidas pesquisas sobre as condições de operação e gerenciamento dos SIS no âmbito municipal (VIDOR et al., 2011; GUIMARÃES et al., 2013; MINTO et al. 2017), instância na qual se inicia a cadeia de produção de dados que alimentam diversos sistemas.

No estudo avaliativo sobre o grau de implantação do Sistema de Informações sobre Nascidos Vivos (SINASC) em municípios de Minas Gerais, em 2010, foi identificado que o SINASC não está implantado adequadamente 
na maioria $(65,9 \%)$ dos municípios avaliados. Como limitações, destacam-se insuficiência de profissional qualificado, ocasionando coleta e preenchimento da Declaração de Nascidos Vivos insatisfatórios, subutilização dos dados e precária divulgação das informações (GUIMARÃES et al., 2013). A avaliação permitiu verificar, entre os municípios estudados, fragilidades na política de informação organizacional, com prejuízos à autonomia política, gerencial e técnica, cujos efeitos repercutem diretamente na qualidade da informação e na sua utilização para a gestão do cuidado em saúde.

Já no estudo realizado com municípios gaúchos com menos de 10 mil habitantes, verificou-se que todos os municípios dispunham de computadores e tinham acesso à Internet. Os responsáveis pela alimentação e análise dos sistemas de informação eram funcionários estatutários que acumulavam outras tarefas. Os sistemas mais utilizados relacionavam-se a controle orçamentário e repasse de verbas. Os indicadores citados como importantes para o planejamento local foram os mesmos utilizados na pactuação com o Estado e apenas 4,7\% estavam plenamente satisfeitos com as informações obtidas dos sistemas de informação em saúde (VIDOR et al., 2011).

\subsubsection{Desafios do SINAN}

O estudo de LAGUARDIA (2004) sobre o SINAN relatou algumas dificuldades em utilizar esse banco de dados tais como: insuficiência de recursos humanos qualificados, de equipamentos compatíveis para apoiar o processo de implementação e gerenciamento dos sistemas de informação em saúde. Além dessas dificuldades, o autor citou outro problema relacionado a falta de integração com os demais sistemas, característica presente nos sistemas de informação em saúde no Brasil.

Na visão de DOMINGUES e SOUZA (2009), o SINAN, embora seja o sistema mais utilizado para a vigilância epidemiológica, ainda apresenta alguns problemas. Parte deles deriva da tentativa de englobar as funções de um sistema de notificação e as funções de um sistema de investigação de casos, o que resulta em um produto moroso com muitas lacunas de informação, 
principalmente no que se refere à localização e à autoctonia dos casos, num nível de desagregação compatível com as necessidades dos serviços locais de saúde.

Estudo realizado pelo Ministério da Saúde (2009) que consultou diversos profissionais apresentou que em especial nos níveis mais locais do sistema de informação, há dificuldade de acessar os bancos de dados, condição necessária para que a grande quantidade e a riqueza de informações disponíveis possam ser efetivamente utilizadas no diagnóstico epidemiológico da situação de saúde e no planejamento e avaliação das ações desencadeadas. A baixa utilização das informações do SINAN, também foi citada como uma dificuldade encontrada pelos serviços. Apesar da evolução do sistema, capaz fornecer dados por qualquer nível de desagregação espacial, o que permite visualizar tanto os seus dados como também compará-los, esta etapa ainda é tênue (CAETANO, 2009).

A disponibilidade de informações apoiadas em dados válidos e confiáveis é condição essencial para a análise objetiva da situação de saúde, assim como para a tomada de decisões baseadas em evidências (OPAS/MS, 2008). Por sua vez, a produção de dados válidos e confiáveis dependerá das condições locais de produção, que envolve aspectos político-administrativos, infraestrutura física e humana, além de capacidade técnica dos profissionais envolvidos (LIMA et al., 2010). A descentralização da operação dos SIS para os municípios permitiu maior autonomia na gestão das informações, mas também trouxe, para alguns, enormes desafios.

As informações com qualidade e disponibilidade oportunas colaboram para que o Sistema Único de Saúde (SUS) se aprimore, se consolide e realize um de seus objetivos, que é a identificação e divulgação do perfil de mobimortalidade relacionada às DNC, bem como dos fatores condicionantes e determinantes da saúde, e também na implementação de medidas de controle das doenças. Apesar da importância do SINAN nas ações de vigilância epidemiológica, a literatura aponta poucos estudos que avaliam especificamente a utilização efetiva desse sistema, na perspectiva de aprimoramento dos serviços de saúde. Sendo assim, o presente estudo tem 
como finalidade conhecer as condições, o uso e os desafios do SINAN nos municípios paulistas, contribuindo para a compreensão de suas necessidades. 


\section{OBJETIVOS}

\subsection{OBJETIVO GERAL:}

Analisar as condições de operação do SINAN segundo o porte populacional dos municípios paulistas, no que diz respeito às condições técnicas e de infraestrutura, bem como de apoio institucional.

\subsection{OBJETIVOS ESPECÍFICOS:}

- Descrever a alocação institucional e constituição da equipe da vigilância epidemiológica, recursos disponíveis e treinamento para operação do SINAN, segundo o porte populacional;

- Comparar se há diferenças de alocação de recursos humanos, equipamentos e gestão do SINAN, segundo o porte populacional;

- Identificar dificuldades e desafios da gestão municipal no processo de operacionalização do SINAN, segundo o porte populacional. 


\section{MATERIAL E MÉTODOS}

\subsection{DELINEAMENTO DO ESTUDO}

Estudo exploratório e descritivo de abordagem quantitativa, realizado em duas etapas. Na primeira etapa foram realizadas entrevistas com alguns responsáveis técnicos pelo SINAN. Na segunda etapa foi aplicado um questionário aos responsáveis técnicos pela Vigilância Epidemiológica nos municípios do estado de São Paulo. Este projeto está vinculado à pesquisa principal "Descentralização dos Sistemas de Informações em Saúde nos Municípios do Estado de São Paulo", que tem como objetivo conhecer a situação atual da descentralização dos sistemas de informações em saúde de base epidemiológica, mais especificamente o SIM, SINASC e o SINAN. Nesta tese foram estudados os dados referentes ao Sistema de Informação de Agravos de Notificação (SINAN).

A pesquisa foi realizada em parceria entre a Faculdade de Saúde Pública - USP e a Secretaria de Estado da Saúde, com apoio financeiro do Conselho Nacional de Desenvolvimento Científico e Tecnológico - CNPq.

\subsection{LOCAL DO ESTUDO}

O estudo foi realizado no estado de São Paulo, que conta com população de 41.223.683 habitantes (2010) distribuídos em 645 municípios, dos quais 90\% registravam IDH alto/muito alto, em 2010 (Fundação SEADE, 2017). Trata-se da unidade da federação mais desenvolvida do país, porém com grande heterogeneidade, com população municipal variando de 804 a mais de 11 milhões de habitantes, com dinâmica demográfica que engloba municípios com taxa de crescimento populacional de até 3,06\% ao ano, 
enquanto 111 municípios registraram diminuição da população entre 2000 e 2010 (Fundação SEADE, 2017). O Estado apresenta um diferencial importante em relação ao porte populacional entre os municípios (FUNDAÇÃO SEADE, 2017),destacando-se municípios de pequeno porte.

- 456 municípios possuem até 30.000 habitantes $(70,70 \%)$;

- 150 municípios possuem de 30.001 a 200.000 habitantes $(23,25 \%)$;

- 39 municípios possuem acima de 200.001 habitantes (6,05\%)

O Estado possui 63.651 estabelecimentos de saúde públicos e privados. Todos os municípios contam com pelo menos uma unidade básica de saúde, que são unidades notificadoras (MINTO, 2015).

Atualmente, a divisão administrativa da Secretaria de Saúde do Estado de São Paulo conta com cinco macrorregiões, 17 Departamentos Regionais de Saúde (DRS) e 28 Grupos de Vigilâncias Epidemiológicas Regionais (GVE) (MINTO, 2015).

Os Grupos de Vigilância Epidemiológica (GVE) tem como função: coordenar, supervisionar e controlar ações de vigilância epidemiológica; analisar epidemiologicamente o comportamento das doenças; propor, executar e realizar inquéritos epidemiológicos; propiciar integração entre os órgãos de vigilância epidemiológica; realizar treinamentos e capacitações; monitorar sistemas de vigilância à saúde; apoiar municípios nas ações; distribuir impressos de notificação.

\subsection{COLETA DE DADOS}

\subsubsection{Etapa 1}

Realizou-se um estudo inicial em dois municípios paulistas (Cajamar e São Bernardo do Campo) e um estudo no Grupo de Vigilância Epidemiológica (GVE) da região de Santos. O estudo piloto foi de fundamental importância para direcionar a viabilidade e adequação do instrumento de coleta. 
Foram selecionados sete municípios de distintos portes populacionais, sendo três pertencentes às regiões metropolitanas (Itapecerica da Serra, Santa Isabel e Holambra), três do interior (Santa Branca, Sorocaba e Itu) e um do litoral (Guarujá), visando contemplar diferentes visões sobre o SINAN. A seleção dos municípios levou em consideração, além dos diferentes portes, a facilidade de locomoção do pesquisador entre os municípios e a capital (local de residência do pesquisador).

Para o levantamento das informações, utilizou-se a entrevista com gestores do SINAN. Para MINAYO (1998), a entrevista é uma estratégia para a coleta de dados, na qual o pesquisador busca, nas falas dos atores sociais, informações relativas às suas ideias, crenças, maneiras de atuar, condutas ou comportamentos, intenções, motivações conscientes ou inconscientes, sentimentos. É uma das técnicas mais usadas no trabalho de campo, a qual consiste em um processo de interação social entre sujeitos que atuam no processo e aquele que estuda o processo. Essa etapa exploratória foi de grande importância para aproximar o autor da realidade local.

As setes entrevistas foram realizadas a fim de identificar os aspectos operacionais e opinião sobre dificuldades e desafios no processo de trabalho com o SINAN. Elas foram agendadas de acordo com as disponibilidades dos entrevistados, ocorrendo nos respectivos locais de trabalho e durante 0 expediente, no período de maio a outubro de 2016. Foram entrevistados os profissionais responsáveis ou que atuavam na equipe do SINAN. O tempo de duração de cada entrevista foi em média de 40 minutos. As entrevistas gravadas foram registradas em arquivos MP3 e transcritas na íntegra.

Como instrumento de coleta de dados, foi utilizado um roteiro (apêndice 1) com oito questões abertas, sendo utilizadas posteriormente como referência na elaboração do questionário eletrônico (Etapa 2). O roteiro contemplou os seguintes tópicos:

- Perfil do Responsável Técnico;

- Organização Institucional;

- Perfil da Equipe que compõe a vigilância epidemiológica; 
- Infraestrutura física e de informática;

- Processo de trabalho: fluxo das notificações, instrumento paralelo, entre outros;

- Apoio técnico e institucional (SMS, GVE ou outro);

- Uso dos dados e indicadores para apoio à gestão;

- Dificuldades para operar o SINAN.

\subsubsection{Etapa 2}

Foi aplicado um questionário eletrônico, fundamentado nas entrevistas realizadas na primeira etapa do projeto, para coleta de dados junto aos 644 municípios do estado de São Paulo. O município de São Paulo foi excluído do estudo por apresentar uma organização administrativa complexa, onde as ações de vigilância estão descentralizadas em 26 UVIS (Unidades de Vigilância em Saúde), que atuam em três áreas: Vigilância Ambiental, Vigilância Sanitária e Vigilância Epidemiológica, sendo esta última onde majoritariamente são realizadas ações referentes ao SINAN. Possivelmente a aplicação da pesquisa nesses serviços necessitaria de adaptação do questionário e de apoio especial da Secretaria Municipal de Saúde, assim como exigiria uma abordagem analítica diferenciada, principalmente em relação à comparação com os municípios paulistas.

Para criação do questionário, foi utilizado o FORMSUS, serviço do DATASUS para a criação de formulários na web. As questões presentes no questionário foram discutidas inicialmente com os responsáveis do SINAN no estado de São Paulo, a diretora técnica e equipe do Centro de Vigilância Epidemiológica/CVE/CCD/SES-SP da Secretaria Estadual e o grupo de pesquisa da Faculdade de Saúde Pública.

O formulário foi enviado para avaliação de dois profissionais com expertise no tema, denominados juízes, para os quais foi solicitado que avaliassem as questões, considerando os seguintes critérios: 
$\checkmark$ Clareza: se o enunciado e as alternativas de cada questão são plenamente inteligíveis, sem gerar interpretações distintas;

$\checkmark$ Aplicabilidade: se a questão se aplica adequadamente ao objetivo proposto;

$\checkmark$ Poder discriminativo: se a questão consegue separar por categorias os resultados esperados;

$\checkmark$ Presença de vieses: se a questão ou as alternativas oferecem possibilidade de desvios de respostas;

$\checkmark$ Redundância: se a questão repete temas abordados em outra questão. Após as avaliações, foram realizados ajustes necessários para versão final do instrumento (Apêndice 3), que ficou composto por 54 questões. Foram investigadas as seguintes variáveis:

1. Perfil do respondente: cargo, sexo, idade, escolaridade, curso de formação mais avançado, vínculo trabalhista, tempo de trabalho na área da saúde, tempo de trabalho com o SINAN e responsabilidade por outros sistemas;

2. Estrutura organizacional da Vigilância Epidemiológica: alocação administrativa da vigilância epidemiológica;

3. Recursos humanos: número de profissionais que trabalham na vigilância epidemiológica por nível de formação; realização e pós-graduação em Epidemiologia e/ou Saúde Pública;

4. Recursos de infraestrutura: adequação da estrutura física do local de trabalho;

5. Recursos de informática: número de computadores, sistemas operacionais utilizados, acesso à internet, suporte técnico, tipo de backup;

6. Recursos materiais: disponibilidade de materiais para operar o SINAN;

7. Processo de trabalho: atividades realizadas e responsáveis por elas, processos para garantia da qualidade dos dados, utilização da ferramenta Tabwin; realização de análise espacial dos dados, existência de instrumentos paralelos;

8. Capacitação profissional: treinamento recebido para trabalhar com 0 SINAN, capacitação das unidades notificadoras; 
9. Disseminação de dados: divulgação dos dados do SINAN para as unidades notificadoras, instrumento disponível com informações do SINAN, principais usos da informação;

10. Avaliação: qualidade do preenchimento das fichas de notificação/investigação; apoio técnico das instituições, dificuldades encontradas na operação do sistema e grau de benefício da descentralização do sistema.

Foi informado na carta de convite que o questionário deveria ser preenchido preferencialmente pelo responsável pela Vigilância Epidemiológica ou outro operador do SINAN indicado por este.

Para divulgação e sensibilização quanto à aplicação do questionário, foi solicitado apoio do COSEMS/SP (Conselho de Secretários Municipais de Saúde de São Paulo), que encaminhou correspondência aos secretários municipais de saúde, solicitando que os diretores municipais de vigilância epidemiológica respondessem o questionário. O COSEMS enviou um convite aos responsáveis pela vigilância epidemiológica, informando o objetivo e justificativa do estudo e o link para acesso ao questionário. Após 30 dias da solicitação, na tentativa de obter uma maior adesão, foi enviando novamente pelo COSEMS um e-mail solicitando a colaboração no preenchimento pelos municípios que ainda não tinham respondido. Como um último esforço em atingir ampla cobertura no preenchimento, foram realizados contatos telefônicos e por email com os municípios que pertenciam aos GVEs com adesão inferior a $50 \%$.

A aplicação do questionário foi realizada entre os dias 6 de junho a 14 de agosto de 2017, com duração de 75 dias.

\subsection{ANÁLISE DOS DADOS}

Os resultados foram analisados segundo porte populacional dos municípios, com base na estimativa da população em 2015 (IBGE), estratificado em três categorias: Grupo 1 (G1), constituindo os municípios com 
até 30.000 habitantes; Grupo 2 (G2), municípios com população de 30.001 a 200.000 habitantes; e Grupo 3 (G3); com população acima de 200.001 habitantes. A escolha destas categorias considerou o recorte de menos de 30.000 habitantes, uma vez que o Ministério da Saúde utiliza este recorte para realização de monitoramento da regularidade na alimentação do SIM, para fins de manutenção do repasse de recursos do Componente de Vigilância e Promoção da Saúde (Portaria MS/SVS n 201/2010). Embora para o SINAN não exista nenhum recorte para monitoramento, foi adotado a mesma categoria populacional usada no SIM, visando manter a padronização definida no projeto principal.

A análise dos dados foi realizada por meio de estatística descritiva, com a elaboração de medidas de distribuição e, em alguns casos, de medidas de tendência central. Os testes de qui-quadrado e a ANOVA foram utilizados para comparação entre proporções e médias, respectivamente, entre os grupos de municípios, utilizando-se nível de significância $p<0,05$.

Para análise estatística, foi utilizado o programa Statistical Package for the Social Sciences (SPSS), versão 17.0 


\subsection{ASPECTOS ÉTICOS}

A coleta das informações foi realizada por meio de entrevistas e questionário online (etapa 1 e 2). O nível de risco à saúde associado à participação nesta pesquisa foi classificado como sendo mínimo. O levantamento de dados não implica danos de qualquer natureza ou desconforto para os respondentes. As entrevistas foram realizadas nos setores da administração municipal em que os respondentes atuavam. Os sujeitos da pesquisa foram informados quanto aos objetivos do estudo e à importância do conhecimento pretendido.

Foi solicitado a todos os entrevistados a leitura e assinatura do "Termo de consentimento livre e esclarecido" (Apêndice 2) e, para os municípios que responderam o questionário online, foi solicitado a leitura e aceitação do termo supracitado em consonância com as diretrizes estabelecidas pela Resolução 466/2012 do Conselho Nacional de Saúde.

As informações coletadas durante a pesquisa foram analisadas de forma agregada e não foram divulgadas com discriminação individual.

O projeto de pesquisa foi aprovado pelo Comitê de Ética em Pesquisa da Faculdade de Saúde Pública da Universidade de São Paulo, sob $\mathrm{n}^{-}$ 1.420 .485 (anexo 1). 


\section{RESULTADOS}

O questionário eletrônico foi encaminhado para 644 municípios do Estado de São Paulo, e obteve-se retorno de 407 (63,2\%). O retorno por grupo do GVE variou de $46,7 \%$ a $88,9 \%$ (Anexo 2 - Tabela 1 A). A participação na pesquisa não foi homogênea, levando em consideração o porte populacional dos municípios. Os municípios com mais de 200.000 habitantes apresentaram maior participação $(71,8 \%)$, seguidos dos municípios entre 30.001 a 200.000 habitantes $(71,1 \%)$ e dos com população abaixo de 30.000 habitantes $(59,6 \%)$. As diferenças foram estatisticamente significantes entre os grupos (Tabela 1).

Tabela 1 - Número e proporção de municípios existentes e participantes da pesquisa, por porte populacional, Estado São Paulo, 2017.

\begin{tabular}{lccc}
\hline \multicolumn{1}{c}{ Porte Populacional } & \multicolumn{3}{c}{ Municípios } \\
\cline { 2 - 4 } & Total & Respondentes & $\%$ \\
\hline Até 30.000 hab. & 446 & 266 & 59,6 \\
De 30.001 a 200.000 hab. & 159 & 113 & 71,1 \\
Maior que 200.000 hab. & 39 & 28 & $\mathbf{7 1 , 8}$ \\
\hline Total & $\mathbf{6 4 4}$ & $\mathbf{4 0 7}$ & $\mathbf{6 3 , 2}$ \\
\hline $\mathrm{p}=0,019$ & &
\end{tabular}

\subsection{PERFIL DO RESPONSÁVEL TÉCNICO}

Foi solicitado que 0 questionário deveria ser preenchido preferencialmente pelo diretor/coordenador/chefe/responsável pela vigilância epidemiológica municipal, o que ocorreu em $86,7 \%$ dos municípios, com proporções semelhantes nos três grupos de municípios. Dos respondentes que não ocupavam os cargos já mencionados $(13,3 \%)$, metade exercia função administrativa ou de digitação, predominantemente nos municípios pequenos e médios.

Em relação ao perfil, houve predomínio do sexo feminino em $88,5 \%$ dos municípios, com representatividade aproximada em todos os grupos (tabela 2). 
A idade dos respondentes variou de 22 a 72 anos, com média de 40,9 anos (IC $\mathrm{I}_{95 \%}: 31,2$ - 50,7) e apresentou diferenças significativas entre os grupos $(p<0,001)$, observando-se que a média de idade aumentou dos municípios menores (38,8 anos; $I C_{95 \%}: 30,0$ - 47,6) para os maiores (50,2 anos; IC ${ }_{95 \%}: 39,4$ - 61,1). Ainda em relação à distribuição por faixa etária, observaram-se outras diferenças estatisticamente significativas entre os grupos. Nos municípios menores, $60,2 \%$ dos respondentes têm menos de 40 anos. Esta proporção regride nos municípios de médio e grande porte $(39,8 \%$ e $21,4 \%$, respectivamente). Destaca-se, ainda, que nos municípios de grande porte $60,7 \%$ dos respondentes têm 50 anos ou mais.

Em relação à escolaridade, 90,4\% dos respondentes apresentaram ensino superior completo, com maior frequência nos municípios maiores $(96,4 \%)$. Porém essas diferenças não foram estatisticamente significantes. 9,6\% dos entrevistados não possuem ensino superior, sendo que apenas dois $(0,5 \%)$ dos profissionais tinham ensino fundamental, situação restrita aos municípios de pequeno porte.

Em relação ao vínculo empregatício do respondente, predomina o efetivo/estatutário $(56,8 \%)$ com maior frequência nos municípios de grande porte $(64,3 \%)$. Já o vínculo CLT possui maior representatividade nos municípios de médio e pequeno porte (34,5\% e $33,8 \%$, respectivamente). 0 cargo em comissão, que pode ser visto como um cargo transitório, destacou-se no grupo de municípios de grande porte $(21,4 \%)$.

Quanto ao tempo de atuação no setor público da área de saúde, predominam os profissionais com 10 a 20 anos de trabalho $(41,5 \%)$, seguidos pelos que têm de 5 a 9 anos (25,8\%); esse perfil é observado nos municípios menores. Já os profissionais que trabalhavam há mais de 20 anos na área estão concentrados nos municípios de grande porte $(60,7 \%)$, mostrando diferenças estatisticamente significantes em relação aos demais grupos. 
Tabela 2 - Número e proporção de responsáveis técnicos municipais pela Vigilância Epidemiológica, segundo características, Estado de São Paulo, 2017.

\begin{tabular}{|c|c|c|c|c|c|c|c|c|}
\hline \multirow{3}{*}{ Variáveis } & \multicolumn{6}{|c|}{ Porte dos Municípios (habitantes) } & & \\
\hline & \multicolumn{2}{|c|}{ Até 30.000} & \multicolumn{2}{|c|}{ De 30.001 a 200.000} & \multicolumn{2}{|c|}{ Maior que 200.000} & \multicolumn{2}{|c|}{ Total } \\
\hline & $\mathrm{N}$ & $\%$ & $\mathrm{~N}$ & $\%$ & $\mathrm{~N}$ & $\%$ & $\mathrm{~N}$ & $\%$ \\
\hline \multicolumn{9}{|l|}{ Sexo* } \\
\hline Masculino & 34 & 12,8 & 10 & 8,8 & 3 & 10,7 & 47 & 11,5 \\
\hline Feminino & 232 & 87,2 & 103 & 91,2 & 25 & 89,3 & 360 & 88,5 \\
\hline \multicolumn{9}{|l|}{ Idade** } \\
\hline Menos de 40 anos & 160 & 60,2 & 45 & 39,8 & 6 & 21,4 & 211 & 51,8 \\
\hline De 40 a 49 anos & 69 & 25,9 & 28 & 24,8 & 5 & 17,9 & 102 & 25,1 \\
\hline De 50 anos e mais & 37 & 13,9 & 40 & 35,4 & 17 & 60,7 & 94 & 23,1 \\
\hline \multicolumn{9}{|l|}{ Escolaridade $* * *$} \\
\hline Inferior a ensino superior completo & 31 & 11,7 & 7 & 6,2 & 1 & 3,6 & 39 & 9,6 \\
\hline Ensino superior completo & 235 & 88,3 & 106 & 93,8 & 27 & 96,4 & 368 & 90,4 \\
\hline \multicolumn{9}{|l|}{ Vínculo $* * * *$} \\
\hline Efetivo/Estatutário & 150 & 56,4 & 63 & 55,8 & 18 & 64,3 & 231 & 56,8 \\
\hline CLT & 90 & 33,8 & 39 & 34,5 & 2 & 7,1 & 131 & 32,2 \\
\hline Contrato temporário/prestação de serviços & 5 & 1,9 & 1 & 0,9 & 0 & 0,0 & 6 & 1,5 \\
\hline Cargo em comissão & 18 & 6,8 & 8 & 7,1 & 6 & 21,4 & 32 & 7,9 \\
\hline Outro & 3 & 1,1 & 2 & 1,8 & 2 & 2,0 & 7 & 1,7 \\
\hline \multicolumn{9}{|l|}{ Tempo de trabalho na área de Saúde $* * * * *$} \\
\hline Menos de 1 ano & 3 & 1,1 & 1 & 0,9 & 1 & 3,6 & 5 & 1,2 \\
\hline 1 a 4 anos & 29 & 10,9 & 7 & 6,2 & 2 & 7,1 & 38 & 9,3 \\
\hline 5 a 9 anos & 78 & 29,3 & 22 & 19,5 & 5 & 17,9 & 105 & 25,8 \\
\hline 10 a 20 anos & 115 & 43,2 & 51 & 45,1 & 3 & 10,7 & 169 & 41,5 \\
\hline Mais de 20 anos & 41 & 15,4 & 32 & 28,3 & 17 & 60,7 & 90 & 22,1 \\
\hline \multicolumn{9}{|l|}{ Tempo de trabalho com SINAN $* * * * * *$} \\
\hline Menos de 1 ano & 34 & 12,8 & 8 & 7,1 & 2 & 7,1 & 44 & 10,8 \\
\hline 1 a 4 anos & 80 & 30,1 & 25 & 22,1 & 5 & 17,9 & 110 & 27,0 \\
\hline 5 a 9 anos & 73 & 27,4 & 35 & 31,0 & 6 & 21,4 & 114 & 28,0 \\
\hline 10 a 20 anos & 71 & 26,6 & 39 & 34,5 & 13 & 46,4 & 123 & 30,2 \\
\hline Mais de 20 anos & 8 & 3,0 & 6 & 5,3 & 2 & 7,1 & 16 & 3,9 \\
\hline Total & 266 & 100,0 & 113 & 100,0 & 28 & 100,0 & 407 & 100,0 \\
\hline
\end{tabular}

O tempo de experiência dos profissionais com o SINAN é inferior ao tempo de trabalho na área da saúde, conforme ilustrado na Figura 3. Observase que $37,8 \%$ dos responsáveis atuavam com o SINAN há menos de 5 anos, enquanto essa proporção para os que atuavam na área de saúde era de apenas 10,5\%. O mesmo se observa para os que atuavam há mais de 20 anos, apenas $3,9 \%$ no SINAN. Foram observadas proporções semelhantes entre si nas categorias de 1 a 4 anos (27,0\%), 5 a 9 anos (28,0\%) e 10 a 20 anos 
$(30,2 \%)$. No entanto, os municípios de médio $(34,5 \%)$ e grande porte $(46,4 \%)$ apresentam maiores proporções de profissionais na faixa de 10 a 20 anos de experiência, e $70,3 \%$ dos pequenos na faixa de $<10$ anos, porém as diferenças não foram estatisticamente significantes (Tabela 2).

Figura 3 - Distribuição dos Responsáveis Técnicos Municipais, segundo tempo de trabalho no setor público de saúde e no SINAN, por porte populacional. Estado de São Paulo, 2017.

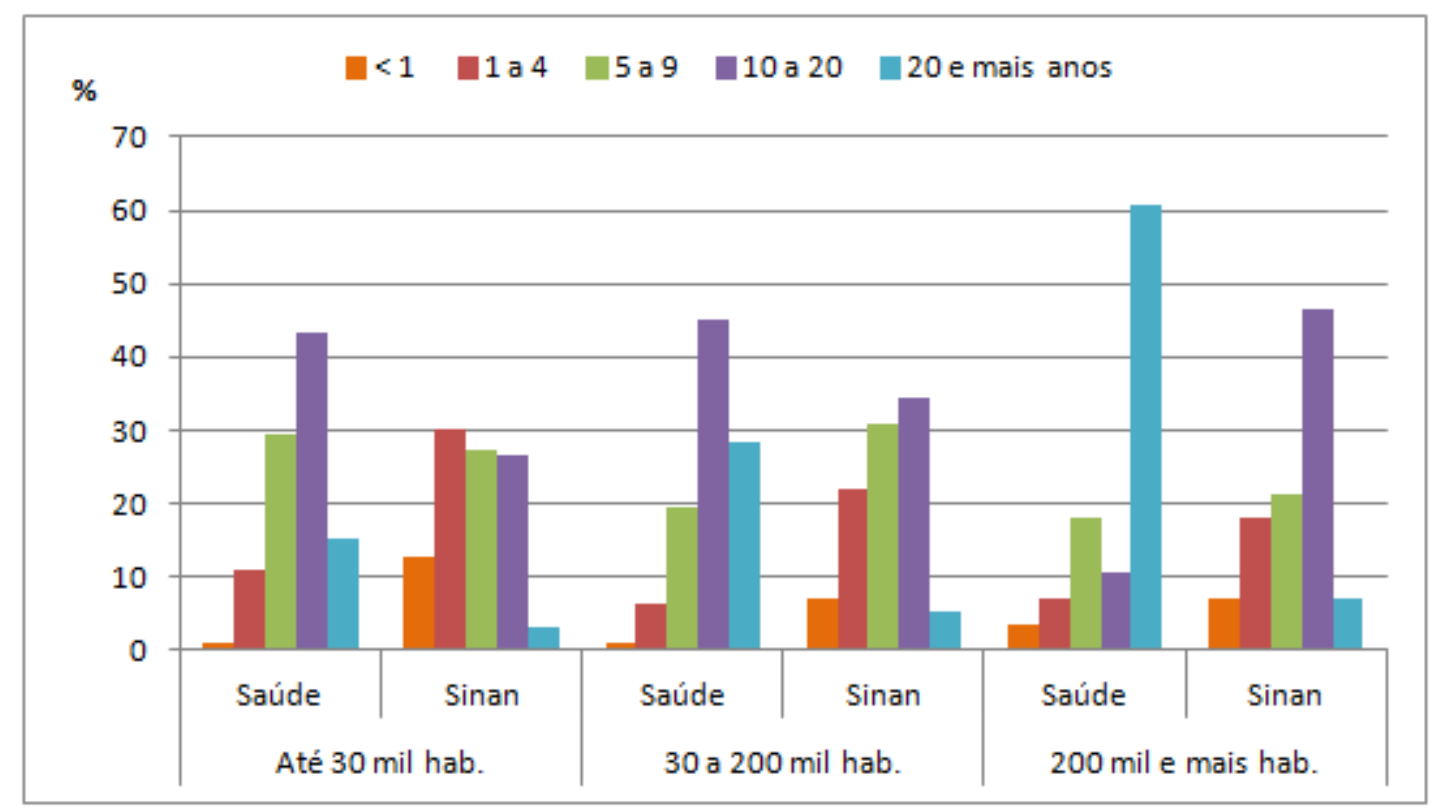

O nível de formação mais avançado do respondente foi pesquisado e verificou-se que predominou a pós-graduação $(52,6 \%)$, com maior proporção nos municípios grandes $(75,0 \%)$ e decréscimo na proporção à medida que diminui o porte populacional ( $58,4 \%$ nos médios e $47,7 \%$ e pequenos). No entanto, também foi observada a presença de $36,6 \%$ de graduados, com maior frequência nos municípios menores $(39,1 \%)$, e de $5,2 \%$ de entrevistados com nível técnico, sendo que a concentração maior dessa categoria se deu nos municípios de pequeno porte, as diferenças não foram estatisticamente significantes (Figura 4). 
Figura 4 - Distribuição dos responsáveis técnicos municipais pela Vigilância Epidemiológica, segundo o nível de formação mais avançada, Estado de São Paulo, 2017.

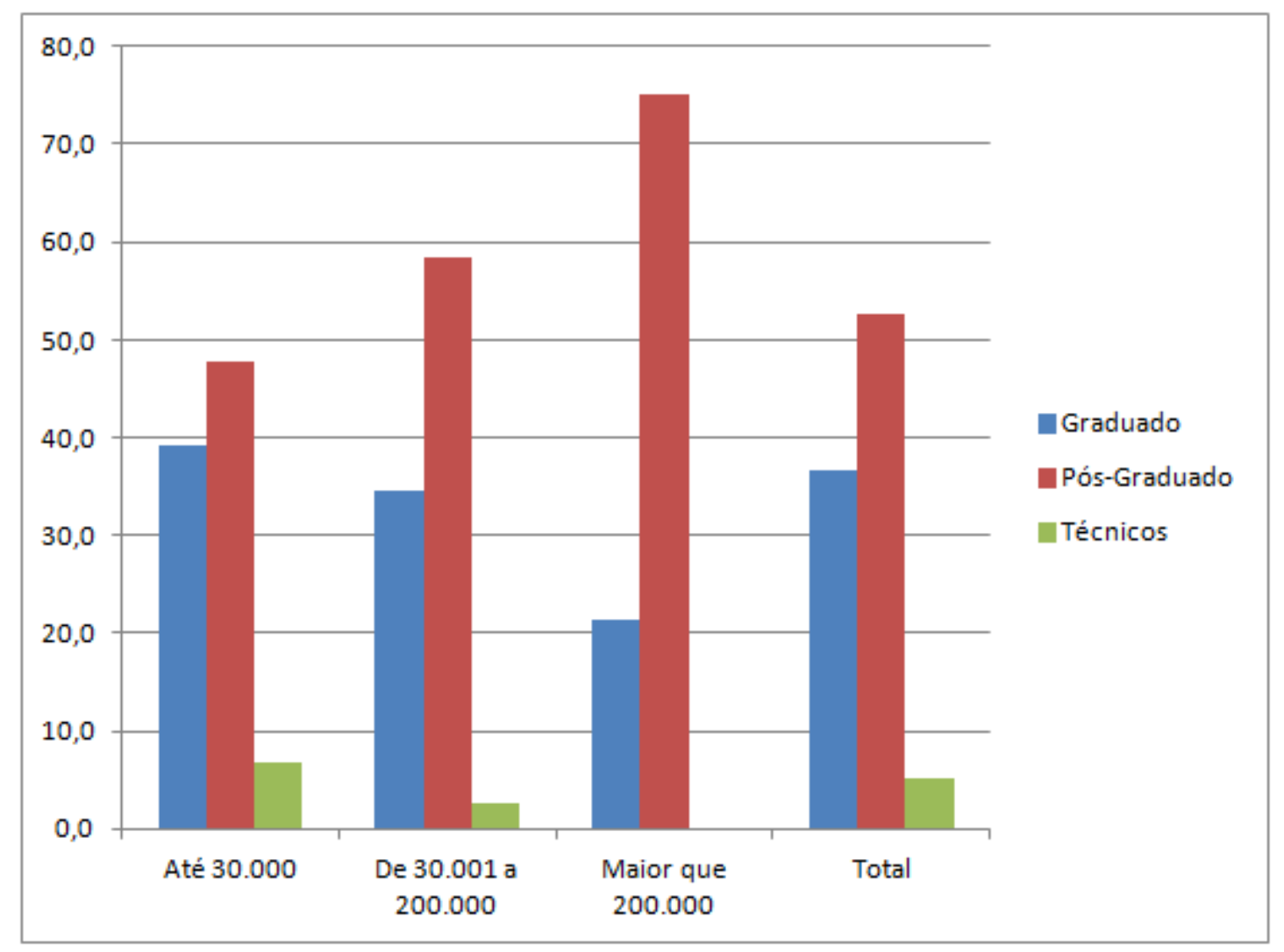

${ }^{*} \mathrm{p}=0,123$

A formação foi analisada segundo a classificação das áreas de conhecimento, que foram categorizadas em: Ciências da Saúde e outras áreas. Entre os profissionais de nível técnico, predominou a formação em outras áreas $(52,2 \%)$. Já entre os profissionais graduados e os com pós-graduação, a área de destaque foi a das Ciências da Saúde (85,2\% e 95,8\%, respectivamente). As diferenças entre os grupos de municípios não foram estatisticamente significantes (Tabela 3).

A análise do curso de formação, em cada categoria, mostrou que, entre o pessoal de nível técnico, a formação em Enfermagem apresentou maior percentual $(30,4 \%)$, concentrada em municípios menores, seguida por Contabilidade $(21,7 \%)$ e distribuída nos municípios de pequeno e médio porte. Quanto aos graduados, a formação em destaque também foi Enfermagem 
(77,9\%), com maior proporção nos municípios pequenos (82,7\%), seguida pelas áreas de Administração e Gestão Pública/Hospitalar com valores bem menores (3,4\%, respectivamente). Quanto à pós-graduação, os cursos em Saúde da Família/ESF e Saúde Pública obtiveram percentuais iguais (19,6\%), sendo que a distribuição por porte foi diferente (Anexo 2 - Tabela 2A).

Tabela 3 - Número e proporção de responsáveis técnicos municipais pela Vigilância Epidemiológica, segundo a área de conhecimento da formação mais avançada, Estado de São Paulo, 2017.

\begin{tabular}{|c|c|c|c|c|c|c|c|c|}
\hline \multirow[t]{2}{*}{ Variáveis } & \multicolumn{2}{|c|}{ Até 30.000} & \multicolumn{2}{|c|}{ De 30.001 a 200.000} & \multicolumn{2}{|c|}{ Maior que 200.000} & \multicolumn{2}{|c|}{ Total } \\
\hline & $\mathrm{N}$ & $\%$ & $\mathrm{~N}$ & $\%$ & $\mathrm{~N}$ & $\%$ & $\mathrm{~N}$ & $\%$ \\
\hline Técnicos* & 17 & 100,0 & 5 & 100,0 & 1 & 100,0 & 23 & 100,0 \\
\hline Ciências da Saúde & 9 & 52,9 & 1 & 20,0 & 1 & 100,0 & 11 & 47,8 \\
\hline Outras áreas & 8 & 47,1 & 4 & 80,0 & 0 & 0,0 & 12 & 52,2 \\
\hline Graduados** & 104 & 100,0 & 39 & 100,0 & 6 & 100,0 & 149 & 100,0 \\
\hline Ciências da Saúde & 90 & 86,5 & 32 & 82,1 & 5 & 83,3 & 127 & 85,2 \\
\hline Outras áreas & 14 & 13,5 & 7 & 17,9 & 1 & 16,7 & 22 & 14,8 \\
\hline Pós-graduados*** & 127 & 100,0 & 66 & 100,0 & 21 & 100,0 & 214 & 100,0 \\
\hline Ciências da Saúde & 126 & 99,2 & 59 & 89,4 & 20 & 95,2 & 205 & 95,8 \\
\hline Outras áreas & 1 & 0,8 & 7 & 10,6 & 1 & 4,8 & 9 & 4,2 \\
\hline
\end{tabular}

Observa-se que a maior parte dos profissionais não se dedica exclusivamente ao SINAN. Proporção expressiva (91,9\%) informou ser responsável por mais de um sistema. $\mathrm{O}$ acúmulo de responsabilidade com outros sistemas de informação foi mais frequente nos grupos de pequeno e médio porte (92,9\% e 92,0\%, respectivamente) do que nos maiores municípios $(82,1 \%)$. As diferenças entre os grupos não foram estatisticamente significantes (Tabela 4).

A responsabilidade conjunta do SINAN com outros sistemas é mais frequente com o SIM (86,9\%), SINASC (86,9\%) e o Sistema de Informação do Programa Nacional de Imunização (SI-PNI) (76,6\%) (Tabela 5). 
Tabela 4 - Número e proporção de responsáveis técnicos municipais pela Vigilância Epidemiológica, segundo a responsabilidade por outros sistemas além do SINAN. Estado de São Paulo, 2017.

\begin{tabular}{|c|c|c|c|c|c|c|c|c|}
\hline \multirow{3}{*}{$\begin{array}{c}\text { Responsável por } \\
\text { outros sistemas }\end{array}$} & \multicolumn{6}{|c|}{ Porte dos Municípios (habitantes) } & & \\
\hline & \multicolumn{2}{|c|}{ Até 30.000} & \multicolumn{2}{|c|}{ De 30.001 a 200.000} & \multicolumn{2}{|c|}{ Maior que 200.000} & \multicolumn{2}{|c|}{ Total } \\
\hline & $\mathrm{N}$ & $\%$ & $\mathrm{~N}$ & $\%$ & $\mathrm{~N}$ & $\%$ & $\mathrm{~N}$ & $\%$ \\
\hline Sim & 247 & 92,9 & 104 & 92,0 & 23 & 82,1 & 374 & 91,9 \\
\hline Não & 19 & 7,1 & 9 & 8,0 & 5 & 17,9 & 33 & 8,1 \\
\hline Total & 266 & 100,0 & 113 & 100,0 & 28 & 100,0 & 407 & 100,0 \\
\hline
\end{tabular}

Tabela 5 - Número e proporção de responsáveis técnicos municipais pela Vigilância Epidemiológica, segundo tipo de sistema com responsabilidade conjunta com SINAN, Estados São Paulo, 2017.

\begin{tabular}{lcc}
\hline \multicolumn{1}{c}{ Sistemas } & N & $\begin{array}{c}\text { Proporção de respodentes } \\
\text { (\%) (1) }\end{array}$ \\
\hline SIM - Sistema de Informações sobre Mortalidade & 325 & 86,9 \\
SINASC - Sistema de Informação sobre Nascidos Vivos & 325 & 86,9 \\
SI-PNI - Sistema de Informação do Programa Nacional de & 287 & 76,7 \\
SISPRENATAL - Sistema de Acompanhamento do Programa & 88 & 23,5 \\
SISSOLO - Sistema de Informação de Vigilância a População & 78 & 20,9 \\
Exposta a Solo Contaminado & & 10,4 \\
SISAGUA - Sistema de Informação de Vigilância da Qualidade & 39 & 7,8 \\
da Água para o Consumo & & 6,1 \\
SIA - Sistema de Informações Ambulatoriais & 29 & 1,6 \\
SIAB - Sistema de Informações de Atenção Básica & 23 & \\
SIOPS - Sistema de Informação sobre Orçamentos Públicos & 6 & 31,8 \\
em Saúde & & 119 \\
Outros & & \\
\hline
\end{tabular}

(1) Refere-se a 374 responsáveis que responderam que são responsáveis por outros sistemas além do SINAN. 


\subsection{ESTRUTURA ORGANIZACIONAL DA VIGILÂNCIA EPIDEMIOLÓGICA}

A Coordenação da Vigilância Epidemiológica (VE) está alocada, predominante, nas Unidades de Saúde $(52,6 \%)$, com proporção decrescente dos municípios pequenos $(70,3 \%)$ para os maiores $(7,1 \%)$, seguida de alocação em instâncias administrativas centrais, como Coordenadorias/Departamentos (30,0\%), com maior proporção nos municípios de grande porte $(64,3 \%)$. As diferenças entre os grupos foram estatisticamente significantes (Tabela 6).

Tabela 6 - Número e proporção de municípios, segundo local de alocação da Vigilância Epidemiológica. Estado de São Paulo, 2017.

\begin{tabular}{|c|c|c|c|c|c|c|c|c|}
\hline \multirow{3}{*}{ Variáveis } & \multicolumn{6}{|c|}{ Porte dos Municípios (habitantes) } & \multirow{2}{*}{\multicolumn{2}{|c|}{ Total }} \\
\hline & \multicolumn{2}{|c|}{ Até 30.000} & \multicolumn{2}{|c|}{ De $30.001 \mathrm{a}$} & \multicolumn{2}{|c|}{ Maior que 200.000} & & \\
\hline & $\mathrm{N}$ & $\%$ & $\mathbf{N}$ & $\%$ & $\mathbf{N}$ & $\%$ & $\mathrm{~N}$ & $\%$ \\
\hline Coordenadoria/Departamento & 52 & 19,5 & 52 & 46,0 & 18 & 64,3 & 122 & 30,0 \\
\hline Divisão/Gerência/Núcleo/Setor & 18 & 6,8 & 25 & 22,1 & 8 & 28,6 & 51 & 12,5 \\
\hline Unidade de Saúde & 187 & 70,3 & 25 & 22,1 & 2 & 7,1 & 214 & 52,6 \\
\hline Outro & 9 & 3,4 & 11 & 9,7 & 0 & 0,0 & 20 & 4,9 \\
\hline Total & 266 & 100,0 & 113 & 100,0 & 28 & 100,0 & 407 & 100,0 \\
\hline
\end{tabular}

$p<0,001$

\subsubsection{Recursos humanos}

Para a variável composição da equipe, foi considerada a data base de 30 de abril de 2017. Foram contabilizados 2.069 profissionais atuando nas Vigilâncias Epidemiológicas municipais, com média de 5,08 por município. Sendo a média de 3,23; nos municípios pequenos, 5,97 nos municípios médios 
e 19,07 nos municípios grandes Quase a metade desse contingente é formada por profissionais com nível superior na área de saúde (46,7\%), com maior proporção nos municípios de grande porte (55,2\%). A segunda formação mais frequente é de nível técnico ou ensino médio (43,1\%). O profissional com o nível superior na área de tecnologia da informação corresponde a 3,3\% (Tabela 7). Apenas 6,8\% possuem nível fundamental, com proporções semelhantes entre os grupos.

Tabela 7 - Número e proporção de profissionais que trabalham na vigilância epidemiológica, segundo o nível de formação, por porte populacional. Estado de São Paulo, 2017.

\begin{tabular}{|c|c|c|c|c|c|c|c|c|}
\hline \multirow{3}{*}{ Nível de Formação } & \multicolumn{6}{|c|}{ Porte dos Municípios (habitantes) } & \multicolumn{2}{|c|}{ Total } \\
\hline & \multicolumn{2}{|c|}{ Até 30.000} & \multicolumn{2}{|c|}{ De 30.001 a 200.000} & \multicolumn{2}{|c|}{ Maior que 200.000} & \multirow[b]{2}{*}{$\mathrm{N}$} & \multirow[b]{2}{*}{$\%$} \\
\hline & $\mathrm{N}$ & $\%$ & $\mathrm{~N}$ & $\%$ & $\mathrm{~N}$ & $\%$ & & \\
\hline Total & 860 & 100,0 & 675 & 100,0 & 534 & 100,0 & 2069 & 100,0 \\
\hline Superior na área da saúde & 397 & 46,2 & 275 & 40,7 & 295 & 55,2 & 967 & 46,7 \\
\hline Tecnologia da Informação & 47 & 5,5 & 18 & 2,7 & 4 & 0,7 & 69 & 3,3 \\
\hline Técnico ou ensino médio & 358 & 41,6 & 333 & 49,3 & 201 & 37,6 & 892 & 43,1 \\
\hline Fundamental & 58 & 6,7 & 49 & 7,3 & 34 & 6,4 & 141 & 6,8 \\
\hline
\end{tabular}

Nota: Situação em 30/04/2017.

Em relação à composição das equipes, a pesquisa mostrou que $34,4 \%$ dos municípios contam com até dois profissionais; 44,5\% têm de 3 a 6 ; e 9,8\% com 11 ou mais. O tamanho das equipes aumenta conforme cresce o porte populacional dos municípios, como era esperado. Os municípios pequenos praticamente dividem-se em equipes com 1 a 2 membros (49,6\%) e com 3 a 6 $(43,2 \%) ; 82,1 \%$ dos grandes municípios contam com 11 ou mais profissionais. Os resultados mostraram diferenças estatisticamente significantes entre os grupos. Observou-se que 39,8\%, dos profissionais que trabalhavam nas Vigilâncias Epidemiológicas municipais possuem pós-graduação em Epidemiologia e/ou Saúde Pública, com uma proporção elevada (85,7\%) nos municípios grandes e decrescente em relação aos médios $(49,6 \%)$ e pequenos $(30,8 \%)$, com diferenças significantes entre os grupos de municípios (Tabela 8$)$. 
Tabela 8 - Número e proporção de municípios, segundo quantidade de profissionais da Vigilância Epidemiológica e formação pós-graduada em Epidemiologia, por porte populacional. Estado de São Paulo, 2017.

\begin{tabular}{|c|c|c|c|c|c|c|c|c|}
\hline \multirow{3}{*}{ Variáveis } & \multicolumn{6}{|c|}{ Porte dos Municípios (habitantes) } & & \\
\hline & \multicolumn{2}{|c|}{ Até 30.000} & \multicolumn{2}{|c|}{$\begin{array}{c}\text { De } 30.001 \text { a } \\
200.000\end{array}$} & \multicolumn{2}{|c|}{$\begin{array}{l}\text { Maior que } \\
200.000\end{array}$} & \multicolumn{2}{|c|}{ Total } \\
\hline & $\mathrm{N}$ & $\%$ & $\mathrm{~N}$ & $\%$ & $\mathrm{~N}$ & $\%$ & $\mathrm{~N}$ & $\%$ \\
\hline \multicolumn{9}{|c|}{ Número de profissionais * } \\
\hline 1 a 2 & 132 & 49,6 & 7 & 6,2 & 1 & 3,6 & 140 & 34,4 \\
\hline 3 a 6 & 115 & 43,2 & 64 & 56,6 & 2 & 7,1 & 181 & 44,5 \\
\hline 7 a 10 & 12 & 4,5 & 32 & 28,3 & 2 & 7,1 & 46 & 11,3 \\
\hline 11 ou mais & 7 & 2,6 & 10 & 8,8 & 23 & 82,1 & 40 & 9,8 \\
\hline
\end{tabular}

Com pós em epidemiologia

e/ou saúde pública *

\begin{tabular}{lcccccccc} 
Sim & 82 & 30,8 & 56 & 49,6 & 24 & 85,7 & 162 & 39,8 \\
Não & 184 & 69,2 & 57 & 50,4 & 4 & 14,3 & 245 & 60,2 \\
\hline Total & $\mathbf{2 6 6}$ & $\mathbf{1 0 0 , 0}$ & $\mathbf{1 1 3}$ & $\mathbf{1 0 0 , 0}$ & $\mathbf{2 8}$ & $\mathbf{1 0 0 , 0}$ & $\mathbf{4 0 7}$ & $\mathbf{1 0 0 , 0}$ \\
\hline
\end{tabular}

$* p<0,001$

Nota: Situação em 30/04/2017.

\subsubsection{Recursos físicos}

A estrutura física do local de trabalho foi considerada adequada em $80,6 \%$ dos municípios. Os municípios pequenos apresentaram maior percentual $(85,6 \%)$ e a proporção diminui à medida que aumenta 0 porte populacional. Os municípios de grande e médio porte são os que registraram as maiores frequências de estrutura inadequada ( $32,1 \%$ e $28,3 \%$, respectivamente), com diferença significativa entre os grupos de municípios (Tabela 9). 
Tabela 9 - Número e proporção de municípios, segundo a classificação da estrutura física do local de trabalho, por porte populacional. Estado de São Paulo, 2017.

\begin{tabular}{|c|c|c|c|c|c|c|c|c|}
\hline \multirow{3}{*}{ Estrutura Física } & \multicolumn{6}{|c|}{ Porte dos Municípios (habitantes) } & \multirow{2}{*}{\multicolumn{2}{|c|}{ Total }} \\
\hline & \multicolumn{2}{|c|}{ Até 30.000} & \multicolumn{2}{|c|}{ De 30.001 a 200.000} & \multicolumn{2}{|c|}{ Maior que 200.000} & & \\
\hline & $\mathrm{N}$ & $\%$ & $\mathrm{~N}$ & $\%$ & $\mathrm{~N}$ & $\%$ & $\mathrm{~N}$ & $\%$ \\
\hline Adequada & 228 & 85,7 & 81 & 71,7 & 19 & 67,9 & 328 & 80,6 \\
\hline Inadequada & 38 & 14,3 & 32 & 28,3 & 9 & 32,1 & 79 & 19,4 \\
\hline Total & 266 & 100,0 & 113 & 100,0 & 28 & 100,0 & 407 & 100,0 \\
\hline
\end{tabular}

p<0,001

Dos 79 municípios que responderam ter uma estrutura física inadequada no local de trabalho, $54,6 \%$ indicaram três ou mais problemas. Os principais motivos foram: espaço insuficiente $(83,5 \%)$, rede elétrica inadequada/insuficiente $(45,6 \%)$, pouca ventilação $(41,8 \%)$ e barulho $(39,2 \%)$ (tabela 10). A falta de espaço foi a mais citada nos três grupos de municípios e problemas com a rede elétrica foi o segundo motivo de inadequação, sendo mais importante para os municípios médios e grandes. Como outros motivos foram mencionados: falta de privacidade, sala compartilhada com outras atividades e local improvisado. 
Tabela 10 - Número e proporção de municípios, segundo os problemas relatados em relação à estrutura física, por porte populacional. Estado de São Paulo, 2017.

\begin{tabular}{|c|c|c|c|c|c|c|c|c|}
\hline \multirow{3}{*}{ Variáveis } & \multicolumn{6}{|c|}{ Porte dos Municípios (habitantes) } & & \\
\hline & \multicolumn{2}{|c|}{ Até 30.000} & \multicolumn{2}{|c|}{ De 30.001 a 200.000} & \multicolumn{2}{|c|}{ Maior que 200.000} & \multicolumn{2}{|c|}{ Total } \\
\hline & $\mathrm{N}$ & $\%$ & $\mathrm{~N}$ & $\%$ & $\mathrm{~N}$ & $\%$ & $\mathrm{~N}$ & $\%$ \\
\hline Espaço insuficiente & 31 & 81,6 & 28 & 87,5 & 7 & 77,8 & 66 & 83,5 \\
\hline Pouco ventilação & 13 & 34,2 & 17 & 53,1 & 3 & 33,3 & 33 & 41,8 \\
\hline Pouca iluminação & 6 & 15,8 & 10 & 31,3 & 2 & 22,2 & 18 & 22,8 \\
\hline Barulho & 14 & 36,8 & 14 & 43,8 & 3 & 33,3 & 31 & 39,2 \\
\hline Rede elétrica indadequada/insuficien & 10 & 26,3 & 20 & 62,5 & 6 & 66,7 & 36 & 45,6 \\
\hline Outros & 5 & 13,2 & 5 & 15,6 & 0 & 0,0 & 10 & 12,7 \\
\hline Total municípios & 38 & & 32 & & 9 & & 79 & \\
\hline
\end{tabular}

Em relação à disponibilidade de materiais de informática e comunicação para operar o SINAN, observou-se que, com exceção ao HD externo, que foi mencionado como insuficiente por $41,5 \%$, os demais materiais foram considerados pelos municípios como sendo suficientes, com percentuais acima de $70,0 \%$, e com proporções semelhantes em todos os grupos. Os resultados não apresentaram diferenças significantes entre os grupos (Tabela 11). 
Tabela 11 - Número e proporção de municípios, segundo a disponibilidade de materiais para operar o SINAN, por porte populacional. Estado de São Paulo, 2017.

\begin{tabular}{|c|c|c|c|c|c|c|c|c|}
\hline \multirow{3}{*}{$\begin{array}{c}\text { Insumos de Informática e } \\
\text { Comunicação }\end{array}$} & \multicolumn{6}{|c|}{ Porte dos Municípios (habitantes) } & \multirow{2}{*}{\multicolumn{2}{|c|}{ Total }} \\
\hline & \multicolumn{2}{|c|}{ Até 30.000} & \multicolumn{2}{|c|}{ De 30.001 a 200.000} & \multicolumn{2}{|c|}{ Maior que 200.000} & & \\
\hline & $\mathrm{N}$ & $\%$ & $\mathrm{~N}$ & $\%$ & $\mathrm{~N}$ & $\%$ & $\mathrm{~N}$ & $\%$ \\
\hline \multicolumn{9}{|l|}{ CD/DVD/pendrive* } \\
\hline Suficiente & 194 & 72,9 & 79 & 69,9 & 21 & 75,0 & 294 & 72,3 \\
\hline Insuficiente & 72 & 27,1 & 34 & 30,1 & 7 & 25,0 & 113 & 27,8 \\
\hline \multicolumn{9}{|l|}{ HD Externo** } \\
\hline Suficiente & 109 & 41,0 & 48 & 42,5 & 12 & 42,9 & 169 & 41,5 \\
\hline Insuficiente & 157 & 59,0 & 65 & 57,5 & 16 & 57,1 & 238 & 58,5 \\
\hline \multicolumn{9}{|l|}{ Impressoras $* * *$} \\
\hline Suficiente & 221 & 83,1 & 94 & 83,2 & 23 & 82,1 & 338 & 83,0 \\
\hline Insuficiente & 45 & 16,9 & 19 & 16,8 & 5 & 17,9 & 69 & 17,0 \\
\hline \multicolumn{9}{|l|}{ Tintas para impressoras $* * * *$} \\
\hline Suficiente & 219 & 82,3 & 89 & 78,8 & 21 & 75,0 & 329 & 80,8 \\
\hline Insuficiente & 47 & 17,7 & 24 & 21,2 & 7 & 25,0 & 78 & 19,2 \\
\hline \multicolumn{9}{|l|}{ Telefone $* * * * *$} \\
\hline Suficiente & 224 & 84,2 & 95 & 84,1 & 22 & 78,6 & 341 & 83,8 \\
\hline Insuficiente & 42 & 15,8 & 18 & 15,9 & 6 & 21,4 & 66 & 16,2 \\
\hline Total & 266 & 100,0 & 113 & 100,0 & 28 & 100,0 & 407 & 100,0 \\
\hline
\end{tabular}

Em relação à quantidade de computadores, observou-se que 61,9\% dos municípios tem apenas um computador para operar o SINAN, com maior proporção nos municípios de pequeno porte $(76,3 \%)$. Os municípios de grande porte apresentam maior disponibilidade de equipamentos, sendo que $42,9 \%$ possuem 11 ou mais computadores para utilização do SINAN. Os resultados apresentaram diferenças significantes entre os grupos (Tabela 12).

Para analisar a modernização da infraestrutura de informática, foi pesquisado o tipo de sistema operacional instalado nos computadores para operar o SINAN, observou-se que $45,2 \%$ dos municípios tinham instalado o Windows 7, com maior percentual nos municípios de grande porte $(64,3 \%)$. Em seguida aparece o Windows XP (a versão mais antiga), com 28,5\%, com maior percentual nos municípios médios $(37,2 \%)$; foi observado a inexistência desse sistema nos grandes municípios. Os sistemas operacionais mais avançados (Windows 8 e 10) estão instalados com maior frequência nos municípios de grande porte (17,9\%); 59 municípios (14,5\%), não souberam informar o tipo de sistema operacional utilizado (Tabela 12). 
Os sistemas de informação, assim como as demais rotinas que dependem da informatização, usualmente apresentam intercorrências, que exigem a ação de profissionais especializados em tecnologia da informação (TI). Nesse aspecto, foi observado que apenas $7,4 \%$ dos municípios não possuem serviço de suporte de TI. Para os que possuem este serviço, predomina o serviço próprio $(68,3 \%)$, com maior proporção nos municípios médios $(87,6 \%)$ e grandes $(82,1 \%)$. Os municípios que possuem esse serviço terceirizado representam $24,3 \%$, com maior presença nos pequenos $(31,2 \%)$ (Tabela 12). Em relação à presteza do atendimento quando o serviço é solicitado, um pouco mais de um terço dos municípios considerou o atendimento lento, com maior proporção nos municípios maiores (43,5\%) (Anexo 2 - Tabela 3A) e essa proporção foi um pouco mais elevada quando 0 serviço era terceirizado $(39,5 \%)$ em comparação ao suporte próprio $(34,7 \%)$ (Anexo 2 - Tabela 4A). 
Tabela 12 - Número e proporção de municípios, segundo número de computadores disponíveis para utilização do SINAN, tipo de sistema operacional e suporte técnico, por porte populacional, Estado de São Paulo, 2017.

\begin{tabular}{|c|c|c|c|c|c|c|c|c|}
\hline \multirow{3}{*}{ Variáveis } & \multicolumn{6}{|c|}{ Porte dos Municípios (habitantes) } & \multirow{2}{*}{\multicolumn{2}{|c|}{ Total }} \\
\hline & \multicolumn{2}{|c|}{ Até $\mathbf{3 0 . 0 0 0}$} & \multicolumn{2}{|c|}{ De 30.001 a 200.000} & \multicolumn{2}{|c|}{ Maior que 200.000} & & \\
\hline & $\mathbf{N}$ & $\%$ & $\mathrm{~N}$ & $\%$ & $\mathrm{~N}$ & $\%$ & $\mathbf{N}$ & $\%$ \\
\hline \multicolumn{9}{|c|}{ Número de computadores* } \\
\hline 1 & 203 & 76,3 & 46 & 40,7 & 3 & 10,7 & 252 & 61,9 \\
\hline 2 & 45 & 16,9 & 26 & 23,0 & 0 & 0,0 & 71 & 17,4 \\
\hline 3 & 7 & 2,6 & 18 & 15,9 & 1 & 3,6 & 26 & 6,4 \\
\hline 4 a 6 & 11 & 4,1 & 13 & 11,5 & 4 & 14,3 & 28 & 6,9 \\
\hline 7 a 10 & 0 & 0,0 & 9 & 8,0 & 8 & 28,6 & 17 & 4,2 \\
\hline 11 e mais & 0 & 0,0 & 1 & 0,9 & 12 & 42,9 & 13 & 3,2 \\
\hline \multicolumn{9}{|l|}{ Sistema Operacional } \\
\hline Windows XP & 74 & 27,8 & 42 & 37,2 & 0 & 0,0 & 116 & 28,5 \\
\hline Windows 7 & 116 & 43,6 & 50 & 44,2 & 18 & 64,3 & 184 & 45,2 \\
\hline Windows 8 e 10 & 31 & 11,7 & 8 & 7,1 & 5 & 17,9 & 44 & 10,8 \\
\hline Outros & 1 & 0,4 & 1 & 0,9 & 2 & 7,1 & 4 & 1,0 \\
\hline Não sabe & 44 & 16,5 & 12 & 10,6 & 3 & 10,7 & 59 & 14,5 \\
\hline \multicolumn{9}{|c|}{ Suporte técnico de informática* } \\
\hline Não & 27 & 10,2 & 3 & 2,7 & 0 & 0,0 & 30 & 7,4 \\
\hline Sim, próprio & 156 & 58,6 & 99 & 87,6 & 23 & 82,1 & 278 & 68,3 \\
\hline Sim, tercerizado & 83 & 31,2 & 11 & 9,7 & 5 & 17,9 & 99 & 24,3 \\
\hline Total & 266 & 100,0 & 113 & 100,0 & 28 & 100,0 & 407 & 100,0 \\
\hline
\end{tabular}

A segurança de armazenamento dos dados do SINAN deve ser garantida com a realização de backup. Em relação às formas utilizadas, 77,6\% dos municípios mencionaram apenas uma forma de armazenagem e 11,3\% não souberam informar (municípios pequenos e médios). Das opções mencionadas, $34,1 \%$ utilizam apenas pen-drive, $14,5 \%$ outro computador e 10,3\% Compact Disk. Considerando as formas mais modernas, apenas 5,4\% utilizam nuvem (cloud computing). Nos municípios pequenos e médios, predomina o uso do pen-drive, já nos maiores foi mais citada a utilização de outro computador (Tabela 13). A figura 5 apresenta a distribuição por grupos de municípios, considerando a somatória de todas as formas citadas. 
Tabela 13 - Número e proporção de municípios, segundo tipo de backup realizado, por porte populacional. Estado de São Paulo, 2017.

\begin{tabular}{|c|c|c|c|c|c|c|c|c|}
\hline \multirow{3}{*}{ Variáveis } & \multicolumn{8}{|c|}{ Porte dos Municípios (habitantes) } \\
\hline & \multicolumn{2}{|c|}{ Até $\mathbf{3 0 . 0 0 0}$} & \multicolumn{2}{|c|}{ De 30.001 a 200.000} & \multicolumn{2}{|c|}{ Maior que $\mathbf{2 0 0 . 0 0 0}$} & \multicolumn{2}{|c|}{ Total } \\
\hline & $\mathbf{N}$ & $\%$ & $\mathbf{N}$ & $\%$ & $\mathbf{N}$ & $\%$ & $\mathbf{N}$ & $\%$ \\
\hline Pen-drive & 109 & 41,0 & 38 & 33,6 & 4 & 14,3 & 151 & 37,1 \\
\hline Outro computador & 33 & 12,4 & 20 & 17,7 & 6 & 21,4 & 59 & 14,5 \\
\hline HD externo & 26 & 9,8 & 11 & 9,7 & 5 & 17,9 & 42 & 10,3 \\
\hline Nuvem & 10 & 3,8 & 10 & 8,8 & 2 & 7,1 & 22 & 5,4 \\
\hline No mesmo computador & 13 & 4,9 & 5 & 4,4 & 0 & 0,0 & 18 & 4,4 \\
\hline Outro (1) & 12 & 4,5 & 7 & 6,2 & 5 & 17,9 & 24 & 5,9 \\
\hline Mais de um forma & 27 & 10,2 & 12 & 10,6 & 6 & 21,4 & 45 & 11,1 \\
\hline Não sabe & 36 & 13,5 & 10 & 8,8 & 0 & 0,0 & 46 & 11,3 \\
\hline Total & 266 & 100,0 & 113 & 100,0 & 28 & 100,0 & 407 & 100,0 \\
\hline
\end{tabular}

(1) Servidor municipal, CD ou email.

Figura 5 - Distribuição do tipo de backup utilizado nos municípios, segundo porte populacional, Estado de São Paulo, 2017.

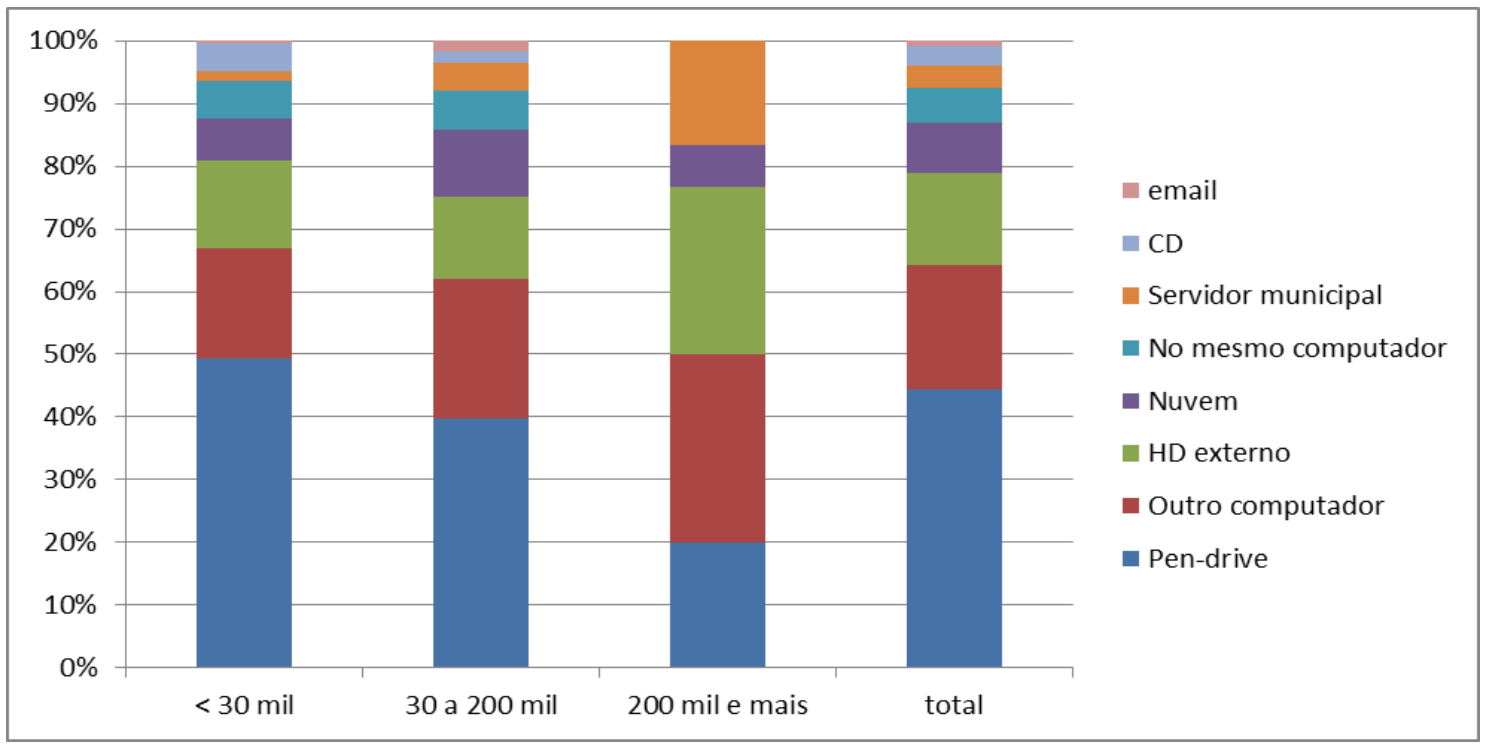

Nota: Referente à somatória de todas as formas citadas. 


\subsection{PROCESSOS DE TRABALHO}

A fim de observar como ocorre a organização dos processos de trabalho na operacionalização do SINAN, foi pesquisada a realização e a distribuição das atividades entre o coordenador da VE e os profissionais da equipe. Identificou-se que as atividades que exigem maior capacitação apresentaram maior frequência de não realização: busca ativa de notificações, definida como busca de casos que podem estar ocorrendo, porém não estão sendo registrados pelos serviços (37,8\%); elaboração de indicadores $(26,0 \%)$; e elaboração de relatórios e/ou boletins periódicos (18,9\%) (Tabela 14). O que chama atenção é que nas atividades de busca ativa de notificações e elaboração de relatórios ou boletins periódicos, os municípios maiores apresentaram maior proporção de não realização, sendo que este grupo de municípios apresenta alto percentual de profissionais com pós-graduação em Epidemiologia e/ou Saúde Pública (85,7\%). Sendo um aparente contradição, que deveria ser melhor investigada em pesquisas futuras. A execução das atividades citadas foi atribuída com maior frequência ao coordenador do serviço, com maior concentração nos municípios de pequeno porte. Por outro lado, a realização das atividades por uma equipe é observada em maior proporção nos municípios de grande porte. Nos municípios de médio porte, quase todas as atividades registram uma distribuição mais equilibrada entre coordenação e equipe (Tabela 14). 
Tabela 14 - Número e proporção de municípios, segundo atividades desenvolvidas, por porte populacional, Estado de São Paulo, 2017.

\begin{tabular}{|c|c|c|c|c|c|c|c|c|}
\hline \multirow{3}{*}{ Variáveis } & \multicolumn{6}{|c|}{ Porte dos Municípios (habitantes) } & \multirow{2}{*}{\multicolumn{2}{|c|}{ Total }} \\
\hline & \multicolumn{2}{|c|}{ Até 30.000} & \multicolumn{2}{|c|}{ De 30.001 a 200.000} & \multicolumn{2}{|c|}{ Maior que 200.000} & & \\
\hline & $\mathrm{N}$ & $\%$ & $\mathrm{~N}$ & $\%$ & $\mathrm{~N}$ & $\%$ & $\mathrm{~N}$ & $\%$ \\
\hline \multicolumn{9}{|c|}{ Backup, envio de lotes * } \\
\hline Coordenador & 136 & 51,1 & 16 & 14,2 & 4 & 14,3 & 156 & 38,3 \\
\hline Equipe & 62 & 23,3 & 51 & 45,1 & 20 & 71,4 & 133 & 32,7 \\
\hline Ambos & 66 & 24,8 & 46 & 40,7 & 4 & 14,3 & 116 & 28,5 \\
\hline $\begin{array}{l}\text { Não Realiza } \\
\text { Envio/recebimento d }\end{array}$ & 2 & 0,8 & 0 & 0,0 & 0 & 0,0 & 2 & 0,5 \\
\hline \multicolumn{9}{|l|}{ de retorno* } \\
\hline Coordenador & 141 & 53,0 & 24 & 21,2 & 4 & 14,3 & 169 & 41,5 \\
\hline Equipe & 64 & 24,1 & 49 & 43,4 & 21 & 75,0 & 134 & 32,9 \\
\hline Ambos & 45 & 16,9 & 37 & 32,7 & 3 & 10,7 & 85 & 20,9 \\
\hline Não Realiza & 16 & 6,0 & 3 & 2,7 & 0 & 0,0 & 19 & 4,7 \\
\hline \multicolumn{9}{|c|}{$\begin{array}{l}\text { Digitação da ficha de } \\
\text { notificação/investigação * }\end{array}$} \\
\hline Coordenador & 138 & 51,9 & 14 & 12,4 & 2 & 7,1 & 154 & 37,8 \\
\hline Equipe & 51 & 19,2 & 37 & 32,7 & 13 & 46,4 & 101 & 24,8 \\
\hline Ambos & 76 & 28,6 & 62 & 54,9 & 13 & 46,4 & 151 & 37,1 \\
\hline Não Realiza & 1 & 0,4 & 0 & 0,0 & 0 & 0,0 & 1 & 0,2 \\
\hline \multicolumn{9}{|l|}{ Análise das fichas } \\
\hline \multicolumn{9}{|c|}{ (duplicidade, campos em } \\
\hline Coordenador & 144 & 54,1 & 29 & 25,7 & 2 & 7,1 & 175 & 43,0 \\
\hline Equipe & 45 & 16,9 & 29 & 25,7 & 11 & 39,3 & 85 & 20,9 \\
\hline Ambos & 72 & 27,1 & 55 & 48,7 & 14 & 50,0 & 141 & 34,6 \\
\hline Não Realiza & 5 & 1,9 & 0 & 0,0 & 1 & 3,6 & 6 & 1,5 \\
\hline \multicolumn{9}{|c|}{ Busca ativa de Notificações * } \\
\hline Coordenador & 105 & 39,5 & 19 & 16,8 & 3 & 10,7 & 127 & 31,2 \\
\hline Equipe & 62 & 23,3 & 34 & 30,1 & 12 & 42,9 & 108 & 26,5 \\
\hline Ambos & 13 & 4,9 & 4 & 3,5 & 1 & 3,6 & 18 & 4,4 \\
\hline Não Realiza & 86 & 32,3 & 56 & 49,6 & 12 & 42,9 & 154 & 37,8 \\
\hline \multicolumn{9}{|c|}{ Análise dos dados do SINAN * } \\
\hline Coordenador & 142 & 53,4 & 47 & 41,6 & 4 & 14,3 & 193 & 47,4 \\
\hline Equipe & 37 & 13,9 & 18 & 15,9 & 5 & 17,9 & 60 & 14,7 \\
\hline Ambos & 68 & 25,6 & 43 & 38,1 & 19 & 67,9 & 130 & 31,9 \\
\hline Não Realiza & 19 & 7,1 & 5 & 4,4 & 0 & 0,0 & 24 & 5,9 \\
\hline \multicolumn{9}{|c|}{ Elaboração de Indicadores ** } \\
\hline Coordenador & 101 & 38,0 & 46 & 40,7 & 8 & 28,6 & 115 & 38,1 \\
\hline Equipe & 44 & 16,5 & 15 & 13,3 & 5 & 17,9 & 64 & 15,7 \\
\hline Ambos & 64 & 24,1 & 17 & 15,0 & 1 & 3,6 & 82 & 20,1 \\
\hline Não Realiza & 57 & 21,4 & 35 & 31,0 & 14 & 50,0 & 106 & 26,0 \\
\hline \multicolumn{9}{|c|}{$\begin{array}{l}\text { Elaboração de relatórios ou } \\
\text { boletins periódicos * }\end{array}$} \\
\hline Coordenador & 109 & 41,0 & 41 & 36,3 & 9 & 32,1 & 159 & 39,1 \\
\hline Equipe & 41 & 15,4 & 16 & 14,2 & 5 & 17,9 & 62 & 15,2 \\
\hline Ambos & 52 & 19,5 & 43 & 38,1 & 14 & 50,00 & 109 & 26,8 \\
\hline Não Realiza & 64 & 24,1 & 13 & 11,5 & 0 & 0,00 & 77 & 18,9 \\
\hline Total & 266 & 100,0 & 113 & 100,00 & 28 & 100,00 & 407 & 100,0 \\
\hline
\end{tabular}

Em relação à realização de ações para garantir a cobertura do sistema, observou-se que $72,0 \%$ dos municípios não fazem nenhum tipo de 
procedimento para monitorar o volume mensal de eventos notificados pelas unidades. Apenas $28,0 \%$ fazem esse controle, com maior proporção nos municípios de grande porte $(67,9 \%)$, seguido pelos médios $(35,4 \%)$ e pequenos $(20,7 \%)$. Os resultados apresentaram diferenças significantes entre os grupos (Tabela 15). Quando os municípios foram questionados sobre a realização de procedimento para complementar as informações do SINAN, 84,8\%, disseram não realizar esta prática, principalmente nos municípios de grande porte $(96,4 \%)$ (Tabela 15).

Tabela 15 - Número e proporção de municípios, segundo a realização de procedimento para monitorar o volume mensal dos eventos notificados pelas unidades, por porte populacional, Estado de São de Paulo, 2017.

\begin{tabular}{|c|c|c|c|c|c|c|c|c|}
\hline \multirow{3}{*}{ Procedimentos } & \multicolumn{6}{|c|}{ Porte dos Municípios (habitantes) } & \multirow{2}{*}{\multicolumn{2}{|c|}{ Total }} \\
\hline & \multicolumn{2}{|c|}{ Até 30.000} & \multicolumn{2}{|c|}{ De $30.001 \mathrm{a}$} & \multicolumn{2}{|c|}{ Maior que } & & \\
\hline & $\mathrm{N}$ & $\%$ & $\mathrm{~N}$ & $\%$ & $\mathrm{~N}$ & $\%$ & $\mathrm{~N}$ & $\%$ \\
\hline \multicolumn{9}{|c|}{$\begin{array}{l}\text { Monitorar o volume mensal } \\
\text { dos eventos* }\end{array}$} \\
\hline Não & 211 & 79,3 & 73 & 64,6 & 9 & 32,1 & 293 & 72,0 \\
\hline Sim & 55 & 20,7 & 40 & 35,4 & 19 & 67,9 & 114 & 28,0 \\
\hline \multicolumn{9}{|c|}{$\begin{array}{l}\text { Complementar as informações } \\
\text { do SINAN** }\end{array}$} \\
\hline Não & 215 & 80,8 & 103 & 91,2 & 27 & 96,4 & 345 & 84,8 \\
\hline Sim & 51 & 19,2 & 10 & 8,8 & 1 & 3,6 & 62 & 15,2 \\
\hline Total & 266 & 100,0 & 113 & 100,0 & 28 & 100,0 & 407 & 100,0 \\
\hline
\end{tabular}

Em relação à utilização do aplicativo SINAN-Relatórios para gerar indicadores, 52,1\% dos municípios responderam que utilizam esse módulo, com proporções menores nos municípios com menos de 30 mil habitantes $(48,9 \%)$, porém sem diferenças estaticamente significantes (Tabela 16). Para os que não o utilizam $(47,9 \%)$, o principal motivo em todos os grupos foi falta de treinamento $(74,9 \%)$; apenas nos pequenos e médios, a falta de pessoal aparece como segundo motivo, apontado por $12,3 \%$ dos municípios. Para $9,7 \%$, foi citado que os relatórios não atendem às necessidades do município (Figura 06). 
Tabela 16. Número e proporção de municípios, segundo a utilização do aplicativo SINAN-Relatórios, por porte populacional, Estado São Paulo, 2017.

\begin{tabular}{|c|c|c|c|c|c|c|c|c|}
\hline \multirow{3}{*}{$\begin{array}{l}\text { Utilização do aplicativo do } \\
\text { SINAN-Relatórios }\end{array}$} & \multicolumn{6}{|c|}{ Porte dos Municípios (habitantes) } & \multirow{2}{*}{\multicolumn{2}{|c|}{ Total }} \\
\hline & \multicolumn{2}{|c|}{ Até 30.000} & \multicolumn{2}{|c|}{ De 30.001 a 200.000} & \multicolumn{2}{|c|}{ Maior que 200.000} & & \\
\hline & $\mathrm{N}$ & $\%$ & $\mathrm{~N}$ & $\%$ & $\mathrm{~N}$ & $\%$ & $\mathrm{~N}$ & $\%$ \\
\hline Sim & 130 & 48,9 & 66 & 58,4 & 16 & 57,1 & 212 & 52,1 \\
\hline Não & 136 & 51,1 & 47 & 41,6 & 12 & 42,9 & 195 & 47,9 \\
\hline Total & 266 & 100,0 & 113 & 100,0 & 28 & 100,0 & 407 & 100,0 \\
\hline
\end{tabular}

Figura 6 - Distribuição dos motivos de não utilização do aplicativo SINANRelatório, segundo porte populacional, Estado de São Paulo, 2017.

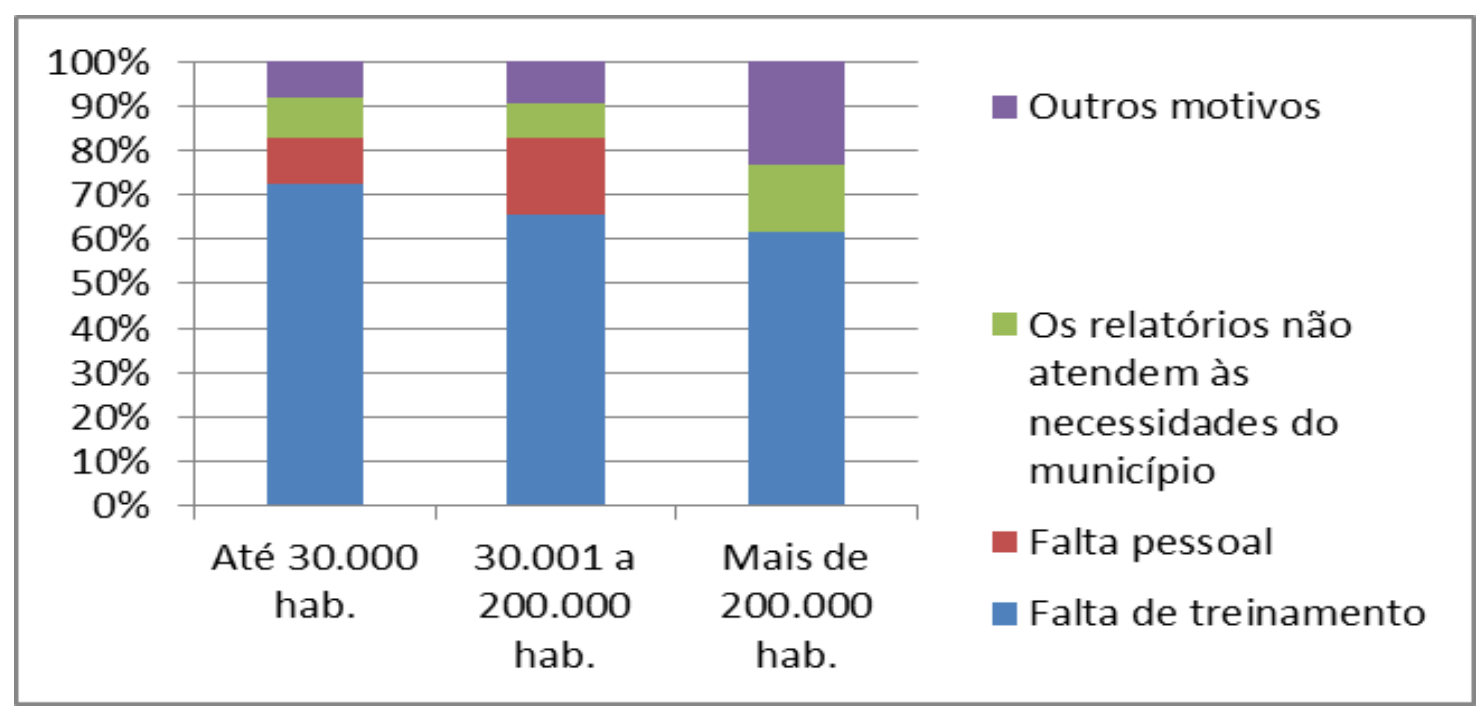

O uso do programa Tabwin para análise de dados foi mencionado por $50,4 \%$ dos municípios, com proporção crescente dos municípios pequenos $(35,0 \%)$ para os maiores $(92,9 \%)$, com diferenças estatisticamente significantes (Tabela 17). As funções mais utilizadas foram as básicas $(80,0 \%)$, seguida da interface Tabwin-SQL $(16,1 \%)$, ferramenta de mapa de fluxo origem-destino $(12,7 \%)$ e módulo de mapas e gráficos (8,8\%) (Tabela 18). A imensa maioria utiliza apenas uma função $(88,8 \%)$ e os grandes municípios destacam-se, utilizando mais de uma função $(11,2 \%)$. O uso das funções básicas e da ferramenta de mapa fluxo origem-destino foi semelhante entre os grupos. No entanto, a função interface Tabwin-SQL apresenta crescimento do uso de acordo com aumento do porte populacional. 
Tabela 17 - Número e proporção de municípios, segundo a análise dos dados através da ferramenta Tabwin, por porte populacional, Estado São Paulo, 2017.

\begin{tabular}{|c|c|c|c|c|c|c|c|c|}
\hline \multirow{3}{*}{ Análise com Tabwin } & \multicolumn{6}{|c|}{ Porte dos Municípios (habitantes) } & \multirow{2}{*}{\multicolumn{2}{|c|}{ Total }} \\
\hline & \multicolumn{2}{|c|}{ Até 30.000} & \multicolumn{2}{|c|}{ De 30.001 a 200.000} & \multicolumn{2}{|c|}{ Maior que 200.000} & & \\
\hline & $\mathrm{N}$ & $\%$ & $\mathrm{~N}$ & $\%$ & $\mathrm{~N}$ & $\%$ & $\mathrm{~N}$ & $\%$ \\
\hline Sim & 101 & 38,0 & 78 & 69,0 & 26 & 92,9 & 205 & 50,4 \\
\hline Não & 165 & 62,0 & 35 & 31,0 & 2 & 7,1 & 202 & 49,6 \\
\hline Total & 266 & 100,0 & 113 & 100,0 & 28 & 100,0 & 407 & 100,0 \\
\hline
\end{tabular}

Tabela 18 - Número e proporção de municípios, segundo as funções utilizadas do Tabwin, por porte populacional, Estado São Paulo, 2017.

\begin{tabular}{|c|c|c|c|c|c|c|c|c|}
\hline \multirow{3}{*}{ Funções do Tabwin } & \multicolumn{6}{|c|}{ Porte dos Municípios (habitantes) } & \multirow{2}{*}{\multicolumn{2}{|c|}{ Total }} \\
\hline & \multicolumn{2}{|c|}{ Até 30.000} & \multicolumn{2}{|c|}{ De 30.001 a 200.000} & \multicolumn{2}{|c|}{ Maior que 200.000} & & \\
\hline & $\mathrm{N}$ & $\%$ & N & $\%$ & N & $\%$ & $\mathrm{~N}$ & $\%$ \\
\hline Funções básicas & 80 & 79,2 & 64 & 82,1 & 20 & 76,9 & 164 & 80,0 \\
\hline Interface Tabwin-SQL & 7 & 6,9 & 16 & 20,5 & 10 & 38,5 & 33 & 16,1 \\
\hline Ferramenta de mapa fluxo origem-destino & 13 & 12,9 & 10 & 12,8 & 3 & 11,5 & 26 & 12,7 \\
\hline Módulos de mapas e gráficos & 7 & 6,9 & 9 & 11,5 & 2 & 7,7 & 18 & 8,8 \\
\hline$\overline{\text { Total }}$ & 101 & & 78 & & 26 & & 205 & \\
\hline
\end{tabular}

Em relação à realização da análise espacial, foi verificado que apenas $20,6 \%$ dos municípios realizam esta atividade, com a proporção maior nos municípios de grande porte $(67,9 \%)$. As diferenças entre os grupos foram estatisticamente significantes (Tabela 19). 
Tabela 19 - Número e proporção de municípios, segundo realização de análise espacial dos dados, por porte populacional, Estado São Paulo, 2017.

\begin{tabular}{|c|c|c|c|c|c|c|c|c|}
\hline \multirow{3}{*}{ Realiza Análise Espacial } & \multicolumn{6}{|c|}{ Porte dos Municípios (habitantes) } & \multirow{2}{*}{\multicolumn{2}{|c|}{ Total }} \\
\hline & \multicolumn{2}{|c|}{ Até 30.000} & \multicolumn{2}{|c|}{ De 30.001 a 200.000} & \multicolumn{2}{|c|}{ Maior que 200.000} & & \\
\hline & $\mathrm{N}$ & $\%$ & $\mathrm{~N}$ & $\%$ & $\mathrm{~N}$ & $\%$ & $\mathrm{~N}$ & $\%$ \\
\hline Sim & 39 & 14,7 & 26 & 23,0 & 19 & 67,9 & 84 & 20,6 \\
\hline Não & 227 & 85,3 & 87 & 77,0 & 9 & 32,1 & 323 & 79,4 \\
\hline Total & 266 & 100,0 & 113 & 100,0 & 28 & 100,0 & 407 & 100,0 \\
\hline
\end{tabular}

A tabela 20 mostra que $33,9 \%$ dos municípios usam algum tipo de instrumento paralelo ao SINAN (planilhas, cadernos, livros de registros, sistemas etc.), com maior proporção nos municípios de médio $(45,1 \%)$ e grande porte $(82,1 \%)$. As diferenças entre os grupos foram estatisticamente significantes.

Tabela 20 - Número e proporção de municípios, segundo a utilização de instrumentos paralelos, por porte populacional, Estado de São Paulo, 2017.

\begin{tabular}{|c|c|c|c|c|c|c|c|c|}
\hline \multirow{3}{*}{ Uso de instrumento paralelo ao SINAN } & \multicolumn{6}{|c|}{ Porte dos Municípios (habitantes) } & \multirow{2}{*}{\multicolumn{2}{|c|}{ Total }} \\
\hline & \multicolumn{2}{|c|}{ Até 30.000} & \multicolumn{2}{|c|}{ De 30.001 a 200.000} & \multicolumn{2}{|c|}{ Maior que 200.000} & & \\
\hline & $\mathrm{N}$ & $\%$ & N & $\%$ & N & $\%$ & N & $\%$ \\
\hline Não & 202 & 75,9 & 62 & 54,9 & 5 & 17,9 & 269 & 66,1 \\
\hline Sim & 64 & 24,1 & 51 & 45,1 & 23 & 82,1 & 138 & 33,9 \\
\hline Total & 266 & 100,0 & 113 & 100,0 & 28 & 100,0 & 407 & 100,0 \\
\hline
\end{tabular}

$\mathrm{p}<0,001$

Dos municípios que utilizam instrumento paralelo ao SINAN, 54,9\% informaram que o fazem por necessidade de incluir informações que não estão presentes nas fichas de notificação/investigação, 18,1\% para ter maior controle e $13,2 \%$ para ter maior facilidade e agilidade no acesso aos dados (Tabela 21). 
Tabela 21 - Número e proporção de municípios, segundo o motivo para utilizar instrumentos paralelos ao SINAN, por porte populacional, Estado de São Paulo, 2017.

\begin{tabular}{|c|c|c|c|c|c|c|c|c|}
\hline \multirow{3}{*}{ Motivo } & \multicolumn{6}{|c|}{ Porte dos Municípios (habitantes) } & \multirow{2}{*}{\multicolumn{2}{|c|}{ Total }} \\
\hline & \multicolumn{2}{|c|}{ Até 30.000} & \multicolumn{2}{|c|}{ De 30.001 a 200.000} & \multicolumn{2}{|c|}{ Maior que 200.000} & & \\
\hline & $\mathrm{N}$ & $\%$ & N & $\%$ & $\mathrm{~N}$ & $\%$ & $\mathrm{~N}$ & $\%$ \\
\hline Lentidão para enviar os dados & 3 & 4,3 & 5 & 9,6 & 2 & 8,7 & 10 & 6,9 \\
\hline Necessidade de incluir informações que não e & 38 & 55,1 & 24 & 46,2 & 17 & 73,9 & 79 & 54,9 \\
\hline Maior controle & 13 & 18,8 & 12 & 23,1 & 1 & 4,3 & 26 & 18,1 \\
\hline Facilidade e agilidade no acesso aos dados & 9 & 13,0 & 9 & 17,3 & 1 & 4,3 & 19 & 13,2 \\
\hline Seguranç̧a & 2 & 2,9 & 3 & 5,8 & 3 & 13,0 & 8 & 5,6 \\
\hline Outros & 9 & 13,0 & 5 & 9,6 & 5 & 21,7 & 19 & 13,2 \\
\hline Total de municípios & 69 & & 52 & & 23 & & 144 & \\
\hline
\end{tabular}

\subsection{CAPACITAÇÃO PROFISSIONAL}

Foi perguntado ao responsável se ele ou a equipe receberam treinamento institucional para trabalhar com o SINAN e 76,7\% afirmaram que sim, com maior proporção nos municípios médios $(79,6 \%)$ e diferença significante entre os grupos de municípios (Tabela 22). Os Grupos de Vigilância Epidemiológica - GVE foram os mais citados como ofertantes de treinamento $(70,2 \%)$, seguidos do Centro de Vigilância Epidemiológica - CVE $(8,2 \%)$ e CRT-Aids (3,6\%). 
Tabela 22 - Número e proporção de municípios, segundo recebimento de treinamento institucional para trabalhar com o SINAN, por porte populacional, Estado de São Paulo, 2017.

\begin{tabular}{ccccccccc}
\hline & \multicolumn{9}{c}{ Porte dos Municípios (habitantes) } & \multicolumn{2}{c}{ Total } \\
\cline { 2 - 7 } Recebeu treinamento & Até 30.000 & \multicolumn{2}{c}{ De 30.001 a 200.000 } & Maior que 200.000 & & \\
\cline { 2 - 7 } & $\mathrm{N}$ & $\%$ & $\mathrm{~N}$ & $\%$ & $\mathrm{~N}$ & $\%$ & $\mathrm{~N}$ & $\%$ \\
\hline Sim & 202 & 75,9 & 90 & 79,6 & 20 & 71,4 & 312 & 76,7 \\
Não & 64 & 24,1 & 23 & 20,4 & 8 & 28,6 & 95 & 23,3 \\
\hline Total & 266 & 100,0 & 113 & 100,0 & 28 & 100,0 & 407 & 100,0 \\
\hline p<0,001 & & & & & & & &
\end{tabular}

Em relação às reuniões com os GVE no último ano, 38,5\% dos municípios informaram que elas ocorreram com periodicidade mensal ou bimestral; sendo em menor proporção $(25,0 \%)$ para os grandes municípios; para $11,1 \%$ foi anual e para $23,8 \%$ não havia periodicidade definida; $8,1 \%$ informaram que não houve reunião, com proporção mais elevada nos maiores municípios $(21,4 \%)$.

Uma das atribuições da equipe responsável pelo sistema é fornecer capacitação para as unidades que notificam as doenças/agravos em relação ao preenchimento das fichas de notificação/investigação. Esse treinamento ocorreu em $50,1 \%$ dos municípios, no último ano, sendo majoritário nos municípios de grande porte $(89,3 \%)$. Os resultados apresentaram diferenças significantes entre os grupos (Tabela 23).

Tabela 23 - Número e proporção de municípios, segundo a capacitação das unidades notificadoras, por porte populacional, Estados de São Paulo, 2017.

\begin{tabular}{|c|c|c|c|c|c|c|c|c|}
\hline \multirow{3}{*}{$\begin{array}{c}\text { Capacitação da unidades } \\
\text { Notificadoras }\end{array}$} & \multicolumn{6}{|c|}{ Porte dos Municípios (habitantes) } & \multirow{2}{*}{\multicolumn{2}{|c|}{ Total }} \\
\hline & \multicolumn{2}{|c|}{ Até 30.000} & \multicolumn{2}{|c|}{ De 30.001 a 200.000} & \multicolumn{2}{|c|}{ Maior que $\mathbf{2 0 0 . 0 0 0}$} & & \\
\hline & $\mathrm{N}$ & $\%$ & $\mathrm{~N}$ & $\%$ & $\mathrm{~N}$ & $\%$ & $\mathrm{~N}$ & $\%$ \\
\hline Sim & 112 & 42,1 & 67 & 59,3 & 25 & 89,3 & 204 & 50,1 \\
\hline Não & 154 & 57,9 & 46 & 40,7 & 3 & 10,7 & 203 & 49,9 \\
\hline Total & 266 & 100,0 & 113 & 100,0 & 28 & 100,0 & 407 & 100,0 \\
\hline
\end{tabular}

$p<0,001$ 


\subsection{DISSEMINAÇÃO DE DADOS}

Em relação à divulgação dos dados provenientes do SINAN para as unidades notificadoras, observou-se que $54,3 \%$ dos municípios afirmaram realizar esta prática, ocorrendo, em maior proporção, nos grandes municípios $(92,9 \%)$ e em menor proporção nos pequenos (47,7\%). Houve diferença significativa entre os grupos estudados (Tabela 24).

Tabela 24 - Número e proporção de municípios, segundo a divulgação dados do SINAN para as unidades notificadoras (hospitais, UBS etc.), por porte populacional, Estado de São Paulo, 2017.

\begin{tabular}{|c|c|c|c|c|c|c|c|c|}
\hline \multirow{3}{*}{$\begin{array}{l}\text { Divulgação dos } \\
\text { Dados do SINAN }\end{array}$} & \multicolumn{6}{|c|}{ Porte dos Municípios (habitantes) } & \multirow{2}{*}{\multicolumn{2}{|c|}{ Total }} \\
\hline & \multicolumn{2}{|c|}{ Até $\mathbf{3 0 . 0 0 0}$} & \multicolumn{2}{|c|}{ De 30.001 a 200.000} & \multicolumn{2}{|c|}{ Maior que 200.000} & & \\
\hline & $\mathrm{N}$ & $\%$ & $\mathrm{~N}$ & $\%$ & $\mathrm{~N}$ & $\%$ & $\mathrm{~N}$ & $\%$ \\
\hline Sim & 127 & 47,7 & 68 & 60,2 & 26 & 92,9 & 221 & 54,3 \\
\hline Não & 139 & 52,3 & 45 & 39,8 & 2 & 7,1 & 186 & 45,7 \\
\hline Total & 266 & 100,0 & 113 & 100,0 & 28 & 100,0 & 407 & 100,0 \\
\hline
\end{tabular}

$\mathrm{p}<0,001$

Em relação à disponibilização das informações geradas pelo SINAN, essa prática ocorre em $64,4 \%$ dos municípios, com valores decrescentes dos maiores municípios (100,0\%) para os menores (56,8\%) (Tabela 25$)$. 
Tabela 25 - Número e proporção de municípios, segundo a disponibilização das informações geradas pelo SINAN, por porte populacional, Estado de São Paulo, 2017.

\begin{tabular}{|c|c|c|c|c|c|c|c|c|}
\hline \multirow{3}{*}{ Disponibiliza Informações } & \multicolumn{6}{|c|}{ Porte dos Municípios (habitantes) } & \multirow{2}{*}{\multicolumn{2}{|c|}{ Total }} \\
\hline & \multicolumn{2}{|c|}{ Até 30.000} & \multicolumn{2}{|c|}{ De 30.001 a 200.000} & \multicolumn{2}{|c|}{ Maior que 200.000} & & \\
\hline & $\mathrm{N}$ & $\%$ & $\mathrm{~N}$ & $\%$ & $\mathrm{~N}$ & $\%$ & $\mathrm{~N}$ & $\%$ \\
\hline Sim & 151 & 56,8 & 83 & 73,5 & 28 & 100 & 262 & 64,4 \\
\hline Não & 115 & 43,2 & 30 & 26,5 & 0 & 0 & 145 & 35,6 \\
\hline Total & 266 & 100,0 & 113 & 100,0 & 28 & 100 & 407 & 100,0 \\
\hline
\end{tabular}

Foi investigada a forma em que essas informações são disponibilizadas. Cerca de $10,0 \%$ dos municípios utilizam mais de um tipo de divulgação, especialmente os maiores (35,7\%); 56,9\% elaboram boletim ou relatório impresso e 19,8\% eletrônico, com o primeiro tipo sendo proporcionalmente mais frequente nos menores municípios $(62,9 \%)$ e o segundo nos maiores (53,6\%) (Tabela 26).

Tabela 26 - Número e proporção de municípios, segundo o tipo de disponibilização das informações geradas pelo SINAN, por porte populacional, Estado de São Paulo, 2017.

\begin{tabular}{|c|c|c|c|c|c|c|c|c|}
\hline \multirow{2}{*}{ Variáveis } & \multicolumn{6}{|c|}{ Porte dos Municípios (habitantes) } & \multicolumn{2}{|c|}{ Total } \\
\hline & $\mathrm{N}$ & $\%$ & $\mathrm{~N}$ & $\%$ & $\mathrm{~N}$ & $\%$ & $\mathrm{~N}$ & $\%$ \\
\hline Elabora boletim ou relatório epidemiológico impresso & 95 & 62,9 & 40 & 48,2 & 14 & 50,0 & 149 & 56,9 \\
\hline Elabora boletim ou relatório epidemiológico eletrônico & 17 & 11,3 & 20 & 24,1 & 15 & 53,6 & 52 & 19,8 \\
\hline Disponibiliza planilhas e/ou indicadores no site & 13 & 8,6 & 16 & 19,3 & 8 & 28,6 & 37 & 14,1 \\
\hline Apresenta reuniões de equipe & 11 & 7,3 & 1 & 1,2 & 3 & 10,7 & 15 & 5,7 \\
\hline Outros & 14 & 9,3 & 18 & 21,7 & 5 & 17,9 & 47 & 17,9 \\
\hline Total de municípios & 151 & & 83 & & 28 & & 262 & \\
\hline
\end{tabular}

Em relação aos principais usos das informações do SINAN geradas pelo município, destacam-se: planejamento de ações de Vigilância Epidemiológica/em Saúde (84,3\%), pactuação de indicadores de saúde (79,1\%), Conselho Municipal de Saúde $(65,8 \%)$ e definição de prioridades $(60,7 \%)$ (Tabela 27). 
Tabela 27 - Número e proporção de municípios, segundo o uso das informações geradas pelo SINAN, Estado de São Paulo, 2017.

\begin{tabular}{|c|c|c|c|c|c|c|c|c|}
\hline \multirow{3}{*}{ Usos das Informações } & \multicolumn{6}{|c|}{ Porte dos Municípios (habitantes) } & \multirow{2}{*}{\multicolumn{2}{|c|}{ Total }} \\
\hline & \multicolumn{2}{|c|}{ Até $\mathbf{3 0 . 0 0 0}$} & \multicolumn{2}{|c|}{ De 30.001 a 200.000} & \multicolumn{2}{|c|}{$\begin{array}{c}\text { Maior que } \\
200.000\end{array}$} & & \\
\hline & $\mathbf{N}$ & $\%$ & $\mathbf{N}$ & $\%$ & $\mathbf{N}$ & $\%$ & $\mathbf{N}$ & $\%$ \\
\hline $\begin{array}{l}\text { Planejamento de ações de Vigilância } \\
\text { Epidemiológica/em Saúde }\end{array}$ & 216 & 81,2 & 100 & 88,5 & 27 & 96,4 & 343 & 84,3 \\
\hline Pactuação de indicadores de saúde & 197 & 74,1 & 99 & 87,6 & 28 & 100,0 & 324 & 79,6 \\
\hline Conselho Municipal de Saúde & 171 & 64,3 & 75 & 66,4 & 22 & 78,6 & 268 & 65,8 \\
\hline $\begin{array}{l}\text { Avaliação e monitoramento das } \\
\text { metas estabelecidas }\end{array}$ & 134 & 50,4 & 82 & 72,6 & 26 & 92,9 & 242 & 59,5 \\
\hline Definição de prioridades & 129 & 48,5 & 77 & 68,1 & 24 & 85,7 & 230 & 56,5 \\
\hline Audiência pública de saúde & 117 & 44,0 & 83 & 73,5 & 19 & 67,9 & 219 & 53,8 \\
\hline Mídia (jornal, rádio, web,TV etc.) & 46 & 17,3 & 60 & 53,1 & 23 & 82,1 & 129 & 31,7 \\
\hline Colegiados de Gestão Regional & 40 & 15,0 & 28 & 24,8 & 6 & 21,4 & 74 & 18,2 \\
\hline Publicações & 30 & 11,3 & 26 & 23,0 & 11 & 39,3 & 67 & 16,5 \\
\hline Conselho Estadual de Saúde & 10 & 3,8 & 12 & 10,6 & 1 & 3,6 & 23 & 5,7 \\
\hline Não é utilizada & 18 & 6,8 & 1 & 0,9 & 0 & 0,0 & 19 & 4,7 \\
\hline Outro & 0 & 0,0 & 3 & 2,7 & 1 & 3,6 & 4 & 1,0 \\
\hline Total de municípios & 266 & & 113 & & 28 & & 407 & \\
\hline
\end{tabular}

\subsection{AVALIAÇÃO DO SINAN}

Para $51,8 \%$ dos municípios entrevistados, o preenchimento das fichas de notificação/investigação é bom, com maior percentual nos municípios pequenos $(59,8 \%)$. Para $60,7 \%$ dos municípios grandes, o preenchimento é razoável, sendo que o percentual decresce à medida que diminui o porte populacional, com $48,7 \%$ e $30,1 \%$, respectivamente, para os médios e pequenos. A classificação ruim obteve maior percentual nos municípios de médio porte $(12,4 \%)$. As diferenças são significantes entre os grupos (Tabela 28). 
Tabela 28 - Número e proporção de municípios, segundo a qualidade do preenchimento das fichas de notificação/investigação, por porte populacional, Estado de São Paulo, 2017.

\begin{tabular}{|c|c|c|c|c|c|c|c|c|c|}
\hline & \multirow{3}{*}{ Variáveis } & \multicolumn{6}{|c|}{ Porte dos Municípios (habitantes) } & \multicolumn{2}{|c|}{ Total } \\
\hline & & \multicolumn{2}{|c|}{ Até $\mathbf{3 0 . 0 0 0}$} & \multicolumn{2}{|c|}{ De 30.001 a 200.000} & \multicolumn{2}{|c|}{ Maior que 200.000} & \multirow[b]{2}{*}{$\mathrm{N}$} & \multirow[b]{2}{*}{$\%$} \\
\hline & & $\mathrm{N}$ & $\%$ & $\mathrm{~N}$ & $\%$ & $\mathrm{~N}$ & $\%$ & & \\
\hline Ruim & & 12 & 4,5 & 14 & 12,4 & 2 & 7,1 & 28 & 6,9 \\
\hline Razoável & & 80 & 30,1 & 55 & 48,7 & 17 & 60,7 & 152 & 37,3 \\
\hline Boa & & 159 & 59,8 & 43 & 38,1 & 9 & 32,1 & 211 & 51,8 \\
\hline Excelente & & 15 & 5,6 & 1 & 0,9 & 0 & 0,0 & 16 & 3,9 \\
\hline Total & & 266 & 100,0 & 113 & 100,0 & 28 & 100,0 & 407 & 100,0 \\
\hline
\end{tabular}

$p<0,001$

Os principais problemas apontados pelos municípios no momento da digitação das fichas de notificação/investigação foram o preenchimento incompleto dos campos obrigatórios (83,5\%), letra ilegível/rasura $(37,6 \%)$, inconsistência das informações $(28,3 \%)$ e, com percentual bem inferior, duplicidade da ficha (2,5\%) (figura 7).

Figura 7 - Principais problemas encontrados nas fichas de notificação/investigação no momento da digitação, Estado de São Paulo, 2017.

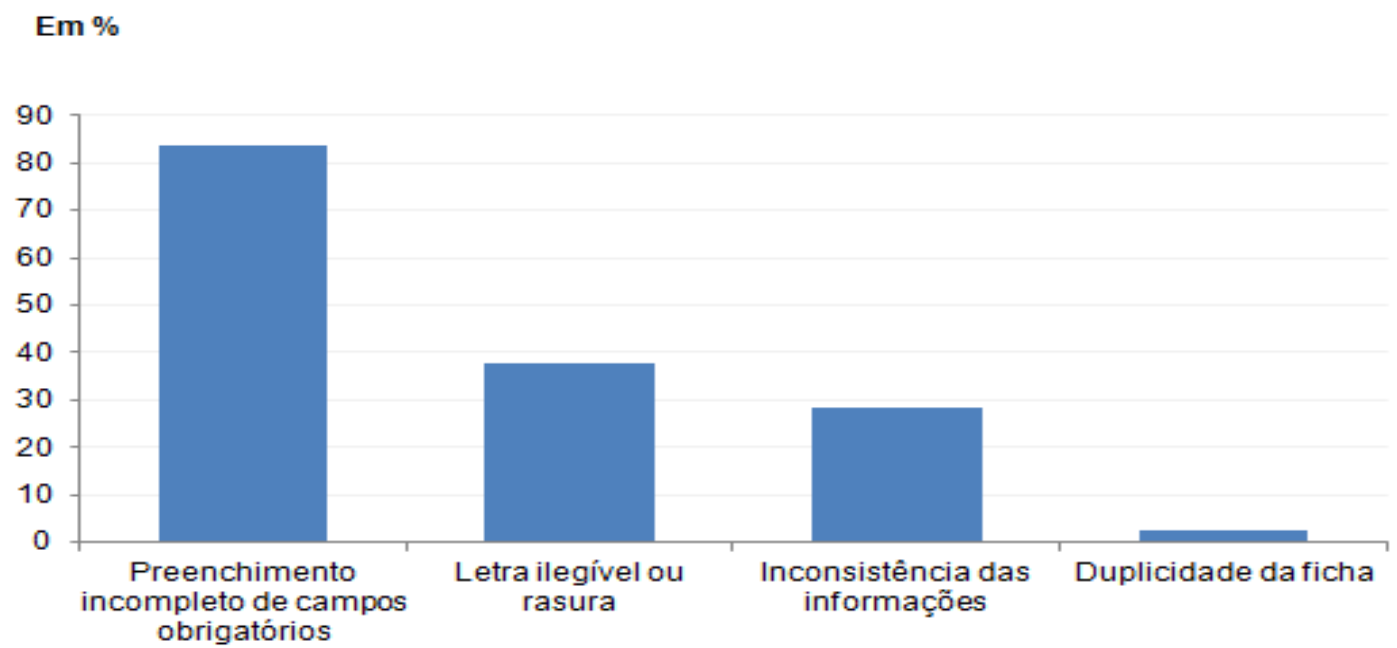

Para $71,7 \%$ dos respondentes, o SINAN, enquanto instrumento epidemiológico, atende totalmente às necessidades dos municípios, em maior 
proporção nos municípios pequenos (78,2\%) e médios (68,1\%). Por outro lado, $26,8 \%$ consideram que o SINAN atende parcialmente, com maior proporção nos municípios grandes $(71,4 \%)$, com diferenças estatisticamente significantes (tabela 29). Em relação à adequação da lista nacional de agravos e doenças de notificação compulsória, 95,6\% dos municípios consideram-na adequada, sem diferença estatisticamente significante entre os três grupos de municípios (Tabela 29).

Tabela 29 - Número e proporção de município, segundo o atendimento do SINAN como instrumento epidemiológico e adequação da lista de Doenças de Notificação Compulsória, por porte populacional, Estado de São Paulo, 2017.

\begin{tabular}{|c|c|c|c|c|c|c|c|c|}
\hline \multirow{3}{*}{ Variáveis } & \multicolumn{6}{|c|}{ Porte dos Municípios (habitantes) } & \multirow{2}{*}{\multicolumn{2}{|c|}{ Total }} \\
\hline & \multicolumn{2}{|c|}{ Até $\mathbf{3 0 . 0 0 0}$} & \multicolumn{2}{|c|}{$\begin{array}{l}\text { De } 30.001 \text { a } \\
200.000\end{array}$} & \multicolumn{2}{|c|}{$\begin{array}{c}\text { Maior que } \\
200.000\end{array}$} & & \\
\hline & $\mathrm{N}$ & $\%$ & $\mathrm{~N}$ & $\%$ & $\mathrm{~N}$ & $\%$ & $\mathrm{~N}$ & $\%$ \\
\hline \multicolumn{9}{|c|}{$\begin{array}{l}\text { SINAN como instrumento } \\
\text { epidemiológico* }\end{array}$} \\
\hline Sim, totalmente & 208 & 78,2 & 77 & 68,1 & 7 & 25,0 & 292 & 71,7 \\
\hline Sim , parcialmente & 53 & 19,9 & 36 & 31,9 & 20 & 71,4 & 109 & 26,8 \\
\hline Não & 5 & 1,9 & 0 & 0,0 & 1 & 3,6 & 6 & 1,5 \\
\hline \multicolumn{9}{|c|}{ Adequação da Lista DNC** } \\
\hline Adequada & 255 & 95,9 & 109 & 96,5 & 25 & 89,3 & 389 & 95,6 \\
\hline Inadequada & 11 & 4,1 & 4 & 3,5 & 3 & 10,7 & 18 & 4,4 \\
\hline Total & 266 & 100,0 & 113 & 100,0 & 28 & 100,0 & 407 & 100,0 \\
\hline
\end{tabular}

Os municípios avaliaram o apoio técnico recebido por alguns setores envolvidos no processo de trabalho do SINAN. Observaram-se elevados percentuais de aprovação, sendo o maior para o GVE (93,9\%). O apoio técnico foi considerado adequado com maior frequência nos municípios pequenos, decrescendo com o aumento do porte populacional. As diferenças foram significantes entre os grupos (Tabela 30). 
Tabela 30 - Número e proporção de municípios, segundo o apoio técnico das instituições em relação ao SINAN, por porte populacional, Estado de São Paulo, 2017.

\begin{tabular}{|c|c|c|c|c|c|c|c|c|}
\hline \multirow{3}{*}{ Variáveis } & \multicolumn{6}{|c|}{ Porte dos Municípios (habitantes) } & \multirow{2}{*}{\multicolumn{2}{|c|}{ Total }} \\
\hline & \multicolumn{2}{|c|}{ Até 30.000} & \multicolumn{2}{|c|}{ De 30.001 a 200.000} & \multicolumn{2}{|c|}{ Maior que 200.000} & & \\
\hline & $\mathrm{N}$ & $\%$ & $\mathrm{~N}$ & $\%$ & $\mathrm{~N}$ & $\%$ & $\mathrm{~N}$ & $\%$ \\
\hline \multicolumn{9}{|c|}{ Grupo de Vigilância Epidemiológica - GVE * } \\
\hline Adequado & 261 & 98,1 & 103 & 91,2 & 180 & 64,3 & 382 & 93,9 \\
\hline Inadequada & 5 & 1,9 & 10 & 8,8 & 10 & 35,7 & 25 & 6,1 \\
\hline \multicolumn{9}{|c|}{ Centro de Vigilância Epidemiológica - CVE* } \\
\hline Adequado & 240 & 90,2 & 98 & 86,7 & 17 & 60,7 & 355 & 87,2 \\
\hline Inadequada & 26 & 9,8 & 15 & 13,3 & 11 & 39,3 & 52 & 12,8 \\
\hline \multirow{2}{*}{\multicolumn{9}{|c|}{$\begin{array}{l}\text { Centro de Referência e Treinamento DST/Aids - } \\
\text { CRTA (SES-SP)* }\end{array}$}} \\
\hline & & & & & & & & \\
\hline Adequado & 236 & 88,7 & 92 & 81,4 & 17 & 60,7 & 345 & 84,8 \\
\hline Inadequada & 30 & 11,3 & 21 & 18,6 & 11 & 39,3 & 62 & 15,2 \\
\hline \multicolumn{9}{|l|}{ Instituto Pasteur (SES-SP) * } \\
\hline Adequado & 229 & 86,1 & 92 & 81,4 & 16 & 57,1 & 337 & 82,8 \\
\hline Inadequada & 37 & 13,9 & 21 & 18,6 & 12 & 42,9 & 70 & 17,2 \\
\hline Total & 266 & 100,0 & 113 & 100,0 & 28 & 100,0 & 407 & 100,0 \\
\hline
\end{tabular}

A fim de avaliar o grau de dificuldade que os municípios têm na realização de algumas atividades, foi solicitado que os mesmos informassem sua opinião numa escala que variou de nenhuma a muita alta dificuldade. Os dados apontam que os municípios têm alta dificuldade nos seguintes quesitos: fluxo de retorno (17,7\%); capacitação das unidades notificadoras (16,7\%); e falta de recursos humanos (15,5\%) (Anexo 2 - Tabela 5A).

Observa-se que as maiores proporções de alta dificuldade foram mencionadas para o item fluxo de retorno nos municípios médios $(22,1 \%)$ e grandes $(21,4 \%)$, para capacitação das unidades notificadoras nos pequenos $(16,9 \%)$ e médios municípios $(16,8 \%)$ e a falta de recursos humanos nos municípios maiores $(21,4 \%)$ (Figura 8$)$. 
Figura 08 - Municípios segundo grau de dificuldade na realização de algumas atividades do SINAN, segundo porte populacional, Estado de São Paulo, 2017.

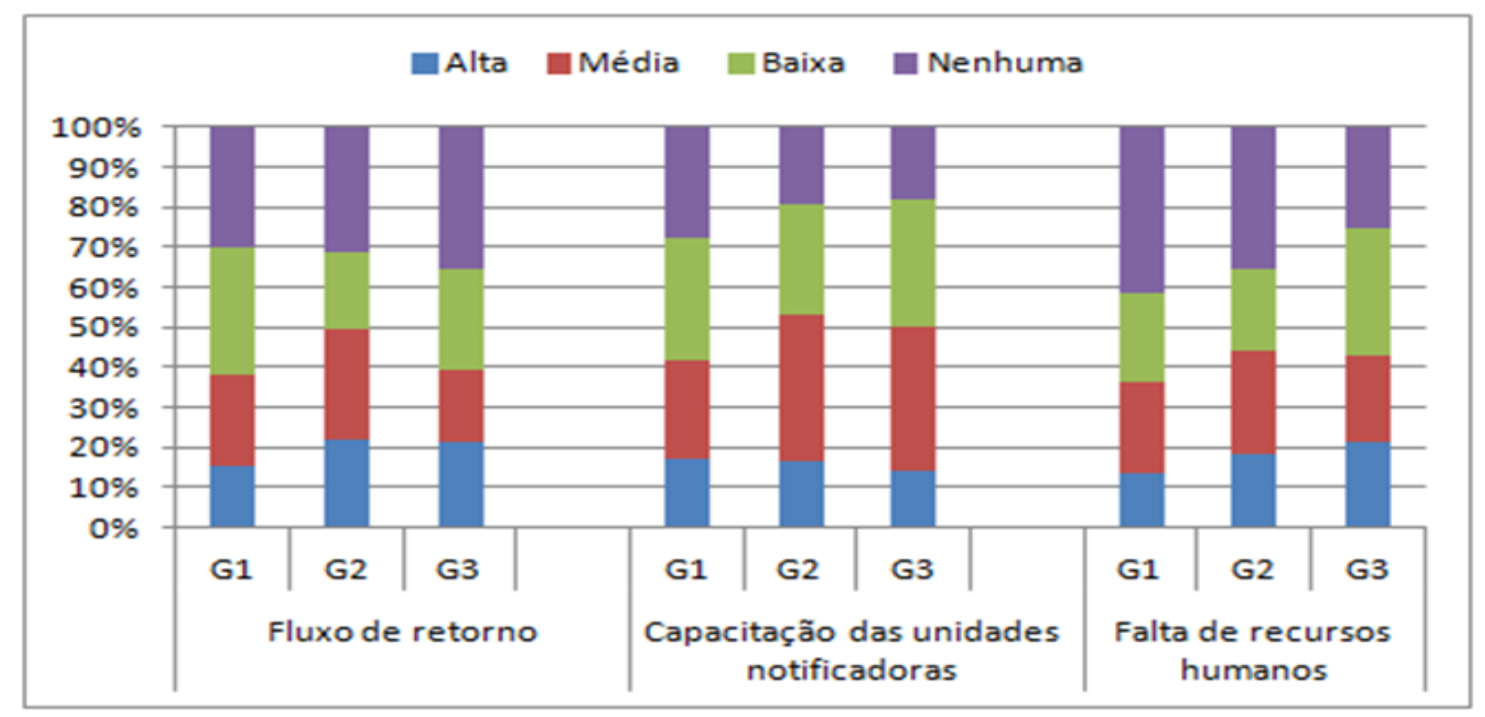

G1: até 30 mil hab. G2: 30.001 a 200.000 hab. G3: >200.000 hab.

A fim de avaliar os benefícios da descentralização do SINAN para os municípios, foram selecionados alguns quesitos, para os quais foi gerada uma escala, que variou de nenhum a muito alto benefício. Observou-se que os municípios avaliaram satisfatoriamente todos os itens, com percentual de alto benefício acima de 50,0\%, com destaque para: acompanhamento da situação epidemiológica do município (65,1\%), autonomia da informação $(57,2 \%)$ e obtenção de informações fundamentais para estratégias de intervenção $(56,3 \%)$ (Anexo 2 - Tabela 6A). Essas proporções foram menores nos municípios grandes (Figura 9). 
Figura 09 - Distribuição dos municípios, segundo avaliação dos benefícios do SINAN para o município, por porte populacional, Estado de São Paulo, 2017.

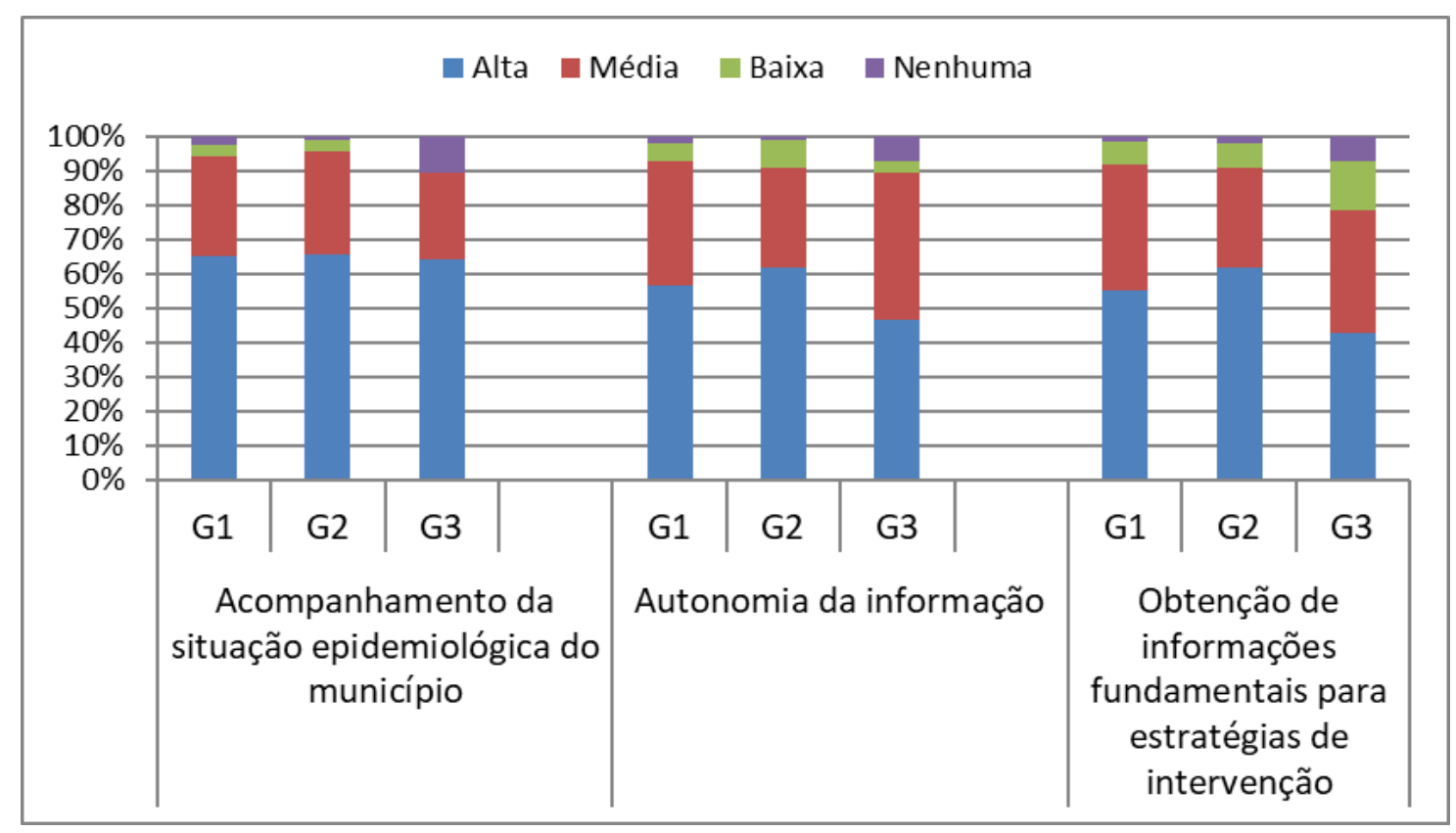

G1: até 30 mil hab. G2: 30.001 a 200.000 hab. G3: >200.000 hab.

\subsection{COMPARAÇÃO DOS RESULTADOS ENTRE OS GRUPOS DE MUNICÍPIOS}

Neste tópico será apresentada uma síntese referente aos principais diferenciais encontrados no estudo, segundo os grupos de municípios estudados.

Quanto aos responsáveis pela vigilância epidemiológica municipal, foram identificadas algumas características predominantes para todos os grupos: responsáveis técnicos do sexo feminino, idade média de 40,9 anos, com nível superior completo. Nos municípios maiores predominam profissionais com maior idade, vínculo efetivo/estatutário e maior nível de formação e, nos pequenos, esses são mais jovens, com menor tempo de trabalho na área e menor escolaridade. 
Verificou-se que nos municípios pequenos houve predomínio da formação em enfermagem; em quase sua totalidade, os responsáveis técnicos apresentam responsabilidade conjunta por outros sistemas, com proporção maior que os demais grupos.

A vigilância epidemiológica, local onde são desenvolvidas as principais atividades do SINAN, está alocada predominantemente nas unidades de saúde. As equipes são compostas por um ou dois profissionais, quase metade sendo graduada. A estrutura física do local de trabalho é adequada, com maior proporção em relação à dos demais grupos. Segundo a avaliação dos respondentes, os recursos materiais classificados como de informática e comunicação são suficientes, com exceção ao HD externo, com proporções semelhantes entre os grupos. A maioria tem apenas 1 computador, com um sistema operacional intermediário (Windows 7), porém alguns ainda apresentam sistema operacional mais antigo (Windows XP). Para mais da metade dos municípios, o suporte de $\mathrm{Tl}$ é um serviço próprio. Em torno de $80,0 \%$ dos municípios não fazem nenhum tipo de procedimento para monitorar o volume dos eventos notificados, percentual alto comparado com municípios de grande porte. Também não realizam procedimentos para complementar as informações do SINAN. A ferramenta Tabwin é utilizada por uma pequena quantidade de municípios. Fazem uso de sistema paralelo ao SINAN, porém em proporção inferior nos municípios médios e grandes. Mais da metade dos municípios foram capacitados para trabalhar com o SINAN e menos da metade retornam os dados para as unidades notificadoras. A disponibilização das informações do SINAN ocorre em menor proporção do que nos municípios médios e grandes. Consideram 0 preenchimento das fichas de notificação/investigação como bom. Esses municípios apresentaram juntamente com os municípios médios, maior percentual de alta dificuldade para realizar a atividade capacitação das unidades notificadoras. Em relação aos benefícios da descentralização do SINAN, observou-se uma avaliação com percentual acima de $50,0 \%$ para todos os itens entre todos os grupos, porém a avaliação dos municípios de grande porte apresentou um percentual inferior aos demais grupos. 
Nos municípios de médio porte, predominou a formação em enfermagem, apresentando pós-graduados em maior proporção que os municípios pequenos. Os responsáveis também têm responsabilidades por outros sistemas, com maior percentual que nos municípios grandes.

A vigilância epidemiológica encontra-se alocada em Coordenadorias/Departamentos, porém em menor proporção que nos municípios de grande porte. A formação mais frequente relatada foi o nível técnico ou ensino médio. A equipe é composta de 3 a 6 profissionais. A estrutura física do local de trabalho é adequada, porém este é o grupo que apresentou mais problemas com ventilação, iluminação, barulho e percentual elevado de problemas com a rede elétrica. Mais da metade dos municípios tem de 1 a 2 computadores, com um sistema operacional Windows 7, ainda apresentam um sistema operacional defasado em maior proporção que os municípios pequenos. Quase a totalidade dos municípios possui suporte de TI próprio. Aproximadamente um terço dos municípios fazem algum tipo de procedimento para monitorar o volume dos eventos notificados, e quase a totalidade dos municípios não realizam procedimentos para complementar as informações do SINAN. A ferramenta Tabwin é utilizada por mais da dos municípios. Este é o grupo de municípios que mais recebeu treinamento para trabalhar com SINAN. A divulgação dos dados para as unidades notificadoras ocorreu em mais da metade dos municípios, em menor proporção que nos municípios grandes; 70,0\% disponibilizam as informações do SINAN e 48,7\% consideram o preenchimento das fichas como razoável. Apresentou juntamente com municípios de grande porte, maior percentual de alta dificuldade para realizar a atividade fluxo de retorno. No grupo dos grandes municípios predominou o responsável técnico com idade $\geq 50$ anos $(60,7 \%)$ e elevado percentual de pós-graduados $(75,0 \%)$ em relação aos demais grupos populacionais; maior número de efetivos $(64,3 \%)$; profissionais com maior tempo de experiência com SINAN; 80,0\% apresenta formação dividida entre enfermagem e outras formações, Apresenta responsabilidade conjunta por outros sistemas, porém em proporção inferior aos municípios pequenos e médios. 
A vigilância epidemiológica está alocada em Coordenadorias/Departamentos, contam com equipe com $\geq 11$ profissionais $(80,0 \%)$ e mais da metade dos profissionais possui graduação. Consideram o local de trabalho adequado, porém com menor proporção que nos municípios de médio e pequeno porte. Apresenta maior número de computadores e sistemas operacionais mais novos, com suporte de informática próprio. Mais da metade dos municípios fazem algum tipo de procedimento para monitorar o volume dos eventos notificados, e a quase totalidade não realiza procedimentos para complementar as informações do SINAN. São os que mais utilizam sistemas paralelos. A maioria dos municípios utiliza a ferramenta Tabwin. É o grupo que menos recebeu treinamento para trabalhar com SINAN, porém é o que mais treinou as unidades notificadoras. A divulgação dos dados para as unidades notificadoras ocorreu em quase sua totalidade. Todos os municípios disponibilizam as informações do SINAN. O grupo considera o preenchimento das fichas razoável. Apresentou maior percentual de alta dificuldade para o item recursos humanos. 


\section{DISCUSSÃO}

O estudo objetivou cobrir um amplo espectro de municípios e, em relação à representatividade, a pesquisa obteve um retorno acima do preconizado para esse tipo de estratégia metodológica, que estima como satisfatório um percentual em torno de 30\% (COOPER, 2003). O nosso estudo se encontra em situação intermediária em relação a outros estudos que apresentam a mesma abordagem, como os estudos realizados em Minas Gerais, que atingiu 33,5\% (GUIMARÃES et al., 2013), no Rio Grande do Sul, com 37,7\% (VIDOR et al. 2011) e em São Paulo, com retorno de 90,5\% (MINTO et al., 2017).

\subsection{GERÊNCIA DO SINAN - PERFIL DO RESPONSÁVEL TÉCNICO}

$\mathrm{Na}$ maioria dos municípios paulistas, o responsável por gerenciar o SINAN é o mesmo profissional responsável pela vigilância epidemiológica, cabendo a esse articular com estabelecimentos de saúde e com as instâncias regionais e estaduais, sendo produtor, divulgador e receptor de informações em saúde. Sendo assim, é de grande importância o envolvimento desse profissional com todos os processos relacionados à qualidade da informação. Em relação ao perfil do responsável técnico pelo SINAN, verificou-se o predomínio do sexo feminino, o que vai ao encontro com o perfil da força de trabalho da área de saúde, já que o fenômeno de feminização nessa área vem ocorrendo há algumas décadas (MACHADO et al., 2006). Alguns fatores influenciaram a entrada da mulher no mercado de trabalho, como o aumento e elevação dos níveis de escolaridade e instrução, acrescidos da diminuição das taxas de fecundidade (BRUSCHINI,1985). A preponderância do trabalho feminino na área de saúde também é observada em outros países; e, no Brasil, 
o setor de serviços de saúde é o que mostra a maior participação de mulheres dentre todos os setores de atividade econômica (DAL POZ et al., 2013).

Em relação à idade média encontrada (40,9 anos), ela se aproxima muito do estudo de MINTO et al., (2017), em relação aos responsáveis técnicos pelo SIM em municípios paulistas (39,3 anos). Também verificou-se que, nos municípios menores, os responsáveis técnicos são mais jovens do que nos municípios grandes, nos quais houve predomínio de profissionais com idade acima de 50 anos. Para MINTO et al., (2017), este panorama pode estar relacionado a estrutura sólida do serviço onde esse profissional está alocado, favorecendo o desenvolvimento de carreira e consequentemente sua permanência.

Quanto à formação dos responsáveis técnicos, verificou-se que 90,4\% possuem graduação, valor mais elevado do que o encontrado no estudo sobre o SIM (78,9\%) (MINTO et al., 2017) e que do estudo com o responsável técnico do SINASC, em municípios mineiros, em que verificou-se que 70,4\% possuíam mais que 12 anos de estudo, não sendo possível saber a proporção exata de profissionais com superior completo (GUIMARÃES et al., 2013).

Em relação ao vínculo empregatício do responsável técnico, um pouco mais da metade dos profissionais possuíam o vínculo efetivo/estatutário, com maior frequência nos municípios de grande porte. Esse tipo de vínculo pode favorecer a permanência dos profissionais nos serviços. O segundo tipo de vínculo que predomina é o regime de Consolidação das Leis do Trabalho (CLT), com frequência maior nos municípios de pequeno e médio porte. Essa modalidade de contratação tem sido muito utilizada no serviço público, principalmente nos municípios pequenos. Provavelmente esse fato ocorra devido às dificuldades administrativas em realizar concursos. Em contrapartida, a contratação no regime CLT é mais ágil, sendo, portanto, uma opção muito utilizada por pequenos municípios (MINTO et al., 2017). Os resultados apresentados se aproximam dos observados sobre o responsável técnico pelo SIM no Estado de São Paulo (MINTO, 2015) e corroboram com estudo em 
municípios gaúchos (VIDOR et al., 2011), que observou que os responsáveis pelos sistemas de informação em saúde eram, na sua maioria, estatutários.

O estudo realizado pelo IBGE (2014), em relação aos funcionários da administração direta dos municípios brasileiros, apresentou resultados semelhantes, onde o vínculo predominante foi de servidores estatutários (63,0\%), seguido dos sem vínculo permanente e de CLT. O cargo em comissão, conhecido pela sua transitoriedade, sobressaiu nos municípios de grande porte, no nosso estudo. Para ALVES et al., (2004), a baixa rotatividade contribui com os gestores nos serviços de saúde, pois favorece a aproximação com a comunidade e com o levantamento das suas necessidades, apoiando a continuidade de projetos, sem as interferências ocasionadas por mudanças governamentais ou partidárias.

Em relação ao tempo de experiência profissional na área de saúde, observou-se que mais da metade tinha dez ou mais anos, o que indica baixa rotatividade e maior experiência na área. Os profissionais que trabalhavam há mais de vinte anos nos serviços estavam concentrados no grupo dos municípios de grande porte. GIL (2005) ressaltou a importância da estabilidade no trabalho com profissionais da saúde:

"Dar estabilidade aos profissionais pode significar aumentar a possibilidade de acúmulo de conhecimentos e habilidades que permitam tornar mais consistentes e duradouras também as propostas de formação destes e dos futuros profissionais"

É importante ressaltar que, diante da escassez atual de realização de concursos públicos nos municípios grandes e também da existência de profissionais prestes a se aposentar em razão da idade mais avançada, é possível prever um desfalque nas equipes desses municípios, comprometendo a realização plena das ações de vigilância e também a manutenção adequada dos sistemas de informação.

Em relação ao tempo de experiência com o SINAN, verificou-se que é inferior ao tempo na área da saúde, indicando que o profissional atuou em 
outras áreas antes de trabalhar com o SINAN, o que se justifica pela inexistência de carreira na área de informações em saúde.

Destacamos que um pequeno percentual de responsáveis técnicos possui menos de um ano de experiência com o SINAN, ocorrendo principalmente nos municípios menores. Estudo realizado em Alagoas mostrou que o desempenho dos profissionais foi avaliado como pior à medida que menor fosse o tempo de exercício no cargo, ressaltando a experiência como fator favorável à qualidade das atividades (MENDES et al., 2016). Uma possível explicação para nosso achado foi que no ano anterior à pesquisa houve eleições municipais. Segundo estudo de PRADO (2012), sobre a produção das informações sobre mortalidade e nascidos vivos no Estado de São Paulo, a rotatividade de profissionais é influenciada por mudanças póseleições municipais.

Quanto à formação mais avançada observa-se que mais da metade dos profissionais possuem pós-graduação, estando, estes concentrados nos municípios de grande porte. Quanto aos somente graduados, esses se encontram em maior proporção nos municípios pequenos, tendo como formação, em destaque, a Enfermagem, resultado semelhante ao encontrado no estudo sobre o SIM (MINTO et al., 2017). O presente estudo obteve valor superior, nos pequenos municípios, ao encontrado no estudo de ALVES et al.; (2004), que avaliou o perfil do gerente em unidades de saúde de Belo Horizonte $(49,1 \%)$.

O acúmulo de responsabilidade pelos gestores foi observado em quase todos os municípios, com maior proporção nos pequenos. Tal achado assemelha-se ao estudo de GUIMARÃES et al., (2013). Conforme concluiu o autor, nos municípios mineiros, os profissionais não são exclusivos de um sistema (no caso, o SINASC), assumindo responsabilidade por mais de um sistema de informação, além de outras funções na área de saúde. No estudo de VIDOR et al., (2011), foi observado que os responsáveis pelo SIS nos municípios gaúchos desempenhavam tarefas diversificadas. O nosso estudo identificou que a responsabilidade conjunta do SINAN com outros sistemas é 
mais frequente com o SIM, SINASC e SI-PNI, considerados de grande importância para a vigilância epidemiológica.

\subsection{ESTRUTURA ORGANIZACIONAL E RECURSOS DA VIGILÂNCIA EPIDEMIOLÓGICA}

Para descrever as condições de operação do SINAN, precisa-se compreender a estrutura da Vigilância Epidemiológica (VE), isto é, o setor onde são desenvolvidas as atividades referentes ao SINAN. Foram visualizados panoramas muito distintos. Em mais da metade dos municípios, a VE está alocada nas unidades de saúde, principalmente nos municípios pequenos. Tal situação está possivelmente relacionada à estrutura de saúde desses municípios, ou seja, estruturas administrativas mais enxutas, pouco espaço físico disponível, baixo número de estabelecimentos, sendo que na maioria das vezes existe somente uma unidade de saúde. Do outro lado, temos os municípios maiores, onde a VE está alocada em instâncias administrativas centrais Coordenadorias/Departamentos, o que está de acordo com estruturas administrativas mais complexas dos municípios grandes.

Para grande parte dos municípios a estrutura física do local de trabalho é adequada. Para a minoria, que considerou inadequada, os motivos foram diversos, dentre eles, a falta de espaço foi o mais citado. Em menor proporção, surgiu a falta de privacidade, sala compartilhada com outras atividades e local improvisado. Esses resultados mostram semelhança com o estudo de GUIMARÃES et al., (2013), pois o autor também observou que os serviços municipais compartilhavam a sala com outros sistemas de informação, ora com a vigilância em saúde, ora com a atenção primária.

A média de profissionais que atuam na vigilância epidemiológica municipal é de 5,08 por município. Não existe uma legislação específica que 
determine a quantidade de profissionais para trabalhar na VE. O que foi verificado é que o número é crescente conforme aumenta o porte populacional, variando de até 2 a 11 ou mais profissionais. Na prática, o volume de eventos do município é o que determina a necessidade de profissionais (MINTO et al., 2017). Quanto à formação desses profissionais, é possível observar que quase a metade tinha curso superior na área de saúde, principalmente nos municípios maiores. Os municípios de grande porte merece destaque em relação à alta proporção de profissionais com pós-graduação em epidemiologia e/ou saúde pública.

A informática é um instrumento de grande auxílio em todo o processo de geração da informação, sendo capaz de sintetizar um grande volume de dados, processando-os e oferecendo diversas opções que facilitam a análise final (BRANCO, 1998). Foi observado no estudo que o número de computadores se eleva à medida que aumenta o porte populacional. Verificou-se que o SINAN está instalado em um número maior de computadores do que outros sistemas, como o SIM e SINASC (MINTO et al., 2017; GUIMARÃES et al., 2013). Possivelmente, este resultado está relacionado ao fato de que para operar o SINAN-Net, o mesmo deve ser instalado separadamente de outros sistemas, devido às particularidades encontradas neste, que geram incompatibilidade no computador, necessitando de máquinas exclusivas para operá-lo.

Quando se pensa em avaliar um sistema de informação, é necessário analisar algumas de suas características, tais como: fluxo de dados fácil; o uso de novas tecnologias, computadores e redes de informação; a forma como as informações são apresentadas, de maneira que facilite o seu uso para subsidiar as intervenções em saúde pública; a rapidez com que os resultados são interpretados e disseminados para chegar até aqueles que tomam decisões, no sentido de redirecionar as ações, quando necessário (DECLICH \& CARTER, 1994).

Devido à variedade de opções tecnológicas para cada campo de aplicação, a escolha de uma opção deve ser baseada no tipo de infraestrutura organizacional e tecnológica existente e dos requisitos locais específicos 
(BRANCO,1998). Os sistemas operacionais mais comuns nos municípios de grande porte são as versões mais atuais do Windows (8 e 10). Quando esses dados foram comparados com estudo sobre o SIM (MINTO et al., 2017), observou-se que no nosso estudo houve um decréscimo pela metade da utilização do sistema $X P$, e um grande aumento do Windows 7,8 e 10, observando um avanço em termos de tecnologia disponível. O sistema operacional Windows $X P$, considerado defasado, predominou nos municípios pequenos e médios, sendo que sua utilização não foi observada nos grandes municípios. Os autores VASCONCELLOS et al., (2002) chamam a atenção para a defasagem existente entre o avanço do conhecimento no campo das tecnologias da informação e a incorporação dessas no processo de gestão em saúde no Brasil. No estudo sobre o SINASC (GUIMARÃES et al., 2013), foram notados avanços na introdução de equipamentos de informática, ainda que em quantidade e qualidade não adequadas.

O suporte técnico predominante é proveniente do serviço próprio, porém municípios pequenos são mais dependentes do serviço terceirizado, achado semelhante ao estudo de MINTO et al. (2017).

Os recursos materiais de informática e de comunicação para operar o SINAN, com exceção ao HD externo, foram considerados suficientes, situação mais favorável do que a observada no estudo sobre o SINASC em Minas Gerais (GUIMARÃES et al., 2013), onde foi apontada escassez de material de consumo, especificamente aos que se referem à impressão. 


\subsection{PROCESSOS DE TRABALHO}

Observou-se, no presente estudo, que as atividades como monitoramento do volume mensal de eventos notificados e a realização de procedimento para complementar as informações não são realizadas por grande parte dos municípios. A Organização Pan-Americana da Saúde (OPAS, 2002), juntamente com Ministério da Saúde (2004), preconiza a verificação da qualidade das informações antes do envio dos dados ao sistema. Segundo ARTS et al. (2002), para assegurar a qualidade das informações é necessário garantir processos adequados na etapa anterior à coleta de dados, como a existência de protocolo de registro e coleta de dados com definições claras, treinamento e motivação dos profissionais responsáveis pelo preenchimento das informações. Fatores institucionais, como a estrutura, organização e tipo dos serviços de saúde podem influenciar a qualidade do registro de dados (SOLOMON et al., 1991). A pouca atenção demonstrada a processos que envolvem a qualidade da informação pode estar atrelada à compreensão que se tem em relação aos sistemas de informação. Para FERLA e FAGUNDES (2002), muitas vezes os sistemas de informação são compreendidos pelas unidades locais de forma burocrática, através de um processo de trabalho isolado, focado somente em atender as atribuições impostas pelos níveis estadual e federal do SUS. No estudo de LIMA et al., (2015), foi observada a fragilidade em relação à apropriação das informações locais. Por vezes, a visão que o gestor tem sobre a participação da unidade de saúde na produção de informações restringe-se apenas ao repasse de dados.

No estudo, verificou-se que parte dos municípios usam algum tipo de instrumento paralelo ao SINAN. O seu uso foi justificado em razão da necessidade de incluir informações que não estão presentes nas fichas de notificação/investigação. Constatou-se fragilidade no sistema, pois o mesmo não consegue dar conta das particularidades de cada município, como por exemplo, em situações epidêmicas, sendo necessário a criação de 
complementos ou sistemas extraoficiais. Problemas relacionados à cobertura e à qualidade das informações nos sistemas tradicionais de vigilância tem incentivado muitos profissionais de saúde a criarem outras formas de coleta de dados, com o objetivo de complementar as informações rotineiras sobre as doenças de notificação, ou até mesmo agravos à saúde não contemplados pela vigilância epidemiológica (PEREIRA, 2013). Para LAGUARDIA (2004), um sistema para ser considerado eficiente deve ser capaz de se moldar às novas situações, sem perder agilidade ou oportunidade de fornecer informação.

O programa Tabwin possibilita a integração de diversas bases de dados, gerenciadas pelo DATASUS, contribuindo com a extração de informações relevantes para disseminação de informações em saúde, como por exemplo, calcular indicadores, taxas e outros dados estatísticos. Estudos sobre a utilização dos programas Tabwin e Tabnet indicam a ausência de planejamento central e de uma programação permanente de capacitação de técnicos dos níveis municipais, a fim de descentralizar o uso dessas ferramentas (SILVA, 2009). No estudo, notou-se que apenas a metade dos municípios utiliza o Tabwin, sendo que ele é utilizado em menor proporção nos municípios pequenos, resultado semelhante ao observado para o SIM no Estado de São Paulo (MINTO 2015). Para MINTO (2015), este fato pode ser proveniente da falta de treinamento e conhecimento da ferramenta, além do pequeno número de eventos em alguns municípios. No estudo de SOUZA e DOMINGUES (2009) sobre o SINAN, as ferramentas Tabwin e Tabnet foram avaliadas pelos gestores centrais do SINAN como sendo de fácil manejo. Já o gestor municipal apontou as dificuldades encontradas para compreender e operar o programa como motivo da restrita utilização por parte dos gestores locais. A incorporação dessas ferramentas pelos gestores locais permitiria apropriação das informações disponíveis, a fim de traçar o perfil epidemiológico de suas populações, identificar prioridades e avaliar a efetividade das ações desenvolvidas. Em relação à elevada utilização do Tabwin pelos municípios de grande porte, essa ocorre devido à disponibilidade de profissionais treinados, ao grande volume de dados processados, à necessidade de gerar indicadores e ampliar o seu uso nas secretarias municipais. 
O georreferenciamento é um instrumento importante no auxílio de sistemas de informações geográficas simplificados, servindo como importante instrumento para o planejamento de intervenções com emprego racional de recursos (CAETANO, 2009) Em outros estudos, já se observa em alguns municípios análises apuradas em relação aos problemas de saúde local, através da separação espacial dos dados e informações provenientes da sua área. Tal técnica é capaz de auxiliar a aproximação da epidemiologia com o planejamento e gestão (TEIXEIRA et. al., 2011). No nosso estudo, apenas a metade dos municípios utiliza essa ferramenta, com proporção inferior nos municípios de pequeno porte. Este fato provavelmente está relacionado à falta de conhecimento do programa e a menor utilidade do recurso para esses municípios, devido ao baixo número de notificações, uma vez que, quanto menor a população existente, em geral, menor é a ocorrência de eventos.

\subsection{CAPACITAÇÃO PROFISSIONAL}

Para LAGUARDIA (2004), ações importantes como a incorporação de inovação tecnológica ao sistema de informação, padronização das rotinas, os incentivos financeiros que garantam aos Estados e Municípios a implementação e ampliação do uso do SINAN, não são sustentáveis sem uma política de gestão da informação e sem a capacitação técnica do profissional de saúde. As capacitações exercem um importante papel, enquanto processo de comunicação e diálogo, no processo de promoção da saúde e prevenção de doenças (HERGESEL, 2014).

Foi observado um número elevado de profissionais treinados para trabalhar com o SINAN, resultado que é superior ao observado no estudo sobre o SIM nos municípios paulistas (MINTO, 2015). O apoio dos Grupos de Vigilância Epidemiológica (GVE) foi fundamental neste processo, corroborando 
resultado do estudo sobre o SIM (MINTO, 2015). Porém, é importante ressaltar que aproximadamente um quarto dos municípios não foram treinados, indicando falha no processo. Para MINTO (2015), tal lacuna pode ser justificada pela rotatividade de pessoal, pelo grande número de municípios no Estado de São Paulo, além de escassez de funcionários nas equipes regionais para atender a demanda.

Os resultados sobre a regularidade das reuniões com os GVEs podem apontar um problema de suporte técnico na relação entre as esferas municipal e estadual, uma vez que apenas um terço dos municípios tiveram reuniões com regularidade no último ano. Com o avanço da descentralização da produção das informações em saúde, os níveis federal e estadual devem assumir a condução de atividades relativas à gerência do sistema de informação e suporte técnico aos municípios (ALMEIDA, 1998).

No último ano, somente a metade dos municípios capacitaram as unidades notificadoras quanto ao preenchimento das fichas de notificação/investigação das doenças/agravos. Porém, os municípios grandes conseguiram, em quase sua totalidade, executar capacitações, enquanto nem metade dos municípios pequenos realizaram a atividade. $\mathrm{O}$ ato da coleta de dados é crucial para a qualidade das informações e alguns autores apontam que esta etapa ainda apresenta grandes deficiências (LAGUARDIA, 2004; MS, 2009). Para ARRETCHE (1999), a realidade do Brasil é caracterizada pela existência de uma maioria de municípios fracos, com pequeno porte populacional, densidade econômica pouco expressiva e significativa dependência de transferências fiscais. Neste caso, a ação dos governos estaduais contribui decisivamente para compensar adversidades à possibilidade técnica de gestão destas políticas, obstáculos estes de ordem econômica ou fiscal ou, ainda, derivados das políticas prévias. 


\subsection{DISSEMINAÇÃO DE DADOS}

O estudo informou que o retorno dos dados provenientes do SINAN para as unidades notificadoras ocorreu em apenas um pouco mais da metade dos municípios. Para PEREIRA (2013), o notificador, quando não recebe alguma devolutiva dos serviços de saúde, tende a ficar desestimulado a notificar. A retroalimentação é fundamental para o contínuo processo de aperfeiçoamento dos sistemas de vigilância; a disseminação para todos os profissionais envolvidos nos diferentes níveis é estratégica, pois leva ao aumento da adesão, repercutindo na capacidade do sistema em gerar respostas em tempo oportuno (BRAGA e WERNECK, 2009). Para PEREIRA (2013), quando o profissional notifica alguma doença, tem apenas o conhecimento parcial do que está acontecendo no coletivo. A notificação pode ser um fato isolado ou não. Somente será possível o conhecimento do panorama geral mediante o retorno das informações sobre as demais notificações, acrescidas das medidas cabíveis diante do quadro encontrado. A eficiência do sistema de vigilância epidemiológica, assim como sua retroalimentação, irá depender, principalmente, das informações que chegam às pessoas certas no tempo oportuno.

A divulgação das informações para a sociedade é essencial para estimular o controle social (BRAGA e WERNECK, 2009). O principal veículo usado na divulgação foi o boletim ou relatório impresso, seguido pelo boletim eletrônico. Os boletins epidemiológicos são considerados os meios mais comuns de divulgação da informação (PEREIRA, 2013). No nosso estudo, mais da metade dos municípios disponibiliza as informações do SINAN, resultado mais favorável do que o encontrado no estudo de CARVALHO et al., 2005, que avaliou a vigilância epidemiológica em municípios do estado de Pernambuco e que verificou que a disseminação das informações não pertence à rotina dos serviços. Para GUIMARÃES (2011), disseminar informações não depende somente da disponibilidade dos dados, mas também do conhecimento que os profissionais têm em lidar com todas as atividades e produtos gerados que, na 
sua visão, ainda é insuficiente para o gerenciamento de informações nos municípios pequenos.

A informação pode ser considerada como fonte fundamental para 0 desenvolvimento do planejamento das ações locais, servindo de base para estabelecer suas programações a partir das necessidades locais (BARBOSA e FORSTER, 2010). Neste estudo, os principais usos das informações fornecidas pelo SINAN foram no planejamento de ações de Vigilância Epidemiológica e na pactuação de indicadores de saúde. Sabe-se da importância das ações de pactuação para a melhoria das atividades de vigilância epidemiológica entre os municípios, porém seu uso pode estar vinculado tanto ao planejamento quanto relacionado ao repasse de verbas pelo nível central (VIDOR et al., 2011).

\subsection{AVALIAÇÃO SOBRE O SINAN}

A descentralização das ações e serviços do Sistema Único de Saúde (SUS) tem colaborado para a qualificação do sistema de saúde, através da aproximação das particularidades epidemiológicas, sociais, políticas e administrativas locais, na medida em que tenta superar as fragmentações das políticas e programas, por meio de uma rede hierarquizada e regionalizada de ações (MS, 2006).

A avaliação é importante ferramenta para a qualificação da produção da informação e tem como objetivo contribuir para a melhoria dos serviços e sistemas de saúde. A qualidade da informação é resultado da qualidade das etapas, desde a coleta até a disponibilização das informações pelos sistemas de informação. No SINAN, a qualidade da informação depende, principalmente, da adequada coleta de dados gerados no local onde ocorre o evento sanitário. A participação dos profissionais de saúde nesta etapa é fundamental, partindo, então, da necessidade de instruir a equipe a respeito da importância dessa 
atividade (CAETANO, 2009; WALDMAN,1998). Para que as informações sejam proveitosas, é imprescindível que as análises da qualidade das bases de dados sejam efetuadas regularmente, com o objetivo de identificar e solucionar as faltas e inconsistências no preenchimento e as duplicidades de registros (MS, 2011). Não existe sistema perfeito, no entanto, os ajustes devem sempre ser realizados (CDC, 2001). Assim, é importante conhecer como os responsáveis pelas vigilâncias municipais avaliam o SINAN e as suas condições operacionais.

Em relação à qualidade do preenchimento das fichas de notificação/investigação, quase a metade dos municípios avaliaram como boa, principalmente os municípios pequenos, enquanto que para uma proporção significativa de municípios grandes o preenchimento foi considerado razoável. O principal problema apontado no momento da digitação das fichas de notificação/investigação foi o preenchimento incompleto dos campos obrigatórios. Embora nas fichas de notificação estejam incluídas as instruções para preenchimento, não é o bastante para que as informações sejam registradas de modo adequado (CAETANO, 2009). No estudo realizado em Alagoas, entre outras dificuldades encontradas, foi destacado o preenchimento deficiente das fichas de investigação epidemiológica pelas equipes de saúde da família (MENDES et al., 2016). Conforme ALMEIDA (2006) é importante, antes de digitar a ficha, verificar a inconsistência das informações, tais como conteúdos discrepantes e campos em branco, possibilitando correções que venham a melhorar a qualidade dos dados em tempo oportuno. Uma outra dificuldade foi apontada por CAETANO (2009) com relação ao grande número de variáveis necessárias para preenchimento das fichas de notificação/investigação, podendo interferir na qualidade das informações.

A maioria dos municípios considera adequado o apoio técnico realizado por alguns setores estaduais, sendo o GVE e o CVE os mais bem avaliados. Para VIDOR (2004), o Estado tem que dar suporte às coordenadorias regionais, dando condições para que as mesmas atuem como apoiadoras técnicas, fornecendo subsídios para que os municípios organizem suas atividades, processos, planejamento e tomada de decisão. 
A maioria dos entrevistados reconhece que o SINAN é um instrumento epidemiológico que atende às necessidades dos municípios. A valorização do papel da informação epidemiológica na definição das políticas públicas da saúde se reflete, diretamente, na qualidade dos sistemas de informação, tornando-os importantes instrumentos dos processos de planejamento, tomada de decisões e atuação nos seus distintos níveis de competência, em consonância com os pressupostos do setor (LARGUARDIA, 2004).

Alguns municípios mencionaram alta dificuldade em realizar algumas atividades, tais como fluxo de retorno, capacitação das unidades notificadoras, além da disponibilidade de recursos humanos.

A atividade de fluxo de retorno consiste em enviar para o município de residência, por meio magnético, os dados da ficha de notificação/investigação dos casos notificados de residentes que foram notificados fora do município de residência. No relatório emitido pelo CONASS (2011), referente à avaliação do SINAN, foram apontados problemas relacionados ao fluxo de retorno, tais como: fichas que não abrem após serem recebidas; fichas que, apesar de habilitadas, não estão disponíveis para o município residente baixar; notificações que estão habilitadas para o fluxo de retorno, mas não estão presentes no site SINAN_net para serem "baixadas ou liberadas". Em relação ao fluxo de retorno, observa-se que a principal dificuldade foi relatada pelos municípios médios e grandes.

Os municípios pequenos e médios apresentaram dificuldade em capacitar as unidades notificadoras. A falta de profissionais foi apresentada como uma dificuldade, principalmente nos municípios grandes. Apesar de apresentarem um número maior de profissionais em relação aos demais portes, a demanda de serviços nesses municípios possivelmente é maior que a sua capacidade de atender essa demanda.

Todos os grupos de municípios avaliaram bem os benefícios que a descentralização trouxe, em destaque observaram-se os seguintes quesitos: acompanhamento da situação epidemiológica do município, autonomia da informação e obtenção de informações fundamentais para estratégias de intervenção. 
Esses benefícios tiveram menor intensidade nos municípios grandes, 0 que pode estar relacionado com a sua estrutura, por apresentarem maior demanda em relação ao número de casos e diversidade de doenças/agravos, consequentemente, maiores desafios.

O reconhecimento da importância do processo de descentralização pelos municípios é notório, ainda que desigual. Os quesitos melhor avaliados confirmam o estabelecido na NOB96, que definia os municípios como corresponsáveis por monitorar, avaliar e divulgar a situação de saúde, organizar e coordenar os SIS, utilizar a epidemiologia para estabelecer prioridades, além de alocar recursos e divulgar a orientação programática sobre a saúde local (MS,1996).

Os diferenciais observados entre os grupos de municípios se relacionam com os desafios enfrentados no processo de municipalização das vigilâncias e do gerenciamento dos SIS, devido, em parte, ao modelo de federalismo, no qual municípios são entes federativos com autonomia política, administrativa e financeira, e com competências constitucionais bem estabelecidas, porém com altíssimos diferenciais sócio-demográficos (BRANCO, 1996; SILVA et al., 2003; VIDOR et al., 2011) que vão se refletir em distintos graus de capacidade administrativa, financeira e gerencial (CALVO et al., 2016) e nas respostas que podem gerar.

A operacionalização do SINAN está ocorrendo de forma heterogênea, sendo que os municípios pequenos são os mais vulneráveis. Eles apresentam maior rotatividade de profissionais, o que interfere na qualificação profissional e na continuidade do serviço, além de apresentarem sistemas operacionais mais defasados, com baixíssima execução de atividade de controle e gestão da informação, pouco capacitação das unidades notificadoras, o que pode comprometer o andamento das atividades locais, com pouca divulgação de informações. Segundo VIDOR et al. (2011), os municípios menores são os que apresentam maiores problemas em relação à capacidade de gestão, especialmente com dificuldades para alocar recursos materiais e humanos adicionais para o trabalho com os SIS e talvez sejam os menos beneficiados 
por esses sistemas. Assim, mostra-se imprescindível prover medidas capazes de ajustar o SIS às necessidades dos municípios de pequeno porte. $O$ apoio aos gestores no processo de planejamento e tomada de decisão é de extrema importância para o reconhecimento das demandas locais, assim como para identificação das informações relevantes, capazes de subsidiar tomada de decisão (VIDOR et al., 2011).

Os municípios de médio porte apresentam condições intermediárias em relação aos demais grupos do estudo, ora apresentam características semelhantes aos municípios pequenos, como, por exemplo, em relação ao perfil profissional; já em outros momentos apresentam perfil semelhante aos dos grandes municípios, como em relação ao número de profissionais e alocação do SINAN em Coordenadorias/Departamentos.

Os municípios grandes apresentam uma estrutura mais consolidada, considera-se que a alta demanda de trabalho no SINAN favorece a preparação das equipes, tanto pela estrutura como pelo tipo de vínculo empregatício, onde predominam os efetivos, contando, ainda, com sistemas operacionais mais modernos. Seus processos de gestão e controle estão melhor estabelecidos, porém apresentam deficiências atreladas a sua dimensão, como necessidade de melhoria no espaço físico, falta de recursos humanos, presença de instrumentos paralelos ao SINAN, o que informa insuficiência do sistema, podendo comprometer a qualidade da informação. Essas características confirmam o que foi apontado por DRUMOND (2011), que destaca "que os municípios de grande porte já têm um embrião de um sistema descentralizado, dado o caráter da intervenção necessária em casos potencialmente epidêmicos, ainda que desarticulado, mas com o estabelecimento de rotinas para seu território".

Para que ocorra o fortalecimento das ações que envolvem todo 0 processo de descentralização e consequentemente a garantia da qualidade da informação, é imprescindível o apoio de outras esferas de governo. O sucesso do processo de descentralização está relacionado com as estratégias propostas pelos governos estaduais e federal, capazes de promover a adesão 
dos municípios (ARRETCHE, 1999). SILVA-JUNIOR (2004) ressalta "o papel da esfera federal neste processo, evidenciando a necessidade de estabelecer um processo permanente de monitoramento e de avaliação, que auxilie o pleno exercício da coordenação do sistema, na medida em que informe sobre: a capacidade do município em executar as atividades previstas; a efetividade com que as ações estão sendo realizadas pelo alcance das metas préestabelecidas; e a rápida identificação de insuficiências e/ou falhas, possibilitando a adoção oportuna de intervenções".

Diante das diferenças apontadas neste estudo e a necessidade do avanço no processo de descentralização, o grande desafio eminente está em assegurar a qualidade dos Sistemas de Informação e, consequentemente, do SINAN. Tendo como foco, a adequação do SINAN em relação as necessidades dos diferentes municípios paulistas. Embora as ações sejam descentralizadas, o sistema de informação em saúde é nacional. Esforços devem ser direcionados aos municípios, a fim de que seja garantida a integridade de suas informações, assim como o aperfeiçoamento das ações de vigilância epidemiológica. A valorização do papel da informação epidemiológica na definição das políticas públicas da Saúde se reflete, diretamente, na qualidade dos sistemas de informação, tornando-os importantes instrumentos dos processos de planejamento, tomada de decisões e atuação nos seus distintos níveis de competência, em consonância com os pressupostos do setor (LAGUARDIA, 2004).

O desafio que se impõe ao SINAN, bem como aos diversos outros sistemas de informação em saúde existentes no país, é implementar ações que superem as resistências ao uso das informações no processo de gestão da saúde (CAETANO, 2009).

Como limitação potencial desse estudo, apontamos que com o uso de formulários autoaplicados, os termos utilizados nas questões podem não ter sido compreendidos da mesma forma por todos os respondentes. Também, em 13\% dos municípios o respondente não era o responsável pela VE, o que pode limitar o conhecimento sobre todos os aspectos pesquisados. No presente 
trabalho, as medidas adotadas para reduzir a proporção de não-resposta permitiram retorno acima do considerado satisfatório para o método adotado, e os municípios respondentes foram representativos da população estudada, porém, deve-se considerar a possibilidade de os municípios que não responderam à pesquisa apresentarem maior insatisfação com o SINAN, o que pode estar subestimando alguns resultados apresentados. 


\section{CONSIDERAÇÕES FINAIS}

O presente estudo partiu da premissa da importância do SINAN para a execução das ações de vigilância epidemiológica dos sistemas municipais de saúde, e do reconhecimento da lacuna existente quanto às suas condições de operacionalização e dos aspectos que envolvem a utilização dos dados na gestão local, procurando conhecer questões outrora não descritas, porém de grande relevância para o entendimento do funcionamento desse sistema.

Foram descritas e analisadas as condições de operacionalização do SINAN, segundo o porte populacional dos municípios, a fim de evidenciar suas diversidades, semelhanças, fragilidades e potencialidades, de maneira que os aspectos levantados possam auxiliar no aprimoramento do SINAN, enquanto ferramenta essencial para 0 planejamento e gestão da vigilância epidemiológica nos diversos níveis de governo.

Os resultados apresentados permitem aos gestores identificar diferentes realidades das administrações municipais, possibilitando um planejamento de ações mais direcionado, capaz de abranger distintos tipos de investimento físico, capacitação e treinamento para operacionalização e gestão desse SIS.

Foi possível observar que o SINAN está implantado no Estado de São Paulo de forma não uniforme, o que abrange dimensões que vão desde o perfil do gestor, como recursos estruturais, processos de trabalho, disseminação da informação e avaliação.

É possível verificar que os municípios paulistas avaliaram favoravelmente a descentralização do SINAN, porém há um caminho a ser percorrido. Os levantamentos e impressões aqui descritas podem contribuir neste processo. Sendo assim, recomenda-se a tomada de medidas de apoio que diminuam a disparidade entre os municípios, principalmente em relação aos pequenos, através de políticas e estratégias que estimulem a estabilidade profissional, bem como investimentos na capacitação profissional, assim com foco nos aspectos que envolvem a qualidade e o uso das informações do 
SINAN, aprimoramento dos recursos tecnológicos, avaliações periódicas do SINAN, assim como incentivos financeiros voltados para gestão do SINAN. 


\section{REFERÊNCIAS}

Almeida MF de. Descentralização de sistemas de informação e o uso das informações a nível municipal. Inf Epidemiol SUS. 1998; 2(3): 28-33.

Alves M, Penna CMM, Brito MJM. Perfil dos Gerentes de Unidades Básicas de Saúde. Rev Bras Enfermagem. 2004; 57(4): 441-6.

Arretche MTS. Políticas sociais no Brasil: descentralização em um Estado federativo. Rev Bras Ciências Soc. 1999; 14(40): 111-41.

Arts DG, De Keizer NF, Scheffer GJ. Defining and improving data quality in medical registries: a literature review, case study, and generic framework. J Am Med Inform Assoc. 2002; 9(6): 600-11.

Barbosa DCM, Forster AC. Sistemas de informação em saúde: a perspectiva e a avaliação dos profissionais envolvidos na atenção primária à saúde de Ribeirão Preto. Cad Saúde Coletiva. 2010; 18(3): 424-33.

Bittencourt SA, Camacho LAB, Leal MC. O Sistema de Informação Hospitalar e sua aplicação na saúde coletiva. Cad Saúde Pública. 2006; 22(1): 19-30.

Branco MAF. Sistemas de Informação em saúde no nível local. Cad Saúde Pública. 1996; 12(2): 267-70.

Branco MAF. Informação e tecnologia: desafios para a implantação da rede nacional de informações em saúde (RNIS). Revista de Saúde Coletiva. 1998; 8(2): 95-123.

Branco MAF. Informação em saúde como elemento estratégico para a gestão. In: Brasil. Ministério da Saúde. Gestão municipal de saúde: textos básicos. Rio de Janeiro: 2001; p. 163-9. 
Braga UJ, Werneck GL. Vigilância Epidemiológica. In: Medronho RA et al. Epidemiologia. 2aㅡ ed. São Paulo: Editora Atheneu; 2009. p.103-21

Bruschini C. Mulher e trabalho: uma avaliação da década da mulher. São Paulo: Nobel; 1985.

Center for Diseases Control and Prevention. Updated guidelines for evaluating public health surveillance systems: recommendations from the guidelines working group. Morbidity and Mortality Weekly Report; 2001;50(13):1-35.

Caetano R. Sistema de Informação de Agravos de Notificação (SINAN). In: Brasil. Ministério da Saúde. A experiência brasileira em sistemas de informação em saúde. Brasília: Editora do Ministério da Saúde, 2009.

Calvo MCM, Lacerda JT, Colussi CF, Schneider IJC, Rocha TAH. Estratificação de municípios brasileiros para avaliação de desempenho em saúde. Epidemiol Serv Saúde. 2016; 25(4): 767-76.

Carvalho, EF de et al. Avaliação da Vigilância Epidemiológica em âmbito municipal. Rev Bras Saude Mater Infant [online]. 2005; 5 (suppl.1): 53-62.

Conass. Avaliação do Sistema de Informações de agravos de notificação (SINAN): Nota Técnica CONASS nº 39/2011. Brasília; 2011.

Conass. Situação atual do Sistema de Informações de Agravos de Notificação (SINAN): Nota Técnica CONASS nº 45/2013. Brasília; 2013.

Cooper DR, Schindler, PS. Métodos de Pesquisa em Administração. 7aㅡ ed. Porto Alegre: Bookman, 2003. 
Da Poz MR, Perantoni CR, Girardi S. Formação, Mercado de Trabalho e Regulação da Força de Trabalho em Saúde no Brasil. In: Fundação Oswaldo Cruz. A saúde no Brasil em 2030 - prospecção estratégica do sistema de saúde brasileiro: organização e gestão do sistema de saúde. Rio de Janeiro: FIOCRUZ. 2013; v. 3. p. 187-233. (Acesso em 30 nov. 2016). Disponível em: http://books.scielo. org/id/98kjw/pdf/noronha-9788581100173-07.pdf.

DATASUS - Departamento de informática do SUS. Sistema de notificação de Agravos a Saúde - SINAN [www2.datasus.gov.br]. Brasil; [acesso 22 ago. 2014]. Disponível: em http://dtr2004.saude.gov.br/sinanweb/.

Declich S, Carter AO. Surveillance health: historical origins, methods and evaluation. Bulletin of the World Health Organization 72: 285-304, 1994.

Domingues CMAS, Souza, WV. Notificação Compulsória de Doenças e Agravos no Brasil: Um Breve Histórico sobre a Criação do Sistema de Informação de Agravos de Notificação SINAN. A experiência brasileira em sistemas de informação em saúde, 2009. p. 39.

Drumond Jr. M. Epidemiologia nos municípios: muito além das normas. São Paulo: Hucitec; 2011.

Ferla AA .Informação como ferramenta de gestão: desenvolvimento de parâmetros para acompanhamento do sistema de saúde a partir da análise integrada dos sistemas de informação em saúde. Bol. da Saúde 2001; 15(1): 910.

Ferla AA, Fagundes SMS. Tempo de inovações: a experiência da gestão na saúde do Rio Grande do Sul. Porto Alegre: DaCasa; 2002. 
Ferreira SMG. Sistema de informação em saúde. In: Campos FE de, Werneck GAF, Tonom LM. Vigilância Sanitária: Cad de Saúde. Belo Horizonte: COOPMED; 2001.

Fundação Seade. Informações dos Municípios Paulistas, São Paulo, 2016. Disponível em: http://www.imp.seade.gov.br/frontend/\#/tabelas [Acesso em 29/03/2017]

Hergesel L. A importância da capacitação do profissional da sala de vacina para um atendimento eficiente e seguro. São Paulo: Universidade Federal de São Paulo; 2014.

Galvão PRS, Ferreira AT, Maciel MGG, Almeida RP, HinderS D, Schreuder PA, Kerrpontes LRS. Uma avaliação do sistema de informação SINAN usado no Programa de Controle de Hanseníase no estado do Pernambuco. Cad.Saúde Colet 2009; 17 (1): 87-102.

Gaze R, Perez MA. Vigilância epidemiológica. In: Medronho RA et al.. Epidemiologia (2006). Rio de Janeiro, Editora Atheneu, p. 73 - 89.

Graciano MMC, Araújo EW, Nogueira DA. Sistema de informação em saúde e atuação do profissional médico. Rev Médica de Minas Gerais. 2009; 19 (3): 198-205.

Gil CRR. Formação de recursos humanos em saúde da família: paradoxos e perspectivas. Cad de Saúde Pública. 2005; 21 (2):

Guimarães EAA et al. A descentralização do Sinasc e a completude das variáveis da declaração de nascido vivo em municípios mineiros de 1998 a 2005. Rev Bras Crescimento Desenvolv. Hum [online]. 2011; 21 (3): 832-40. 
Guimarães EAA et al. Avaliação da Implantação do Sistemas de Informação sobre Nascidos Vivos em Municípios de Minas Gerais, Cad de Saúde Pública. 2013; 29 (10): 2105-18.

Guimarães EM, Évora YDM. Sistema de informação: instrumento para tomada de decisão no exercício da gerência. Ci. Inf.2004; 33 (1):72-80.

IBGE. Instituto Brasileiro de Geografia e Estatística. Pesquisa de informações básicas municipais: perfil dos municípios brasileiros 2013 [Internet]. Rio de Janeiro: IBGE; 2014 [citado 2017 ago 21]. Disponível em: http://www.ibge.gov.br/home/estatistica/ economia/perfilmunic/2013/

Laguardia J, Domingues CMA, Carvalho C, Lauerman CR, Macário E, Glatt R. Sistema de Informação de Agravos de Notificação (SINAN): desafios no desenvolvimento de um sistema de informação em saúde. Epidemiologia e Serviços de Saúde. 2004; 13 (3): 135-47.

Lima CRA, Schramm JMA, Coeli CM. Gerenciamento da qualidade da informação: uma abordagem para o setor saúde. Cad Saúde Pública. 2010; 18 (1): 19-31.

Lima KWS, Antunes JLF, Silva ZP. Percepção dos Gestores Sobre o Uso de Indicadores nos Serviços de Saúde Soc. [Internet]. 2015; 24(1): 61-71.

Machado MH, Wermelinger M, Tavares MFL, Moysés NMN, Teixeira M, Oliveira ES. Análise da força de trabalho do setor saúde no Brasil: focalizando a feminização [Internet]. Rio de Janeiro: Rede de Observatórios de Recursos Humanos em Saúde; 2006 [citado 2017 ago 21]. 136 p. Disponível em: http://www.observarh.org.br/observarh/repertorio/ Repertorio_ObservaRH/ENSPSA-FIOCRUZ/Analise_forca_trabalho.pdf 
Maia DA. Avaliação da Implantação do Sistema de Informações de Agravos De Notificação em Pernambuco. [dissertação]. Recife: Instituto de Medicina Integral Prof. Fernando Figueira; 2015.

Malhão TA, Oliveira GP, Codennoti SB, Moherdaui F. Avaliação da completitude do Sistema de Informação de Agravos de Notificação da Tuberculose, Brasil, 2001-2006. Epidemiol Serv Saude. 2010; 19(3): 245-56.

Mendes TKA, Oliveira SP, Delamarque EV, Seta MH. Reestruturação da gestão das vigilâncias em saúde em Alagoas: a precarização da formação e do trabalho. Trab Educ Saúde. 2016; 14(2): 421-43

Ministério da Saúde. Lei Orgânica de Saúde 6.259 de 30/10/1975. Dispõe sobre a organização das ações de Vigilância Epidemiológica, sobre 0 Programa Nacional de Imunizações, estabelece normas relativas à notificação compulsória de doenças, e dá outras providências. Diário Oficial da União. Brasília, DF; 1975.

Ministério da Saúde. Decreto no 78231, de 12 de agosto de 1976. Regulamenta a Lei no 6259 , de 30 de outubro de 1975, que dispõe sobre a organização das ações de vigilância epidemiológica, sobre o Programa Nacional de Imunização, estabelece normas relativas à notificação compulsória de doenças e dá outras providências. Senado Federal. Subsecretária de Informações. Brasília, DF; 1976.

Ministério da Saúde. Lei Orgânica da Saúde 8.080 de 20/09/1990. Dispõe sobre as condições para a promoção, proteção e recuperação da saúde, a organização e o funcionamento dos serviços correspondentes e dá outras providências. Diário Oficial da União. Brasília, 20 set 1990. 
Ministério Saúde. Portaria $\mathrm{n}^{\circ} 2203$, de 5 de novembro de 1996. Norma Operacional Básica do Sistema Único de Saúde - NOB-SUS 01/96. Diário Oficial da União, Brasília, p. 58, 06 nov. 96.

Ministério da Saúde. Portaria GM/MS no 1882 de 18 de dezembro de 1997. Estabelece o Piso da Atenção Básica - PAB e sua composição. Brasília,1998.

Ministério da Saúde. Portaria GM/MS no 1.399, de 15 de dezembro de 1999. Regulamenta a NOB SUS 01/96 no que se refere às competências da União, Estados, Municípios e Distrito Federal, na área de epidemiologia e controle de doenças, define a sistemática de financiamento e dá outras providências. Diário Oficial da União, Brasília, 25 nov 1999. [Acessado em 24 out. 2017]. Disponível em: http://portal.saude.gov.br/portal/svs/visualizar texto.cfm?idtxt=21247.

Ministério da Saúde. Portaria ${ }^{\circ} 950$, de 23 de dezembro de 1999. Define os valores anuais per capita e por quilômetro quadrado, relativos aos recursos federais destinados à composição do Teto Financeiro de Epidemiologia e Controle de Doenças TFECD, de cada um dos estratos previstos no art. 14 da Portaria GM/MS nº1.399/99. Diário Oficial da União, Brasília, p.40-1.

Ministério da Saúde. Portaria GM 1.172/04, de 15 de junho de 2004. Regulamenta a NOB SUS 01/96 no que se refere às competências da União, Estados, Municípios e Distrito Federal, na área de Vigilância em Saúde, define a sistemática de financiamento e dá outras providências. Diário Oficial República Federativa do Brasil [DOU] 2004 jun 17; Seção 1: 58-9. 23

Ministério da Saúde. Portaria $n^{\circ} 2529$, de 23 de novembro de 2004. Institui o Subsistema Nacional de Vigilância Epidemiológica em Âmbito Hospitalar. Diário Oficial da União; Poder Executivo, de 26 de dezembro de 2004. 
Ministério da Saúde. Secretaria de Vigilância em Saúde. Departamento de Vigilância Epidemiológica. Grupo Técnico do Sinan. Sistema de Informação de Agravos de Notificação - Sinan.Brasília: Ministério da Saúde, 2004b. Nota Técnica da Oficina de Vigilância Epidemiológica sobre o Sinan.

Ministério da Saúde, Secretaria de Vigilância em Saúde. Guia de Vigilância Epidemiológica. 7. ed. Brasília, DF; 2005.

Ministério da Saúde. Portaria n. 399/GM/MS, de 22 de Fevereiro de 2006. Divulga o Pacto pela Saúde 2006. Consolidação do SUS e aprova as Diretrizes Operacionais do Referido Pacto. Brasília: Ministério da Saúde, 2006.

Ministério Da Saúde. Secretaria de Vigilância em Saúde. Departamento de Vigilância Epidemiológica. Sistema de Informação de Agravos de Notificação SINAN: normas e rotinas. Série A: Normas e Manuais Técnicos. Brasília: Ministério da Saúde; 2007.

Ministério da Saúde, Secretaria de Vigilância em Saúde. Guia de Vigilância Epidemiológica. 7. ed. Brasília, DF; 2009.

Ministério da Saúde Secretaria de Vigilância em Saúde. Departamento de Vigilância Epidemiológica. Doenças Infecciosas e Parasitárias: Guia de Bolso. 8. ed., Brasília, 2010.

Ministério da Saúde (BR). Portaria no 201/GM de 03 de novembro de 2010. Diário Oficial da República Federativa do Brasil, Brasília, (DF), 2010 nov 4; Seção 1:88.

Ministério da Saúde. Secretaria de Vigilância em Saúde. Departamento de Vigilância Epidemiológica. Programa Nacional de Controle da Tuberculose. Situação epidemiológica. 1. ed. Brasília, DF; 2011. 
Ministério da Saúde. Portaria ํㅡ 204, de 17 de fevereiro de 2016. Define a Lista Nacional de Notificação Compulsória de doenças, agravos e eventos de saúde pública nos serviços de saúde públicos e privados em todo o território nacional, nos termos do anexo, e dá outras providências. Diário Oficial União. Brasília, DF.

Ministério da Saúde. Portaria $n^{\circ}$ 47, de 3 de maio de 2017. Parâmetros para monitoramento da regularidade na alimentação do Sistema de Informação de Agravos de Notificação (SINAN) e do Sistema de Informações sobre Mortalidade (SIM), para fins de manutenção do repasse de recursos do Componente de Vigilância e Promoção da Saúde do Bloco de Vigilância em Saúde. Brasília, 2016.

Minto CM. Sistema de informação de Mortalidade nos Municípios do Estado de São Paulo: análise situacional [Dissertação de Mestrado]. São Paulo: Faculdade de Saúde Pública da USP; 2015.

Minto CM, Alencar, Gizelton P, Almeida MF, Silva ZP. Descrição das características do Sistema de Informações sobre Mortalidade nos municípios do estado de São Paulo. Epidemiologia e Serviços de Saúde. 2017; 26(4): 86980.

Mutale W, Chintu N, Amoroso C, Awoonor-Williams K, Phillips J, Baynes C, Michel C, Taylor A, Sherr K. Improving health information systems for decision making across five sub-Saharan African countries: implementation strategies from the African Health Initiative. BioMed Central Health Services Research. 2013;13(Suppl 2): S9.

OPAS. La base de datos regional del sarampión: ¿cuán“limpios y completos" son los datos? Boletín Informativo PAI, [S.I.], v. 24, n. 2, p. 4-5, 2002. Disponívelem: <www.paho.org/Spanish/HVP/HVI/sns2402.pdf> 
OPAS/MS. Indicadores Básicos para a Saúde no Brasil: conceitos e aplicações. Brasília, $2^{\underline{a}}$ ed. 2008.

Paim JS e Teixeira MGLC. Reorganização do Sistema de Vigilância Epidemiológica na perspectiva do Sistema Único de Saúde. Informe Epidemiológico do SUS. 1992; 5: 27-57.

Penna GO, Domingues CM, Siqueira Jr JB, Elkhoury AN, Cechinel MP, Grossi MA, et. Doenças Dermatológicas de Notificação Compulsória no Brasil. An Bras Dermatol. 2011; 86(5): 865-77.

Pereira MG. Epidemiologia: teoria e prática. Rio de Janeiro: Guanabara Koogan; 2013.

Prado MF, Marques CCA. Sistemas de Informações em Saúde: uma experiência da descentralização da produção das informações sobre mortalidade e nascidos vivos para o uso em vigilância à saúde no estado de São Paulo. Boletim Eletrônico Paulista - BEPA 2012; 9(100):4-15.

Silva ZP, Barreto Junior IF, Sant'ana MC. Saúde do trabalhador no âmbito municipal. São Paulo Perspec. 2003; 17(1): 47-57.

Silva NP. A utilização dos programas TABWIN e TABNET como ferramentas de apoio à disseminação das informações em saúde [dissertação]. Rio de Janeiro: Escola Nacional de Saúde Pública Sergio Arouca, Fundação Oswaldo Cruz; 2009. 
Silva Junior, JB da. Epidemiologia em serviço: uma avaliação de desempenho do Sistema Nacional de Vigilância em Saúde [tese]. São Paulo: Faculdade de Ciências Médicas da Universidade Estadual de Campinas; 2004.

Selig L, Guedes R, Kritski A, Spector N, Lapa e Silva JR, Braga JU, et al. Proposta de vigilância de óbitos por tuberculose em sistemas de informação. Rev Saúde Pública. 2010; 44 (6): 1072-8.

Solomon DJ, Henry RC, Hogan JG, Van Amburg GH, Taylor J. Evaluation and implementation of public health registries. Public Health Rep.1991; 106:141-50.

Sousa LMO, Pinheiro RS. Óbitos e internações por tuberculose não notificados no município do Rio de Janeiro. Revista de Saúde Pública 2011; 45 (1): 31-39.

Souza VMM, Brant JL, Arsky MLS, Araujo WN. Avaliação do sistema nacional de vigilância epidemiológica da leptospirose Brasil, 2007. Cad Saude Coletiva. 2010; 18(1): 95-105.

Stansfield SK, et al. "Information to improve decision making for health. Disease control priorities in developing countries. 2nd Ed. (2006): 1017-30.

Teixeira MG, Penna GO, Risi JB, Penna ML, Alvim MF, Moraes JC, Luna E. Seleção das doenças de notificação compulsória: critérios e recomendações para as três esferas de governo. Informe Epidemiológico do SUS 1998; VII (1): 7-28.

Teixeira MG, N.Costa MC, Dias JP, Silva-Júnior JB. In: Barreto ML, Almeida Naomor, editores. Vigilância e Monitoramento de Eventos Epidemiologia e 
Saúde: Fundamentos, Métodos e Aplicações. Rio de Janeiro: Guanabara Koogan; 2011. p. 643-53.

Troccoli FT. Sistema de Informação. In: Ibañez N, Elias PEM, Seixas PHD Ângelo, coordenadores. Política e Gestão Pública em Saúde. São Paulo: Hucitec Editora: Cealag; 2011. p. 407- 45.

Vasconcellos MM, Moraes IHS, Cavalcante MT. Política de saúde e potencialidades de uso das tecnologias de informação. Saúde Debate 2002; 6: 219-35.

Vidor AC. Sistemas de informação em saúde: situação atual em municípios de pequeno porte [dissertação]. Porto Alegre: Universidade Federal do Rio Grande do Sul; 2004.

Vidor AC, Fisher PD, Bordin R. Utilização dos sistemas de informação em saúde em municípios gaúchos de pequeno porte. Rev de Saúde Pública. 2011; 45: 24-30.

Waldman EA . Usos da vigilância e da monitorização em saúde pública. Informe Epidemiológico do SUS (1998) 7(3):7-26.

WHO - World Health Organization. Developing health management information systems: a practical guide for developing countries. Geneva: WHO; 2004.

WHO - World Health Organization. Strengthening Health Systems to Improve Health Outcomes. Geneva: WHO; 2007. 


\title{
Apêndices
}

\author{
Apêndice 1 - Roteiro de Entrevista
}

\section{TíTULO DO PROJETO: DIAGNÓSTICO DAS CONDIÇÕES DE OPERAÇÃO DO SISTEMA DE INFORMAÇÃO DE AGRAVOS DE NOTIFICAÇÃO (SINAN) NO ESTADO DE SÃO PAULO.}

\section{QUESTÕES}

1. Como está organizada a Vigilância Epidemiológica no município?

2. Como está organizada a operação do SINAN no município?

3. Como está organizada a equipe que opera o SINAN? Você considera adequada em relação aos números de funcionários e a formação?

4. Conte sobre a infraestrutura disponível para operar o SINAN. Você considera adequada?

5. Explique como ocorre o fluxo das notificações a partir das unidades notificadoras (UBS, UPA, AMA etc.)

6. Com que frequência os dados do SINAN são utilizados na gestão de saúde municipal? Quem os utiliza?

7. Quais as principais dificuldades encontradas para operação do SINAN? Há sistemas ou planilhas paralelas?

8. Como é o apoio técnico (informática, problemas com SINAN, treinamento) institucional (SMS, GVE e outros)?

9. Quais as vantagens e desvantagens do SINAN? 


\title{
Apêndice 2 - Termo de Consentimento
}

INSTITUIÇÃO RESPONSÁVEL: Faculdade de Saúde Pública/USP

\author{
TERMO DE CONSENTIMENTO LIVRE E ESCLARECIDO
}

O(a) $\operatorname{Sr}(a)$. está sendo convidado como voluntário a participar da pesquisa: DESCENTRALIZAÇÃO DOS SISTEMAS DE INFORMAÇÕES EM SAÚDE NOS MUNICÍPIOS DO ESTADO DE SÃO PAULO. Este é um projeto em parceria entre a Secretaria de Estado da Saúde de São Paulo e a Faculdade de Saúde Pública da USP, com apoio do Conselho Nacional de Desenvolvimento Científico e Tecnológico CNPq. O motivo que nos leva a estudar a descentralização dos sistemas de informações em saúde é sua importância como subsidio para planejamento, monitoramento e avaliação das ações em saúde. O objetivo do projeto é conhecer as características estruturais (recursos humanos, infraestrutura, informática), processo de trabalho e uso das informações na gestão em saúde nos municípios do Estado do São Paulo. Com isso pretende-se gerar novos conhecimentos que possibilitem ações para o aprimoramento desses sistemas. Assim, ressaltamos que sua participação é de extrema importância, a fim de contribuir para construção de evidências científicas referentes a este tema. Você será esclarecido (a) sobre a pesquisa em qualquer aspecto que desejar e é livre para recusar-se a participar, retirar seu consentimento ou interromper a participação a qualquer momento. A sua participação é voluntária e a recusa em participar não irá acarretar problema de qualquer natureza. O presente estudo apresenta riscos mínimos, devido ao tempo despendido para participar da entrevista. Os pesquisadores irão tratar a sua identidade com padrões profissionais de sigilo. Os resultados da pesquisa serão disponibilizados de forma agregada, sem identificação do respondente ou do município e permanecerão confidenciais. Você não será identificado (a) em nenhuma publicação que possa resultar deste estudo. A participação no estudo não acarretará custos para você e não será disponível nenhuma 
compensação financeira adicional. Em caso de dúvidas, você poderá chamar a professora Zilda Pereira da Silva, no telefone (11) 3061-7930 ou Comitê de Ética em Pesquisa da Faculdade de Saúde Pública da Universidade de São Paulo, sito à Av. Dr. Arnaldo, 715, Cerqueira César - São Paulo, SP, no telefone (11) 3066-7779.

$\mathrm{Eu}$, fui informada (o) dos objetivos da pesquisa acima de maneira clara e detalhada e esclareci minhas dúvidas. Sei que em qualquer momento poderei solicitar novas informações e modificar minha decisão se assim o desejar. Declaro que aceito participar do estudo: DESCENTRALIZAÇÃO DOS SISTEMAS DE INFORMAÇÕES EM SAÚDE NOS MUNICÍPIOS DO ESTADO DE SÃO PAULO, em data e local marcado antecipadamente, e estou ciente que a entrevista será gravada e que seus resultados serão tratados sigilosamente. Recebi uma cópia deste termo de consentimento livre e esclarecido e me foi dada a oportunidade de ler e esclarecer as minhas dúvidas.

Data

1

Nome legível e assinatura

Responsável pela pesquisa: Prof ${ }^{\mathrm{a}}$. Dra ${ }^{\mathrm{a}}$ Zilda Pereira da Silva Faculdade de Saúde Pública da Universidade de São Paulo Av. Dr. Arnaldo, 715 CEP 01246-904, São Paulo, SP. Tel. (11) 3061-7930 
Apêndice 3 - Questionário SINAN

\section{FormSU3 \\ veraba 3.0}

Você está sendo convidado(a) a participar da pesquisa que integra o projeto de "Diagnóstico do Sistema de Informação de Agravos de Notificação - SINAN nos Municípios do Estado de São Paulo".

BEM VINDOS!

Solicitamos que o questionário seja preenchido, preferencialmente, pelo diretor/responsável pela Vigilância Epidemiológica. O questionário é de fácil

Antes de preenchimento, com uma duração média de 15 mais nada, muito obrigada minutos. Por favor, leia abaixo o Termo de Consentimento Livre e Esclarecido antes de iniciar o preenchimento.

pela

oportunida

de de

apresentar

o projeto.

Meu nome

é KELER

WERTZ

SCHENDER

DE LIMA,

sou aluna

no

doutorado

do

Programa

de Pós-

Graduação

da

Faculdade

de Saúde

Pública

(FSP) da

Universida

de de São

Paulo

(USP). 


\section{TERMO DE CONSENTIMENTO LIVRE E ESCLARECIDO}

Prezado(a) Senhor(a):

Você está sendo convidado(a) como voluntário(a) a participar da pesquisa sobre Diagnóstico do Sistema de Informação de Agravos de Notificação - SINAN, nos municípios do Estado de São Paulo. O motivo que nos leva a estudar este sistema é a importância que este apresenta dentro da Vigilância Epidemiológica, sendo a principal fonte de informação de doenças e agravos, capaz de monitorar tendências e estimar a sua magnitude como problema de saúde na população; uma ferramenta para diagnóstico de situação de saúde, capaz de gerar informações que contribuam na gestão e planejamento do município. $O$ objetivo desse projeto é conhecer as características estruturais (recursos humanos, infraestrutura, informática), processo de trabalho e uso das informações na gestão nos municípios do Estado do São Paulo. Com isso pretende-se gerar novos conhecimentos que possibilitem ações para o aprimoramento desse sistema de informações. Assim, esclarecemos que sua participação é de extrema importância, a fim de contribuir para construção de evidências científicas referentes a este tema.

Você será esclarecido(a) sobre a pesquisa em qualquer aspecto que desejar e é livre para recusar-se a participar, retirar seu consentimento ou interromper a participação a qualquer momento. A sua participação é voluntária e a recusa em participar não irá acarretar problema de qualquer natureza.

Os pesquisadores irão tratar a sua identidade com padrões profissionais de sigilo. Os resultados da pesquisa serão disponibilizados de forma agregada, sem identificação do respondente ou do município e permanecerão confidenciais. Você não será identificado(a) em nenhuma publicação que possa resultar deste estudo. Uma cópia deste consentimento será fornecida a você via email.

A participação no estudo não acarretará custos para você e não será disponível nenhuma compensação financeira.

Este é um projeto em parceria entre a Secretaria de Estado da Saúde de São Paulo e a Faculdade de Saúde Pública da USP, com apoio do Conselho Nacional de Desenvolvimento Científico e Tecnológico - CNPq e do COSEMS/SP.

Em caso de dúvidas, você poderá chamar a estudante Keler Wertz Schender de Lima ou a professora orientadora, nos telefones (11) 98295-1440, (11) 3061-7930 ou no Comitê de Ética em Pesquisa da Faculdade de Saúde Pública da Universidade de São Paulo, sito à Av. Dr. Arnaldo, 715, Cerqueira César - São Paulo, SP, no telefone (11) 3066-7779. 
"Eu fui informado(a) dos objetivos da pesquisa acima de maneira clara e detalhada $e$ esclareci minhas dúvidas. Sei que, em qualquer momento, poderei solicitar novas informações $e$ modificar minha decisão se assim o desejar. A professora orientadora Dra. Zilda Pereira da Silva, da Universidade de São Paulo, Faculdade de Saúde Pública, certifica-me de que todos os dados desta pesquisa serão confidenciais.

Declaro que concordo em participar desse estudo. Recebi uma cópia deste termo de consentimento livre e esclarecido e me foi dada a oportunidade de ler e esclarecer as minhas dúvidas."

\section{* Preenchimento Obrigatório}

Atenção: nos campos marcados com 'Visível ao público' não devem ser colocados dados de sua intimidade e privacidade.

Clique aqui em caso de dúvidas relativas a este formulário.

1) Declaro que concordo em participar deste estudo: *

Aceito

Identificação do Município

2) GVE: *

3) Municípios São Paulo: * 
Dados Pessoais

4) O respondente do formulário é diretor/coordenador/chefe/responsável pela Vigilância Epidemiológica? *

Sim

C Não

5) Sexo : *

Masculino

Feminino

6) dade: *Anos

7) Escolaridade : *

Ensino Fundamental Incompleto

Ensino Fundamental

Ensino Médio Incompleto

Ensino Médio

Ensino Superior Incompleto

Ensino Superior

Pós-Graduação Completa

Pós-Graduação Incompleta

8) Qual o seu curso de formação mais avançado? *

Técnico em:

Graduado em:

Cós-Graduado em:

Não se aplica

9) Qual o tipo de vínculo trabalhista com o Município? *

Efetivo/estatutário

C CLT 
Contrato temporário/prestação de serviços

Cargo em comissão

Estágio

- Outro. Especifique

9.1) Especifique: *

10) Há quanto tempo o(a) Sr.(a) trabalha no setor público da área de saúde? *

menos de 6 meses

6 a 11 meses

1 ano

2 anos

3 anos

4 anos

5 a 9 anos

C 10 a 20 anos

mais de 20 anos

11) Há quanto tempo o(a) Sr.(a) trabalha com o SINAN? *

menos de 6 meses

6 a 11 meses

C 1 ano

C 2 anos

3 anos

4 anos

(C) 5 a 9 anos

C 10 a 20 anos

mais de 20 anos

12) O(a) Sr.(a) é responsável por outros sistemas? *

Não, apenas o SINAN

Sim. Especifique 


\section{Estrutura Organizacional}

13) Em qual setor está a alocação administrativa da Vigilância Epidemiológica? *

Coordenadoria

Departamento

Divisão

Gerência

Núcleo/Setor

Unidade de Saúde

(- Outro. Especifique

13.1) Outro Local. Especifique: *

14) Em qual setor está alocada a gestão do SINAN? *

Unidade de Saúde

Vigilância Epidemiológica

Núcleo de Vigilância Epidemiológica Hospitalar

Área da Atenção Básica

Setor de Informações da SMS (Secretaria Municipal de Saúde)

C Coordenadoria Outro. Especifique

14.1) Outro Local. Especifique: *

Processo de Trabalho

15) Em qual local é feita a digitação das

fichas de notificação/investigação? *

Em todas as unidades notificadoras públicas (hospital, UBS etc.)

$\Gamma$

Em apenas algumas unidades notificadoras

$\Gamma$

Vigilância Epidemiológica

W

Outro. Especifique 


\section{1) Outro Local. Especifique: *}

16) Indique as atividades que o(a) Sr.(a) e ou/sua equipe realizam:

Sr Equipe Ambos

Não

realiza

Backup, envio de lotes : *

Envio/recebimento do fluxo de retorno: *

Digitação da ficha de notificação/investigação: *

Análise das fichas (duplicidade, campos em branco, campos

incompletos): *

Busca ativa de Notificações

(Procedimento realizado com vistas ao conhecimento da magnitude de ocorrência do evento, quando se suspeita que casos possam estar ocorrendo sem registro nos serviços de saúde):

Análise dos dados do SINAN: *

Elaboração de indicadores: *

Elaboração de relatórios ou boletins periódicos: *

17) É realizado algum procedimento para monitorar o volume mensal dos eventos notificados pelas unidades? *

Sim

Não

18) O município realiza algum procedimento para complementar as informações do SINAN? *

Г Não

$\Gamma$

Sim, busca nos prontuários físicos das unidades de saúde.

$\Gamma$

Sim, busca em cadastro informatizado ou em prontuário eletrônico.

Г Sim, busca em outros sistemas de informações de base epidemiológica (SIM, SIH, etc...)

ॠ Sim, relacionamento de bancos de dados com outros sistemas Sim, outros. Especifique

18.1) Especifique: * 
19) O município utiliza o aplicativo do SINAN-Relatórios para gerar indicadores? *

Tim

Г

Não, por falta de treinamento

$\Gamma$

Não, por falta pessoal

$\Gamma$

Não, os relatórios não atendem à necessidade do município

Não, por outros motivos

20) A equipe realiza a análise dos dados do SINAN

utilizando a ferramenta Tabwin? *

Não utiliza

Sim, utiliza ferramenta de mapa fluxo origem-destino

Sim, utiliza módulos de mapas e gráficos

Tat

Sim, utiliza interface Tabwin-SQL

$\Gamma$

Sim, utiliza funções básicas

21) O município realiza análise espacial dos dados do SINAN? Se sim, quais ferramentas são utilizadas? *

Não

Sim, utiliza mapas em papel

Sim, utiliza ferramentas de geoprocessamento

22) O município utiliza algum outro instrumento paralelo ao SINAN (planilhas, cadernos, livros de registros, sistemas etc.?): *

Não $\rightarrow$ pule para questão número 25

Sim $\rightarrow$ responda as questões 23 e 24 
23) Qual o motivo que o município tem para utilizar esse instrumento paralelo?

Lentidão para enviar os dados

Г Necessidade de incluir informações que não estão presentes nas

fichas de notificação/investigação

幽

Outro.Especifique

23.1) Especifique: *

24) Para qual(is) doença(s)/agravo(s) e qual instrumento(s) é utilizado?

Recursos Humanos - Quantas pessoas atuavam na Vigilância Epidemiológica, em 30/04/2017.

25) Com Nível Superior de formação da área da saúde : * Preencher com números e utilizar o 0

(zero) para nenhum

26) Com Nível Superior da área de Tecnologia da

Informação: * Preencher com números e utilizar o 0 (zero)

para nenhum

27) Com Nível Técnico ou ensino médio: *

Preencher com números e utilizar o 0 (zero) para nenhum

28) Com Nível Fundamental: *

Preencher com números e utilizar o 0 (zero) para nenhum

29) Total dos profissionais: *

Lembre-se de conferir se o campo Total bate com a soma das parcelas das questões 25 a 28.

30) Dos profissionais que atuavam na Vigilância Epidemiológica, quantos possuíam pós-graduação em epidemiologia e/ou saúde pública? * 
31) Dos profissionais que atuavam na Vigilância Epidemiológica, quantos operavam o SINAN? *

32) Os profissionais que digitam as fichas de notificação/investigação são os mesmos que fazem Vigilância Epidemiológica? *

Sim, todos

Sim, alguns

C Não

Capacitação Profissional

33) O(a) Sr.(a) e/ou sua equipe receberam treinamento institucional para trabalhar com o SINAN? *

Г Não<smiles>[Hg]</smiles>
Sim, ministrado pelo Município

Tit Sim, ministrado pelo Grupo de Vigilância Epidemiológica - GVE

ГSim, ministrado pelo Centro de Vigilância Epidemiológica - CVE (SES-SP)

Г Sim, ministrado pelo Centro de Referência e Treinamento DST/Aids - CRTA (SES-SP)

$\Gamma$

Sim, ministrado pelo Instituto Pasteur (SES-SP)

$\Gamma$

Sim, ministrado por outra instituição

34) Com qual periodicidade o GVE fez reunião no último ano com o município? *

Mensal
Bimestral
Trimestral
Semestral
Anual
Não fez
Não tem periodicidade 
Outra. Especifique

34.1) Especifique: *

35) No último ano, o(a) Sr.(a) ou a sua equipe promoveram capacitação para os profissionais das unidades notificadoras em relação ao preenchimento das fichas de notificação/investigação? *

$$
\begin{aligned}
& \text { Sim } \\
& \text { Não }
\end{aligned}
$$

\section{Recursos de Informática}

36) Quantos computadores estão disponíveis para utilização do SINAN (NET e on-line)? *

37) Em quantos computadores estão instalados o SINAN Net? *

38) Indique qual o sistema operacional que está instalado no(s) computador(es) que operam o SINAN? * Em caso de computador(es) com sistemas diferentes, informar o mais atualizado.
Windows XP
Windows 7 - 32 Bits
Windows $7-64$ Bits
Windows 8 - 32 Bits
Windows 8 - 64 Bits
(C) Windows 10 - 32 Bits
Windows $10-64$ Bits
(6) Outro. Especifique

Não sabe

\section{1) Especifique: *}

39) Como é a conexão dos computadores com a internet? *

Não sabe

Através do acesso direto

Através do acesso rápido tipo "banda larga" 
Através de link de rádio

Outro. Especifique

39.1) Especifique: *

40) Qual(is) a(s) opção(es) utilizada(s) para backup dos dados do SINAN NET? *

Outro computador/CPU

Г

Pen drive

$\Gamma$

$C D$

HD externo

Nuvem

Não sabe

Outro. Especifique

40.1) Especifique : *

41) O município dispõe de suporte técnico de informática? *

Não

(- Sim, serviço próprio

Sim, serviço terceirizado

41.1) Como é prazo de atendimento em relação ao serviço solicitado?

Lento
Rápido

Disseminação de Dados

42) Os dados provenientes do SINAN são divulgados para as unidades notificadoras (hospitais, UBS etc.)? *
(c) $\operatorname{sim}$
(C) Não

42.1) Qual a periodicidade? * 
43) Como o município disponibiliza as informações geradas pelo SINAN?

* Não disponibiliza

$\Gamma$

Elabora boletim ou relatório epidemiológico impresso

F

Elabora boletim ou relatório epidemiológico eletrônico

『 Disponibiliza tabelas e ou indicadores no site da SMS ou prefeitura Outro. Especifique

43.1) Especifique: *

44) Indique quais os principais usos das informações do SINAN geradas pelo município: *

Planejamento de ações de Vigilância Epidemiológica/em Saúde

$\Gamma$

Definição de prioridades

Avaliação e monitoramento das metas estabelecidas

Pactuação de indicadores de saúde

Audiência pública de saúde

Publicações

Mídia ( jornal, rádio, web,TV etc.)

Conselho Municipal de Saúde

Conselho Estadual de Saúde

$\Gamma$

Colegiados de Gestão Regional

$\Gamma$

Não é utilizada

$\sqrt{\checkmark}$

Outro. Especifique

44.1) Especifique: * 
Avaliação

45) Como é a estrutura física do seu local de trabalho? *
Adequada
(- Inadequada

45.1) Se inadequada, indique o motivo: *

Espaço insuficiente

$\Gamma$

Pouco ventilado

$\Gamma$

$$
\text { Pouca iluminação }
$$

$\Gamma$ Barulhento

$\sqrt{\star}$ Rede elétrica inadequada/insuficiente

Outro

45.1) Especifique: *

46) De maneira geral como o(a) Sr.(a) classifica a qualidade do preenchimento das fichas de notificação/investigação? *

$\begin{array}{ll}C & \text { Ruim } \\ C & \text { Razoável } \\ C & \text { Boa } \\ C & \text { Excelente }\end{array}$

47) Quais os principais problemas encontrados nas fichas de notificação/investigação no momento da digitação? *

Falta de preenchimento de alguns campos essenciais obrigatórios<smiles>[CH]</smiles>
Inconsistência das informações

$\Gamma$ Duplicidade da ficha

$\Gamma$ Letra ilegível ou rasura 
$\sqrt{6}$

Outro. Especifique

47.1) Especifique: *

48) O(a) Sr.(a) tem dificuldade de operar o SINAN on-line? *

Não

Sim, dificuldade com a conexão local da internet

Sim, dificuldade com Dengue On-Line

Sim, dificuldade com Influenza On-Line

Sim, dificuldade em acessar o site do SINAN (problemas com o servidor)

Outro. Especifique

48.1) Outro. Especifique: *

49) Avalie a disponibilidade de materiais para operar o SINAN:

CD/DVD/pendrive: *

suficiente insuficiente

HD externo: *

Telefones: *

Impressoras: *

Tintas para impressora: *

Impressos para Notificação: *

Armários sem chave: *

Armários com chave: *

50) O SINAN como instrumento epidemiológico atende as necessidades do seu município? *

Sim, totalmente

Sim, parcialmente

(C) Não 
51) O(a) Sr.(a) considera que a lista nacional de agravos e doenças de notificação está: *
Adequada
(- Inadequada

51.1) Se inadequada, para qual doença(s) e motivo(s): *

52) Como o(a) Sr.(a) considera o apoio técnico para o SINAN realizado pelos setores abaixo?

Adequado Inadequado

Grupo de Vigilância Epidemiológica - GVE: *

Centro de Vigilância Epidemiológica - CVE (SES-SP): *

Centro de Referência e Treinamento DST/Aids - CRTA (SES-SP): * Instituto Pasteur (SES-SP): *

53) Avalie as dificuldades encontradas na operação do SINAN:

Nenhuma Baixa
dificuldade dificuldade dificuldade dificuldade
Instalação do
SINAN-Net:
Operação do
SINAN-Net:
Operação
SINAN on-
line: *
Uso dos
indicadores
gerados pelo
SINAN no
munícipio: ${ }^{*}$




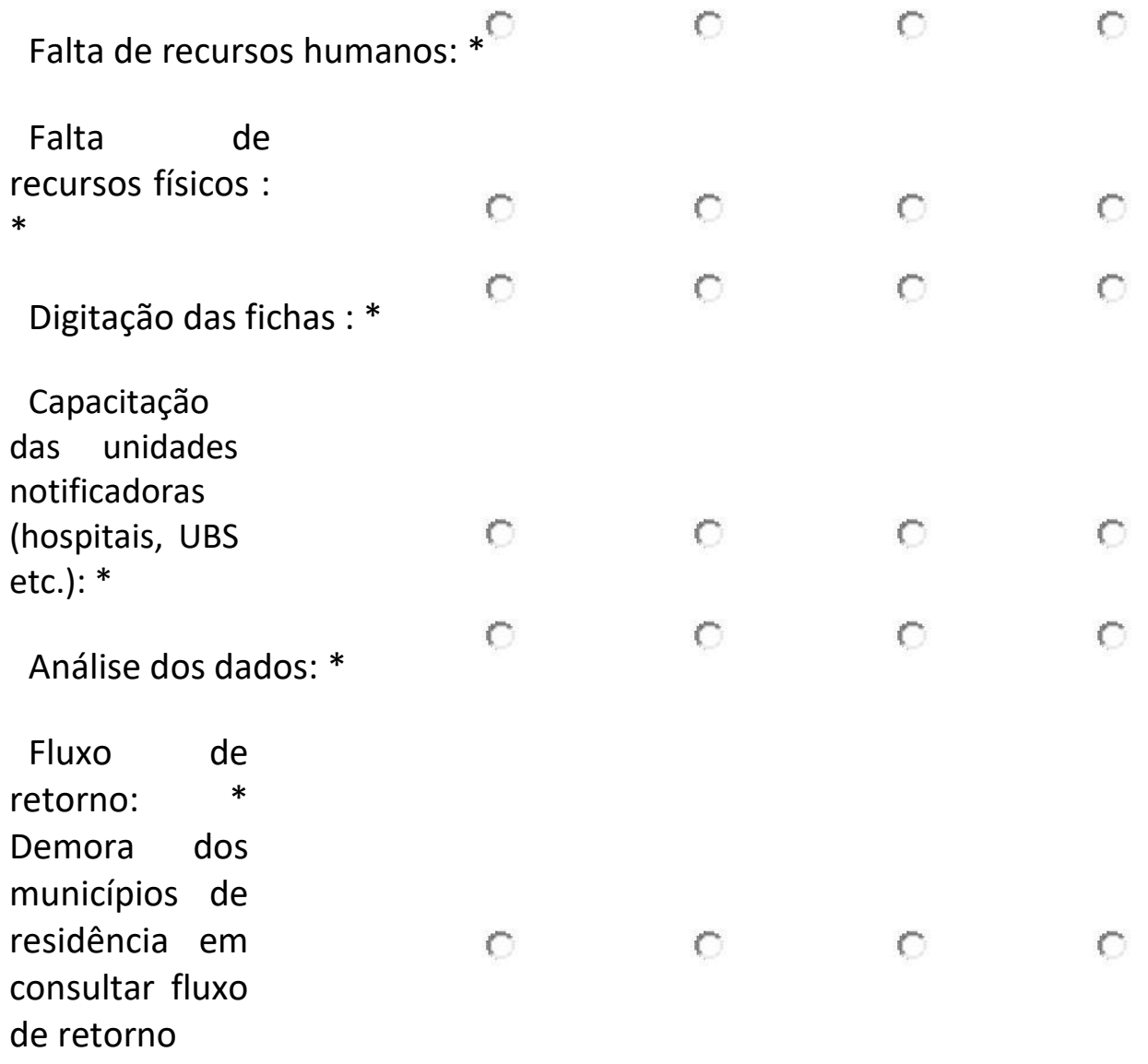

54) Avalie os benefícios do SINAN para o município:

Nenhum Baixo Médio Alto
benefício benefício benefício benefício

Rapidez em obter os dados: *

Agilidade na

tomada de

decisão: *

Autonomia da informação: *

Acompanhamento da

situação

epidemiológica do

município: *

Distribuição

geográfica dos

casos: * 


\begin{tabular}{lr}
\multicolumn{1}{c}{ Obtenção } & de \\
informações & \\
fundamentais & para \\
estratégias & de \\
intervenção: * &
\end{tabular}

55) Se desejar, faça comentários adicionais: 
Apêndice 4 - Convite COSEMS

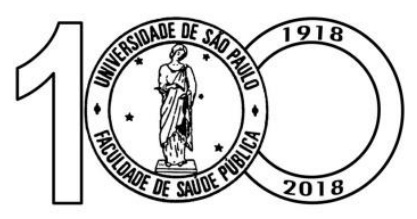

UNIVERSIDADE DE SÃo PAULO

Faculdade de Saúde Pública

DEPARTAMENTO DE EPIDEMIOLOGIA

Prezado Senhor,

São Paulo, 20 de fevereiro de 2017.

Estamos desenvolvendo a pesquisa Descentralização dos Sistemas de Informações em Saúde nos municípios do Estado de São Paulo, que visa conhecer as condições de operacionalização dos sistemas de informação de base epidemiológica nos municípios paulistas. O projeto é uma parceria entre a Faculdade de Saúde Pública e a Secretaria de Estado da Saúde, com apoio do CNPq.

A fase atual contempla o estudo do Sistema de Informação de Agravos de Notificação - SINAN. O motivo que nos leva a estudar este sistema é sua importância para a Vigilância Epidemiológica, sendo a principal fonte de informação de doenças e agravos, capaz de monitorar tendências e estimar a sua magnitude como problema de saúde na população. Nosso objetivo é conhecer as características estruturais, processo de trabalho e uso das informações na gestão nos municípios paulistas. Com isso pretende-se gerar novos conhecimentos que possibilitem ações para o aprimoramento do SINAN.

Para coleta dos dados, foi desenvolvido um questionário eletrônico (em anexo), que será aplicado, via FormSUS, aos responsáveis municipais pela vigilância epidemiológica.

Venho assim, solicitar o apoio do COSEMS na fase de divulgação e sensibilização dos municípios para aplicação do questionário.

Desde já agradeço a colaboração e coloco-me à disposição para quaisquer esclarecimentos necessários.

Atenciosamente,

Zilda Pereira da Silva

Professora do Departamento de Epidemiologia

Faculdade de Saúde Pública - FSP/USP 
Ilmo. Sr

Stênio José Correia Miranda

Presidente do Conselho de Secretários Municipais de Saúde do Estado de São Paulo - COSEMS/SP 


\title{
Anexo 1- Comitê de Ética
}

\author{
FACULDADE DE SAÚDE \\ PÚBLICA DA UNIVERSIDADE \\ DE SÃO PAULO
}

\section{PARECER CONSUBSTANCIADO DO CEP}

\section{DADOS DO PROJETO DE PESQUISA}

Título da Pesquisa: DESCENTRALIZAÇÃO DOS SISTEMAS DE INFORMAÇÕES EM SAÚDE NOS MUNICÍPIOS DO ESTADO DE SÄO PAULO

Pesquisador: ZILDA PEREIRA DA SILVA

Área Temática:

Versão: 2

CAAE: 49293815.2 .0000 .5421

Instituição Proponente: Faculdade de Saúde Pública da Universidade de São Paulo - FSP/USP

Patrocinador Principal: MINISTERIO DA CIENCIA, TECNOLOGIA E INOVACAO

DADOS DO PARECER

Número do Parecer: 1.420 .485

Apresentação do Projeto:

Trata-se da segunda versão de um projeto sobre a situação atual dos sistemas de informações em saúde (SIs) nos municípios paulistas, decorrente do processo de descentralização. Os dados serão coletados por meio de formulário eletrônico e entrevistas. A pendência anterior foi de adequar o TCLE da entrevista, o que foi realizado na versão apresentada.

Objetivo da Pesquisa:

Realizar diagnóstico da situação da descentralização dos sistemas de informações em saúde nos municípios do Estado de São Paulo.

Avaliação dos Riscos e Benefícios:

Riscos mínimos.

Benefícios: O conhecimento gerado pelo projeto sobre as condições, o uso e os desafios dos SISs nos municípios contribuirá para a compreensão de suas necessidades e subsidiará a utilização desses sistemas de vigilância à saúde como ferramenta na gestão municipal. Além disso, informações de qualidade e oportunas colaboram para que o Sistema Único de Saúde (SUS) se aprimore e realize um de seus objetivos, que é a identificação e divulgação dos fatores condicionantes e determinantes da saúde.

Endereço: Av. Doutor Arnaldo, 715

Bairro: Cerqueira Cesa

UF: SP $\quad$ Municipio:
Telefone:

CEP: $01.246-904$

E-mail: coep@fsp.usp.br 
FACULDADE DE SAÚDE

PÚBLICA DA UNIVERSIDADE

DE SÃO PAULO

Continuaçăo do Parecer: 1.420 .485

Comentários e Considerações sobre a Pesquisa:

Pesquisa relevante com metodologia adequada.

Considerações sobre os Termos de apresentaçăo obrigatória:

Apresenta TCLEs do questionário online e da entrevista adequados

Recomendaçōes:

Conclusōes ou Pendências e Lista de Inadequaçōes:

Aprovado

Consideraçōes Finais a critério do CEP:

Este parecer foi elaborado baseado nos documentos abaixo relacionados:

\begin{tabular}{|c|c|c|c|c|}
\hline Tipo Documento & Arquivo & Postagem & Autor & Situação \\
\hline $\begin{array}{l}\text { Informações Básicas } \\
\text { do Projeto }\end{array}$ & $\begin{array}{l}\text { PB_INFORMAÇOES_BÁSICAS_DO_P } \\
\text { ROJETO 520762.pdf }\end{array}$ & $\begin{array}{l}15 / 01 / 2016 \\
16: 01: 04\end{array}$ & & Aceito \\
\hline $\begin{array}{l}\text { TCLE / Termos de } \\
\text { Assentimento / } \\
\text { Justificativa de } \\
\text { Ausência }\end{array}$ & TCLE_porjSIS_entrevista_v2.pdf & $\begin{array}{l}15 / 01 / 2016 \\
15: 59: 57\end{array}$ & $\begin{array}{l}\text { ZILDA PEREIRA DA } \\
\text { SILVA }\end{array}$ & Aceito \\
\hline $\begin{array}{l}\text { Projeto Detalhado / } \\
\text { Brochura } \\
\text { Investigador }\end{array}$ & Projeto_SISmunic_CEP.pdf & $\begin{array}{c}14 / 09 / 2015 \\
16: 55: 14\end{array}$ & $\begin{array}{l}\text { ZILDA PEREIRA DA } \\
\text { SILVA }\end{array}$ & Aceito \\
\hline Folha de Rosto & folhaDeRosto_assinada.pdf & $\begin{array}{c}14 / 09 / 2015 \\
16: 39: 58\end{array}$ & $\begin{array}{l}\text { ZILDA PEREIRA DA } \\
\text { SILVA }\end{array}$ & Aceito \\
\hline $\begin{array}{l}\text { TCLE / Termos de } \\
\text { Assentimento / } \\
\text { Justificativa de } \\
\text { Ausência }\end{array}$ & TCLE_projSIS_entrevista.pdf & $\begin{array}{l}11 / 09 / 2015 \\
14: 58: 42\end{array}$ & $\begin{array}{l}\text { ZILDA PEREIRA DA } \\
\text { SILVA }\end{array}$ & Aceito \\
\hline $\begin{array}{l}\text { TCLE / Termos de } \\
\text { Assentimento / } \\
\text { Justificativa de } \\
\text { Ausência }\end{array}$ & TCLE_projSIS.pdf & $\begin{array}{c}11 / 09 / 2015 \\
14: 58: 28\end{array}$ & $\begin{array}{l}\text { ZILDA PEREIRA DA } \\
\text { SILVA }\end{array}$ & Aceito \\
\hline
\end{tabular}

Situação do Parecer:

Aprovado

Necessita Apreciação da CONEP:

Não

Endereço: Av. Doutor Arnaldo, 715

Bairro: Cerqueira Cesar

UF: SP Município: SAO PAULO

CEP: $01.246-904$

Telefone: (11)3061-7779 Fax: (11)3061-7779

E-mail: coep@fsp.usp.br 
FACULDADE DE SAÚDE

PÚBLICA DA UNIVERSIDADE

DE SÃO PAULO

\section{Continuação do Parecer: 1.420 .485}

SAO PAULO, 23 de Fevereiro de 2016

\begin{tabular}{c}
\hline Assinado por: \\
Maria Regina Alves Cardoso
\end{tabular}

(Coordenador)

Endereço: Av. Doutor Arnaldo, 715

Bairro: Cerqueira Cesar

CEP: $01.246-904$

UF: SP Municipio: SAO PAULO

Telefone: (11)3061-7779

Fax: (11)3061-7779

E-mail: coep@fsp.usp.br 


\section{Anexo 2}

\section{Tabelas Complementares}

Tabela 1A - Número e proporção de municípios participantes da pesquisa, por GVE. Estado São Paulo, 2017.

\begin{tabular}{lccc}
\hline \multicolumn{1}{c}{ GVE } & No municípios & Total de & $\%$ \\
Respondentes & municípios & \\
\hline GVE IX - FRANCO DA ROCHA & 3 & 5 & 60,0 \\
GVE VII - SANTO ANDRÉ & 6 & 7 & 85,7 \\
GVE VIII - MOGI DAS CRUZES & 8 & 11 & 72,7 \\
GVE X - OSASCO & 7 & 15 & 46,7 \\
GVE XI - ARAÇATUBA & 25 & 40 & 62,5 \\
GVE XII - ARARAQUARA & 13 & 24 & 54,2 \\
GVE XIII - ASSIS & 15 & 25 & 60,0 \\
GVE XIV - BARRETOS & 11 & 18 & 61,1 \\
GVE XIX - MARÍLIA & 23 & 37 & 62,2 \\
GVE XV - BAURÚ & 20 & 38 & 52,6 \\
GVE XVI - BOTUCATU & 19 & 30 & 63,3 \\
GVE XVII - CAMPINAS & 24 & 42 & 57,1 \\
GVE XVIII - FRANCA & 13 & 22 & 59,1 \\
GVE XX - PIRACICABA & 16 & 26 & 61,5 \\
GVE XXI - PRESIDENTE PRUDENTE & 18 & 24 & 75,0 \\
GVE XXII - PRESIDENTE VENCESLAU & 12 & 21 & 57,1 \\
GVE XXIII - REGISTRO & 9 & 15 & 60,0 \\
GVE XXIV - RIBEIRÃO PRETO & 20 & 26 & 76,9 \\
GVE XXIX - SÃO JOSÉ DO RIO PRETO & 43 & 67 & 64,2 \\
GVE XXV - SANTOS & 8 & 9 & 88,9 \\
GVE XXVI - SÃO JOÃO DA BOA VISTA & 15 & 20 & 75,0 \\
GVE XXVII - SÃO JOSÉ DOS CAMPOS & 5 & 8 & 62,5 \\
GVE XXVIII - CARAGUATATUBA & 2 & 4 & 50,0 \\
GVE XXX - JALES & 20 & 35 & 57,1 \\
GVE XXXI - SOROCABA & 12 & 33 & 75,8 \\
GVE XXXII - ITAPEVA & 407 & 644 & 80,0 \\
GVE XXXIII - TAUBATÉ & & 15 & 55,6 \\
\hline Total do Estado & 27,2 \\
\hline
\end{tabular}


Tabela 2A - Número e proporção de responsáveis técnicos municipais do SINAN, segundo formação mais avançada, por porte populacional do município, Estado de São Paulo, 2017.

\begin{tabular}{|c|c|c|c|c|c|c|c|c|}
\hline \multirow{3}{*}{$\begin{array}{c}\text { Formação Mais } \\
\text { Avançada }\end{array}$} & \multicolumn{6}{|c|}{ Porte dos Municípios (habitantes) } & \multirow{2}{*}{\multicolumn{2}{|c|}{ Total }} \\
\hline & \multicolumn{2}{|c|}{ Até 30.000} & \multicolumn{2}{|c|}{ De 30.001 a 200.000} & \multicolumn{2}{|c|}{ Maior que 200.000 } & & \\
\hline & $\mathrm{N}$ & $\%$ & $\mathrm{~N}$ & $\%$ & $\mathrm{~N}$ & $\%$ & $\mathrm{~N}$ & $\%$ \\
\hline Técnicos* & 17 & 100,0 & 5 & 100,0 & 1 & 100,0 & 23 & 100,0 \\
\hline Enfermagem & 6 & 35,3 & 0 & 0,0 & 1 & 100,0 & 7 & 30,4 \\
\hline Contabilidade & 3 & 17,6 & 2 & 40,0 & 0 & 0,0 & 5 & 21,7 \\
\hline Admin/RH & 2 & 11,8 & 2 & 40,0 & 0 & 0,0 & 4 & 17,4 \\
\hline Informática/TI & 3 & 17,6 & 0 & 0,0 & 0 & 0,0 & 3 & 13,0 \\
\hline Outros & 3 & 17,6 & 1 & 20,0 & 0 & 0,0 & 4 & 17,4 \\
\hline Graduados** & 104 & 100,0 & 39 & 100,0 & 6 & 100,0 & 149 & 100,0 \\
\hline Enfermagem & 86 & 82,7 & 28 & 71,8 & 2 & 33,3 & 116 & 77,9 \\
\hline Admininistração & 3 & 2,9 & 2 & 5,1 & 0 & 0,0 & 5 & 3,4 \\
\hline Gestão Pública/Hospitalar & 3 & 2,9 & 2 & 5,1 & 0 & 0,0 & 5 & 3,4 \\
\hline Veterinária/Zootecnia & 2 & 1,9 & 1 & 2,6 & 0 & 0,0 & 3 & 2,0 \\
\hline Pedagogia & 2 & 1,9 & 1 & 2,6 & 0 & 0,0 & 3 & 2,0 \\
\hline Direito & 1 & 1,0 & 1 & 2,6 & 0 & 0,0 & 2 & 1,3 \\
\hline Biomedicina & 2 & 1,9 & 0 & 0,0 & 0 & 0,0 & 2 & 1,3 \\
\hline Informática/TI & 2 & 1,9 & 0 & 0,0 & 0 & 0,0 & 2 & 1,3 \\
\hline Odontologia & 0 & 0,0 & 1 & 2,6 & 1 & 16,7 & 2 & 1,3 \\
\hline Saúde Pública & 0 & 0,0 & 0 & 0,0 & 1 & 16,7 & 1 & 0,7 \\
\hline Outros & 3 & 2,9 & 3 & 7,7 & 2 & 33,3 & 8 & 5,4 \\
\hline Pós-graduados $* * *$ & 127 & 100,0 & 66 & 100,0 & 21 & 100,0 & 214 & 100,0 \\
\hline Saúde da Família/ESF & 31 & 24,4 & 10 & 15,2 & 1 & 4,8 & 42 & 19,6 \\
\hline Saúde Pública & 23 & 18,1 & 13 & 19,7 & 6 & 28,6 & 42 & 19,6 \\
\hline Enfermagem & 30 & 23,6 & 10 & 15,2 & 1 & 4,8 & 41 & 19,2 \\
\hline Gestão/Auditoria & 11 & 8,7 & 13 & 19,7 & 2 & 9,5 & 26 & 12,1 \\
\hline Epidemiologia/Vigilâncias & 3 & 2,4 & 3 & 4,5 & 6 & 28,6 & 12 & 5,6 \\
\hline Urgência e Emergência & 10 & 7,9 & 0 & 0,0 & 1 & 4,8 & 11 & 5,1 \\
\hline $\begin{array}{l}\text { Unidade de Terapia } \\
\text { Intensiva - UTI }\end{array}$ & 5 & 3,9 & 1 & 1,5 & 0 & 0,0 & 6 & 2,8 \\
\hline $\begin{array}{l}\text { Educação em Saúde } \\
\text { Pública }\end{array}$ & 2 & 1,6 & 2 & 3,0 & 1 & 4,8 & 5 & 2,3 \\
\hline Obstetrícia & 3 & 2,4 & 2 & 3,0 & 0 & 0,0 & 5 & 2,3 \\
\hline Saúde do trabalhador & 5 & 3,9 & 0 & 0,0 & 0 & 0,0 & 5 & 2,3 \\
\hline Outros & 4 & 3,1 & 12 & 18,2 & 3 & 14,3 & 19 & 8,9 \\
\hline
\end{tabular}


Tabela 3A - Número e proporção de responsáveis técnicos municipais do SINAN, segundo prazo de atendimento do suporte de TI, por porte populacional do município, Estado de São Paulo, 2017.

\begin{tabular}{|c|c|c|c|c|c|c|c|c|}
\hline \multicolumn{9}{|c|}{ Porte dos Municípios (habitantes) } \\
\hline \multirow{2}{*}{$\begin{array}{c}\text { Prazo de } \\
\text { Atendimento }\end{array}$} & \multicolumn{2}{|c|}{ Até 30.000} & \multicolumn{2}{|c|}{ De 30.001 a 200.000} & \multicolumn{2}{|c|}{ Maior que $\mathbf{2 0 0 . 0 0 0}$} & \multicolumn{2}{|c|}{ Total } \\
\hline & $\mathrm{N}$ & $\%$ & $\mathrm{~N}$ & $\%$ & $\mathrm{~N}$ & $\%$ & $\mathrm{~N}$ & $\%$ \\
\hline Lento & 69 & 33,7 & 37 & 38,9 & 10 & 43,5 & 116 & 35,9 \\
\hline Rápido & 136 & 66,4 & 58 & 61,0 & 13 & 56,5 & 207 & 64,1 \\
\hline Total & 205 & 100,0 & 95 & 100,0 & 23 & 100,0 & 323 & 100,0 \\
\hline
\end{tabular}

Tabela 4A - Número e proporção de responsáveis técnicos municipais do SINAN, segundo formação mais avançada, por porte populacional do município, Estado de São Paulo, 2017.

\begin{tabular}{lccccccc}
\hline \multirow{2}{*}{ Tipo de Serviço } & \multicolumn{5}{c}{ Prazo de Atendimento } & \multirow{2}{*}{ Total } \\
\cline { 2 - 6 } & \multicolumn{9}{c}{ Lento } & \multicolumn{2}{c}{ Rápido } & \\
\cline { 2 - 6 } & 82 & 34,7 & 154 & 65,3 & 236 & 100,0 \\
Serviço próprio & 34 & 39,5 & 52 & 60,5 & 86 & 100,0 \\
\hline Serviço terceirizado & 116 & 36,0 & 206 & 64,0 & 322 & 100,0 \\
\hline Total & & & & & & &
\end{tabular}


Tabela 5A - - Proporção de municípios, segundo grau de dificuldade na realização de algumas atividades do SINAN, Estado de São Paulo, 2017.

\begin{tabular}{lr}
\hline \multicolumn{1}{c}{ Dificuldades } & Alta (\%) \\
\hline Fluxo de retorno & 17,7 \\
Capacitação das unidades notificadoras & 16,7 \\
Falta de recursos humanos & 15,5 \\
Falta de recursos físicos & 10,3 \\
Instalação do SINAN-Net & 9,8 \\
Análise dos dados & 9,1 \\
Uso dos indicadores gerados & 8,1 \\
Operação SINAN on-line & 2,0 \\
Digitação das fichas & 1,7 \\
Operação do SINAN-Net & 1,0 \\
Envio dos lotes para o GVE &, 5 \\
\hline
\end{tabular}


Tabela 6A - Proporção de municípios que avaliaram como alto o benefício à descentralização do SINAN, por tipo de benéfico, Estado de São Paulo, 2017.

\section{Benefícios}

Acompanhamento da situação

epidemiológica do município

Autonomia da informação

Obtenção de informações

fundamentais para estratégias de

intervenção

Rapidez em obter os dados

Agilidade na tomada de decisão

Análise da istribuição geográfica dos

casos
Alto (\%)

65,1

57,2

56,3

54,3

53,1

51,4 


\section{CURRICULUM LATTES}

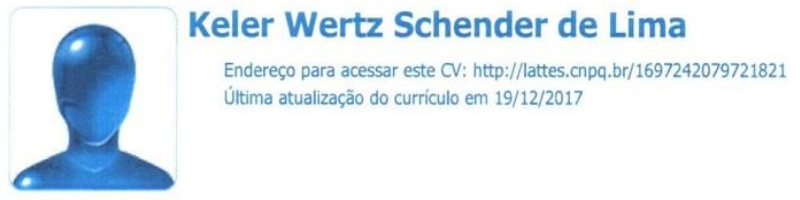

Doutoranda do Programa de Pós-Graduação em Saúde Pública da USP (2013). Mestre em ciências pela Faculdade de Saúde Pública da USP (2013). Participou do programa de aperfeiçoamento em docência (PAE) como estágiaria em docência na faculdade de Farmácia da USP (2012) e na faculdade de Saúde Pública. Graduada em farmácia (2001), Especialista em Farmácia Hospitalar com enfâse em farmácia clínica (2003) e em Gestão Hospitalar e Políticas Públicas(2010). Experiência de 6 anos na aréa de gestão de farmácia hospitalar e gerenciamento de risco. Atuou como membro de grupo de planejamento e gestão; membro grupo de infecção hospitalar; na elaboração de parecer técnico de materiais; elaboração de manuais de procedimentos (POPS); capacitação de colaboradores; elaboração de relatório de gestão PNGS; auditorias de estoque nas áreas internas hospitalar. (Texto informado pelo autor)

\section{Identificação}

Nome Keler Wertz Schender de Lima

Nome em citações bibliográficas SCHENDER, K. W; LIMA, K.W.S;LIMA, KELER WERTZ SCHENDER DE

Endereço

Formação acadêmica/titulação

\begin{tabular}{|c|c|}
\hline \multirow[t]{2}{*}{2013} & $\begin{array}{l}\text { Doutorado em andamento em Doutorado em Ciências. } \\
\text { Universidade de São Paulo, USP, Brasil. } \\
\text { Titulo: DIAGNÓSTICO DAS CONDIÇŌES DE OPERAÇÃO DO SISTEMA DE } \\
\text { INFORMAÇÃOO DE AGRAVOS DE NOTIFICAÇÃOO (SINAN) NO ESTADO DE SÃO } \\
\text { PAULO., }\end{array}$ \\
\hline & $\begin{array}{l}\text { Orientador: } \\
\text { Grande área: Ciências da Saúde } \\
\text { Setores de atividade: Atividades de atenção à saúde humana. }\end{array}$ \\
\hline $2011-2013$ & $\begin{array}{l}\text { Mestrado em Saúde Pública. } \\
\text { Faculdade de Saúde Pública da Universidade de São Paulo, FSP, Brasil. } \\
\text { Titulo: Percepção dos Gestores Sobre o Uso de Indicadores nos Serviços de } \\
\text { Saúde,Ano de Obtenção: } 2013 \text {. }\end{array}$ \\
\hline & $\begin{array}{l}\text { Orientador: (9) José Leopoldo Ferreira Antunes. } \\
\text { Bolsista do(a): Conselho Nacional de Desenvolvimento Científico e Tecnológico, } \\
\text { CNPq, Brasil. } \\
\text { Grande área: Ciências da Saúde }\end{array}$ \\
\hline $2009-2010$ & $\begin{array}{l}\text { Especialização em Gestão Hospitalar e Politicas Públicas. (Carga Horária: } 360 \mathrm{~h} \text { ). } \\
\text { Faculdade Carlos Drumond de Andrade, DRUMOND, Brasil. } \\
\text { Titulo: A IMPORTÂNCIA DA EPIDEMIOLOGIA NA GESTÃO DE SERVIÇOS DE SAÚDE - } \\
\text { A UTLIZAÇÃO DE INDICADORES EPIDEMIOLÓGICOS COMO FERRAMENTA NA } \\
\text { TOMADA DE DECISÃOO. } \\
\text { Orientador: Fiorela D?Acquarica. }\end{array}$ \\
\hline $2002-2003$ & $\begin{array}{l}\text { Especialização em Farmácia Hospitalar- Introdução a Farmácia Clinica. (Carga } \\
\text { Horária: } 1700 \mathrm{~h}) \text {. } \\
\text { Faculdade de Medicina da Universidade de São Paulo, USP, Brasil. } \\
\text { Titulo: Análise das Reações Adversas de } 2001 \text { da Central de Abastecimento }\end{array}$ \\
\hline
\end{tabular}




\section{Zilda Pereira da Silva}

Endereşo para acessar este CV: http: ///attes.cnpo,br/4481599643491362

iltima atualizacio do curriculo em 13/12/2017

Possui mestrado (2001) e doutorado (2008) em Saúde Pública, pela Universidade de São Paulo. Atualmente, é professora doutora no Departamento de Epidemiologia da Faculdade de Saúde Pública da USP. É orientadora no Programa de Pós-Graduação em Saúde Pública e no Programa de Pós-graduação em Epidemiologia. Atuou como analista de projetos, assessora técnica e gerente na Fundação Seade. Tem experiência na área de Saúde Pública, atuando principalmente nos seguintes temas: estatísticas e sistemas de informação em saúde, mortalidade infantil e acesso a serviços de saúde. (Texto informado pelo autor)

Identificação

Zilda Pereira da Silve

Nitaçöes bibliográficas

SILVA, Z.P. S. Silva, Zilda Pereira da;da Silva, Z. P.jDA SILVA, ZILDA PEREIRA

Endereço

Endereço Profissional

Faculdade de Saúde Pública da USP.

Av. Dr. Amaldo, 715

Cerqueira Cesar

Telefone: (11) 30617930

Fax: (11) 30617926

URi da Homepage: hetro://www.fsp usp. br

Formação acadêmica/titulação

$2005-2008$

Doutorado em Saúde Pública (Conceito CAPES 6 ).

Universidade de São Paulo, USP, Brasi.

Titulo: Perfil dos nascimentos e da mortalidade neonatal precoce, segundo local de parto, complexidade hospitalar e rede SUS e não-SUS, regläo metropolitana de São PAulo, 2006, Ano de obtençăo: 2008.

Orientador: (*) Marcia Furquim de Almeida.

Palavras-chave: saúde pública; mortalidade neonatal precoce; complexidade hospitalar; local de

parto; Sistema Único de Saúde.

Grande área: Ciências da Saýde

Grande Área: Ciências da Saúde / Área: Saúde Coletiva

Setores de atividade: Saúde e Serviços Sociais.

$1998-2001$

Mestrado em Saúde Pública (Conceito CAPES 6).

Universidade de São Paulo, USP, BrasiL

Titulo: Transformaçōes na Administração Municipal de Saúde no Estado de Săo Paulo: aspectos de recursos humanos e financeiros, Ano de Obtençăo: 2001.

Orientador: (6) Evelin Naked de Castro Sá.

Palavras-chave: saúde pública: informaç̄o en saúde; politicas públicas.

Grande área: Ciências da Saíde

Grande Área: Ciências Humanas / Área: Sociologia / Subárea: Sociologia da Saúde.

$1995-1995$

Setores de atvidade: Saíde Humana:

Especializaçāo em em Saúde Pública. (Carga Horária: 800h).

$1980-1986$

Universidade de Sao Pauth, USP, Brasi.

Graduaçáo em Cièncias Sociais.

Universidade de São Paulo, USP, Brasi.

Formação Complementar

2014- 2014

Saúde Global. (Carga horária: 32h.

USP, FSP/USP, Bras

Obstetricia e Neonatalogia. (Carga horária: $10 \mathrm{~h}$ ).

$2013-2013$

$2013 \cdot 2013$

Treinamento no Uso do Software RECLINK. (Carga horária: 16h).

$2013-2013$

Medición de la Classe Social Ocupicio

Sociedad Espanto So Enidemiologia, SEE, Espanta.

2010 - $2010 \quad$ Extensão universitária em II Oficina de Escrita Cientifica

Faculdade de Saúde Pública da USP, FSP/USP, Brasil.

2010 - 2010 Inquéritos de Saúde. (Carga horária: 24b).

$2007 \cdot 2007$

Fac. Saúde Pública , Univ São Paut, FSP IUSP, Brast. 